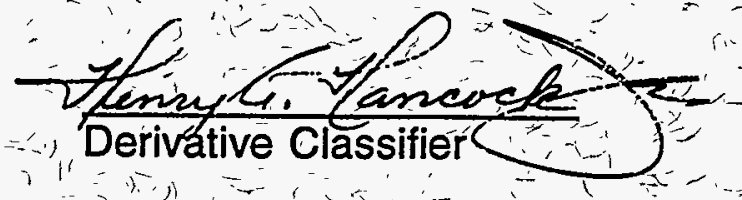

\title{
Assessment of Noble Gases in the Savannah River Site Environment(U)
}

\author{
W. H. Carltón \\ C. E. Murphy, Jr.
}

Approved by

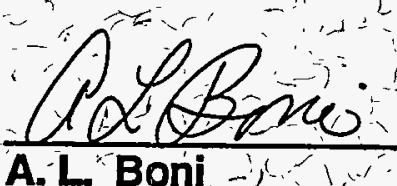

\section{Research Manáger}

Environmental Technology Section

Westinghouse Savannah River Company Savannah River Technology Center

Aiken, SC 29808

PREPARED FORTHE U.S. DEPARTMENT OF-ENERGY UNDER CONTRACT NO. DE-AC09-89SR18035 


\section{Disclaimer}

This report was prepared as an account of work sponsored by an agency of the United States Government. Neither the United States Government-nor any agency thereof, nor any of their employees, màkes any warranty, express or implied, or assumes añy legal liability or responsibility for the accuracy, completeness, or usefulness of any information, apparatus, product, or process disclosed, or represented that it use would not infringe privately owned rights. Refêrence herein to any specific commercial product, process, or service by trade name, trademark, manufacturer, or otherwise does nor necessarily constitute or imply it's endoršement- recommendation, of favoring by the United States Government or any agency thereof. the views and opinions of authors expressed herein do not necessarily state or reflect those of the United States-Government or any agency thereof. 


\section{DISCLAIMER}

Portions of this document may be illegible in electronic image products. Images are produced from the best available original document. 


\section{Assessment of Noble Gases in the Savannah River Site Environment(U)}

W. H. Carlton .

C. E. Murphy, Jr.

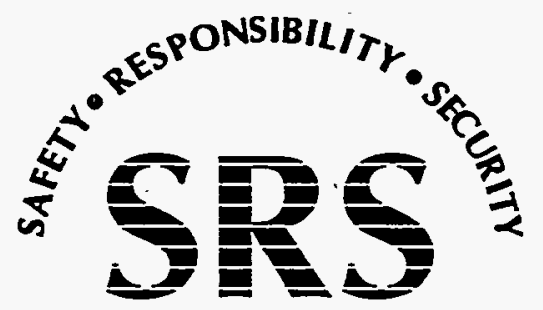

SAVANNAH RIVER SITE

Westinghouse Savannah River Company

Savannah River Technology Center

Aiken, SC 29808 


\section{Contents}

Executive Summary.

\section{Chapter 1.}

Introduction.

1-1

Basic Information on Noble Gases .................................... 1-3

References to Chapter 1................................................. 1-4

Chapter 2.

Origin and Disposition of Noble Gases at SRS 2-1

Origin of Noble Gases at SRS ......................................... $\quad 2-3$

Irradiation in Production Reactors...................................... 2-3

Other Sources Attributable to SRS Operations.................... 2-3

SRS Test Reactors................................................................................... . 2-3

Spontaneous Fission................................................................................ $\quad 2-4$

Neutron Activation Analysis.................................................................. $\quad 2-4$

Materials Originating Offsite................................................. 2 2-4

Disposition of Noble Gases at SRS ................................. 2 2-4

Noble Gases in Fuel and Targets Irradiated in Production

Reactors

Noble Gases in Certain Fuels Irradiated. Offsite.................. 2-5

Noble Gases in Fuel and Targets Irradiated

in Test Reactors................................................................. ' 2-5

Chapter 3.

Release of Noble Gases at SRS.................. 3-1

Reactor Facilities....................................................................... 3-3

Facility Operations ........................................................ 3-3

Production of Noble Gases.................................................... 3-3

History of Measured and Calculated Releases .................... 3-3

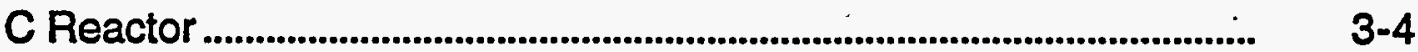

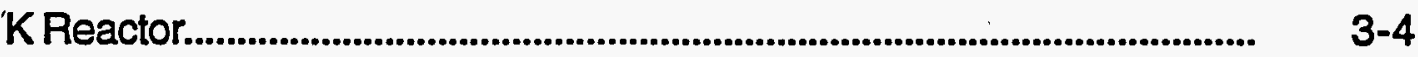

L Reactor ............................................................................................

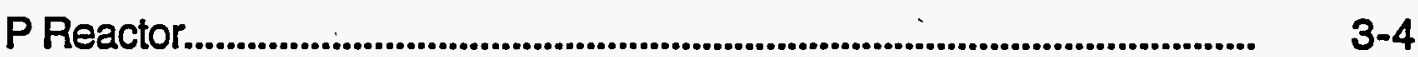


R Reactor.

Separations Facilities

Facility Operations

Production of Noble Gases.

History of Calculated Releases

References

Chapter 4.

Noble Gas Concentration and Transport

Mechanisms.

Atmospheric Transport of Noble Gases

Chapter 5.

Assessment of Dose/Risk from SRS Noble Gas Release ....................................................... 5-1

Relationship of Dose to Risk and Health Effects............. 5-3

lonizing Radiation ................................................................. $5-3$

Cancer Risk Estimates......................................................... $\quad 5: 3$

Noble Gas Exposure and Dose to Man .............................. 5-3

Distribution and Retention of Noble Gases

in the Human Body................................................................ $5-3$

Noble Gas Dosimetry.......................................................... 5-3

Models of Noble Gas Transport and Dose ........................ 5-4

Modeling Atmospheric Dispersion of Radioactive Releases 5-4 MAXIGASP ................................................................................................. $5-5$

POPGASP......................................................................................... 5-5

Modeling Doses from Liquid Releases ................................ 5-5

Verification of Atmospheric Transport Models

using Monitoring Data................................................... 5-6

Impact of SRS Noble Gas Releases

on the Offsite Population..................................................... 5-6 Comparison of Noble Gas Doses near SRS

with Applicable Regulations............................................ 5 5-6

Summary of Dosimetric Impacts ....................................... 5-7

References 


\section{List of Figures}

2.1. Areas within SRS which may be sources of noble gas releases 2-3

3.1. ${ }^{41} \mathrm{Ar}, \mathrm{C}$-Area Atmospheric Releases.

3-12

3.2. $85 \mathrm{mKr}, \mathrm{C}$-Area Atmospheric Releases

3-12

3.3. $87 \mathrm{Kr}$, C-Area Atmospheric Releases

3-13

3.4. ${ }^{88} \mathrm{Kr}$, C-Area Atmospheric Releases.

3-13

3.5. ${ }^{133} \mathrm{Xe}, \mathrm{C}-$ Area Atmospheric Releases

3-14

3.6. ${ }^{135} \mathrm{Xe}, \mathrm{C}$-Area Atmospheric Releases.

3-14

3.7. 41 Ar, K-Area Atmospheric Releases

3-15

3.8. $85 \mathrm{mKr}, \mathrm{K}$-Area Atmospheric Releases

3-15

3.9. $87 \mathrm{Kr}, \mathrm{K}$-Area Atmospheric Releases

3-16

3.10. ${ }^{88} \mathrm{Kr}$, K-Area Atmospheric Releases.

3-16

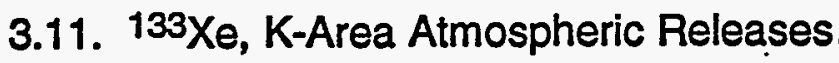

3-17

3.12. ${ }^{135} \mathrm{Xe}$, K-Area Atmospheric Releases

3-17

3.13. ${ }^{41} \mathrm{Ar}$, L-Area Atmospheric Releases

3-18

3.14. ${ }^{85 \mathrm{mKr}}$, L-Area Atmospheric Releases.

3-18

3.15. $87 \mathrm{Kr}$, L-Area Atmospheric Releases

3-19

3.16. ${ }^{88} \mathrm{Kr}$, L-Area Atmospheric Releases

3-19

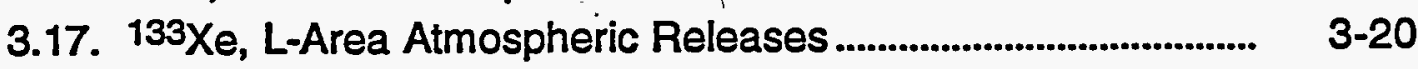

3.18. ${ }^{135} \mathrm{Xe}$, L-Area Atmospheric Releases ....................................... $\quad 3-20$

3.19. 41 Ar, P-Area Atmospheric Releases........................................... 3-21

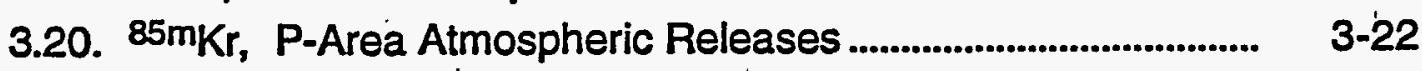

3.21. ${ }^{87} \mathrm{Kr}$, P-Area Atmospheric Releases........................................ 3-22

3.22. ${ }^{88} \mathrm{Kr}$, P-Area Atmospheric Releases............................................. 3-23

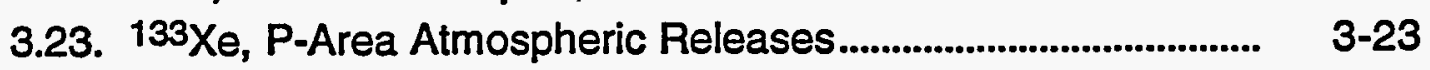

3.24. ${ }^{135} \mathrm{Xe}$, P-Area Atmospheric Releases........................................ 3-24

3.25. ${ }^{41}$ Ar, R-Area Atmospheric Releases .......................................... 3-24

3.26. $85 \mathrm{mK}$, R-Area Atmospheric Releases...................................... $\quad 3-25$

3.27. ${ }^{88} \mathrm{Kr}$, R-Area Atmospheric Releases............................................ $\quad 3-25$

3.28. ${ }^{133} \mathrm{Xe}$, R-Area Atmospheric Releases....................................... 3-26

3.29. ${ }^{135} \mathrm{Xe}$, R-Area Atmospheric Releases........................................ 3-26

3.30. ${ }^{85} \mathrm{Kr}$, F-Area and H-Area Atmospheric Releases.................... 3-. 3-27

3.31. $131 \mathrm{mXe}, \mathrm{F}$-Area and $\mathrm{H}$-Area Atmospheric Releases............... 3-. 3-27

3.32. ${ }^{133} \mathrm{Xe}$, F-Area and H-Area Atmospheric Releases ................... 3-28 


\section{List of Figures (continued)}

4.1. The Air Concentration of ${ }^{85} \mathrm{Kr}$ and the Comparison of the BestFit Straight Line of the ${ }^{85} \mathrm{Kr}$ and Tritium Air Concentration Samples in 1976

4.2. Comparison of the Contours of $85 \mathrm{Kr}$ and Tritium Air Concentrations in the Vicinity of SRS.

5.1. Simplified Pathways between Radioactive Releases to the Atmosphere and Man

\section{List of Tables}

1-1. Noble Gases Produced at SRS

3-1. C-Area Atmospheric Releases....................................................... 3-.

3-2. K-Area Atmospheric Releases......................................................... 3-7

3-3. L-Area Atmospheric Releases .......................................................... 3-8

3-4. P-Area Atmospheric Releases........................................................ 3-9

3-5. R-Area Atmospheric Releases...................................................... 3-10

3-6. F-Area and H-Area Atmospheric Releases ............................... 3-11

5-1. Site-Specific Parameters for Atmospheric Releases................ 5-7

5-2. Sum of Atmospheric Releases from SRS..................................... 5- 5-8

5-3. Dose to the Maximum Individual from SRS Atmospheric Releases................................................. 5-9

5-4. Population Dose from SRS Atmospheric Releases.................. $\quad 5-10$ 


\section{EXECUTIVE SUMMARY}

A series of documents has been published that assesses the impact of various radionuclides released to the environment by Savannah River Site (SRS) operations. The quantity released, the disposition of the radionuclides in the environment, and the dose to offsite individuals has been presented for carbon, cesium, iodine, plutonium, strontium, technetium, tritium, and uranium. An assessment of the impact of non-radioactive mercury also has been published.

This document assesses the impact of radioactive noble gases released from $S R S$ facilities since the first reactor became operational late in 1953. Various isotopes of argon, krypton, and xenon have contributed radiation dose to people living near SRS.

Release pathways, emission control features, and annual releases to the atmosphere are discussed. No single incident has resulted in a major acute release of noble gases to the environment. The releases were the result of normal operations of the reactors and separation facilities. Releases declined over the years as better controls were established and production declined.

Routine air concentration measurements are not made of noble gases released by SRS operations $\left({ }^{41} \mathrm{Ar},{ }^{85} \mathrm{Kr},{ }^{85} \mathrm{~m} \mathrm{Kr},{ }^{87} \mathrm{Kr},{ }^{88} \mathrm{Kr},{ }^{131} \mathrm{nXe},{ }^{133} \mathrm{Xe}\right.$, and $\left.{ }^{135} \mathrm{Xe}\right)$. However, studies have been conducted in which the noble gases released from $S R S$ facilities were traced in the atmosphere.

The overall radiological impact of SRS noble gas releases between 1954 and 1992 on the offsite maximum individual can be characterized by a total dose of 8.3 mrem. During this same period such an individual received a total dose of 13,500 mrem from non-SRS sources of ionizing radiation present in the environment.

The impact of SRS noble gas releases on offsite populations also has been evaluated. The total collective dose from atmospheric releases between 1954 and 1992 was estimated as 220 person-rem, distributed among 555,100 individuals. Using international dose factors, less than one cancer death is predicted from SRS releases while about 90,000 fatal cancers will occur from all other causes.

Noble gases released from SRS present a negligible risk to the offsite environment and the population it supports. 
This page intentionally left blank. 


\section{Chapter 1. Introduction}

A series of documents has been published that assesses the impact of various radionuclides released to the environment by SRS operations. The quantity released, the disposition of the radionuclides in the environment, and the dose to offsite individuals has been presented for carbon, cesium, iodine, plutonium, strontium, technetium, tritium, and uranium. An assessment of non-radioactive mercury also has been published.

Radioactive noble gases have been released from SRS facilities since the first reactor became operational late in 1953. This chapter will describe the noble gases and set the stage for understanding their importance in the SRS environment. 
This page intentionally left blank. 


\section{Basic Information on Noble Gases}

The noble gases are helium (He), neon (Ne), argon (Ar), krypton (Kr), xenon (Xe), and radon (Rn). They are colorless and tasteless, and-prior to 1962-they were called inert gases because it was believed that they did not react with other atoms. Compounds now have been reported for $\mathrm{Kr}, \mathrm{Xe}$, and $\mathrm{Rn}$, bùt the others do not appear to be able to form compounds (Brady, 1978). In any event, the noble gases rarely react chemically. Some noble gas nuclides were produced in SRS reactors, were radioactive, and were released to the environment. All releases were to the atmosphere; there were no releases to streams or groundwater. The SRS-produced noble gas nuclides are listed in Table 1-1.

Table 1-1. Noble Gas Nuclides Produced at SRS (Lederer, 1967)

\begin{tabular}{lll} 
Nuclide & Half-Life & Method of Production \\
\hline${ }^{41} \mathrm{Ar}$ & $1.8 \mathrm{hrs}$ & $\mathrm{AP}$ \\
${ }^{85} \mathrm{Kr}$ & $10.8 \mathrm{yrs}$ & $\mathrm{AP}$ and FP \\
${ }^{85 \mathrm{~m} \mathrm{Kr}}$ & $4.4 \mathrm{hrs}$ & $\mathrm{AP}$ and FP \\
${ }^{87} \mathrm{Kr}$ & $76 \mathrm{~min}$ & $\mathrm{AP}$ and FP \\
${ }^{88} \mathrm{Kr}$ & $2.8 \mathrm{hrs}$ & $\mathrm{FP}$ \\
${ }^{131 \mathrm{~m} \mathrm{Xe}}$ & 12 days & $\mathrm{AP}$ \\
${ }^{133 \mathrm{Xe}}$ & 5.3 days & $\mathrm{AP}$ and FP \\
${ }^{135 \mathrm{Xe}}$ & $9.1 \mathrm{hrs}$ &. $\mathrm{AP}$ and FP
\end{tabular}

AP = Activation Product

FP $=$ Fission Product

The nuclides produced by activation (absorption of a neutron by the nucleus) generally are produced in a reactor outside the fuel cladding and are released to the environment soon after creation. The nuclides that are fission products are generally released only when the fuel undergoes chemical processing, which at SRS almost always was more than 200 days after the fuel was removed from a reactor. The short half-life - nuclides decayed to insignificance either before processing began or shortly after release to the environment. All the nuclides listed in Table 1-1 will be discussed in this document, but it soon will become clear that ${ }^{85} \mathrm{Kr}$ was released in the largest quantities while ${ }^{41} \mathrm{Ar}$ delivered the highest dose to humans.

Krypton-85 is produced naturally by cosmic ray interactions in the upper atmosphere and by spontaneous fission of natural uranium. The worldwide equilibrium activity is approximately 10 $\mathrm{Ci}$ from cosmic ray interactions and $2 \mathrm{Ci}$ from spontaneous fission (NCRP, 1975). These quantities are insignificant when compared to weapons tests and reactor production. Between 1945 and 1962, approximately $5,000,000 \mathrm{Ci}$ of ${ }^{85} \mathrm{Kr}$ was produced as a result of nuclear weapons tests (NCRP, 1975), and it will be seen in later chapters of this document that even larger quantities were released from SRS operations.

Very little of the ${ }^{85} \mathrm{Kr}$ produced by reactors is released during operation of the reactors because the fuel cladding provides a tight seal. Most fuel used in U.S. power reactors has not been reprocessed; the $85 \mathrm{Kr}$ is tightly contained and decaying with a half-life of 10.8 years. Countries that do reprocess fuel are contributing to the worldwide atmospheric inventory of ${ }^{85} \mathrm{Kr}$.

Noble gases in the atmosphere remain there and are dispersed worldwide. Only about 3\% of krypton dissolves in the oceans, and an even smaller fraction is dispersed in the soils and rocks of the earth.

Argon-41 has a much shorter half-life (1.8 hours) than ${ }^{85} \mathrm{Kr}$. Despite this, ${ }^{41} \mathrm{Ar}$ delivers a much higher dose per Curie released. There are two reasons: the beta particle released by ${ }^{41} \mathrm{Ar}$ has almost twice the energy of the ${ }^{85} \mathrm{Kr}$ beta, and an energetic gamma $(1.29 \mathrm{MeV})$ is released during $99 \%$ of the ${ }^{41} \mathrm{Ar}$ disintegrations, while a lower energy gamma $(0.5$ $\mathrm{MeV}$ ) is released during $0.4 \%$ of the ${ }^{85} \mathrm{Kr}$ disintegrations. 


\section{References}

Brady, J. E., and G. E. Humiston, 1978, "General

Chemistry," John Wiley \& Sons, pp. 592-594.

Lederer, C. M., J. M. Hollander, and I. Perlman, 1967, "Table of Isotopes," Sixth Edition, John' Wiley \& Sons.

National Council on Radiation Protection and Measurements, 1975, "Krypton-85 in the Atmosphere-Accumulation, Biological Significance, and Control Technology, "Report No. 44. 


\section{Chapter 2. Origin and Disposition of Noble Gases at SRS}

This chapter offers a general overview of the origin, uses, and disposition of noble gases at SRS under normal operating conditions. Releases of noble gases have occurred throughout the years of site operation and originated from the chemical separation facilities and the reactor facilities located near the center of the 800-square-kilometer site. Figure 2.1 shows the location of site facilities. The history of actual releases from specific SRS facilities is presented in Chapter 3. 


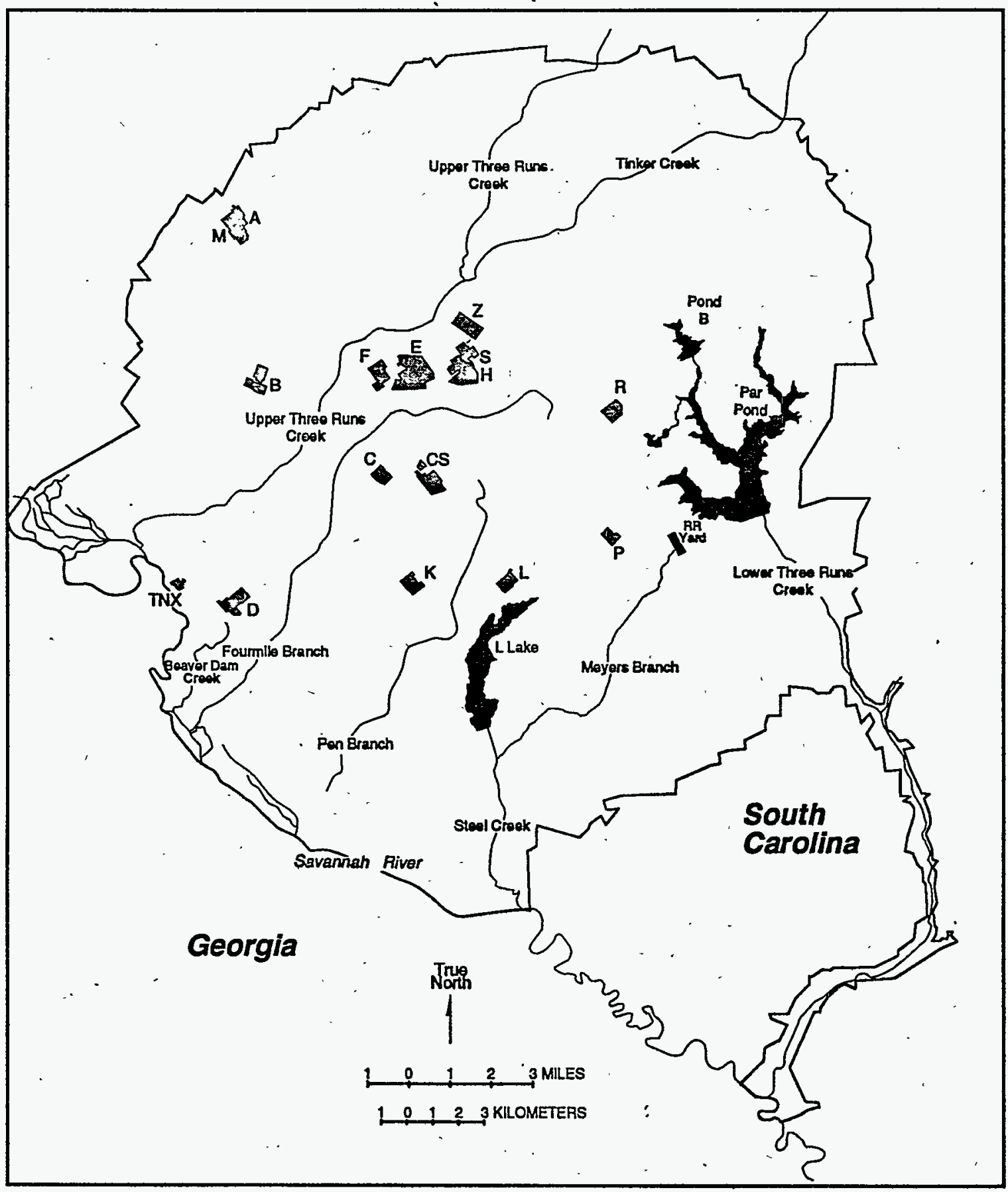

Figure 2.1. Areas within SRS which may be sources of noble gas releases

No3A030.04 


\section{Origin of Noble Gases at SRS}

Noble gases at SRS originated in two ways: (1) as fission products in the fuel and targets that were irradiated in the nuclear materials production reactors and released when the fuel and targets were chemically processed in the separation areas, and (2) as activation products when neutrons produced in the reactor vessel irradiated air surrounding the vessel or air dissolved in the moderator. Other site operations and offsite sources contributed small amounts to the inventory of noble gases at SRS.

\section{Irradiation in Production Reactors}

Most of the noble gases at SRS were formed during role of these reactors was to produce special nuclear materials-principally tritium and plutonium-for national defense purposes. Additional radionuclides such as ${ }^{238} \mathrm{Pu}$, a power source for certain deep-space missions, occasionally were produced for other government purposes.

Although SRS reactors became operational in 19531955, they have not operated continuously. They alternated between operating periods for production and shutdown periods for maintenance or the replacement of fuel and targets. As of 1995, all reactors are shut down, although one is on standby status. The history of individual reactor operations is discussed in Chapter 3.

Neutron-induced fission was one mechanism for production of noble gases in the reactors. When a reactor was operating, neutron-induced fission reactions occurred in the ${ }^{235} \mathrm{U}$ fuel of the reactor core. Fission reactions formed a variety of fission products, including ${ }^{85} \mathrm{Kr},{ }^{85} \mathrm{Kr},{ }^{87} \mathrm{Kr}$, ${ }^{88} \mathrm{Kr}$, ${ }^{133} \mathrm{Xe}$, and ${ }^{135} \mathrm{Xe}$.

In addition to fission products, each neutron-induced fission reaction in the fuel produced several neutrons, some of which induced additional fission reactions and maintained a chain reaction. Some of the remaining neutrons interacted with target materials in the reactor. (Fuel and targets were encapsulated separately and referred to as elements.) One such interaction, neutron capture in a ${ }^{238} \mathrm{U}$ target, resulted in the production of a special nuclear material, ${ }^{239} \mathrm{Pu}$. Other neutrons escaped from the reactor vessel and interacted with air in space around the reactor, creating activation products such as ${ }^{41} \mathrm{Ar},{ }^{85} \mathrm{Kr}$, ${ }^{85 \mathrm{~m} K r},{ }^{87} \mathrm{Kr},{ }^{131 \mathrm{~m} X e},{ }^{133} \mathrm{Xe}$, and ${ }^{135} \mathrm{Xe}$.

In certain target materials such as ${ }^{238} \mathrm{U}$, neutroninduced fission is a competing reaction. In the case of
${ }^{238} \mathrm{U}$ targets, fission also occurs in the minor constituents such as ${ }^{235} \mathrm{U}$ and ${ }^{239} \mathrm{Pu}$.

\section{Other Sources Attributable to SRS Operations}

Small quantities of noble gases were produced at SRS by test reactors, spontaneous fission, and neutron activation analysis. The activity levels of noble gases from these sources were insignificant when compared to the activity levels created in the reactors. However, these sources are discussed in the following subsections to provide a complete overview of potential noble gas releases.

\section{SRS Test Reactors}

Several small nuclear reactors were in use at two SRS locations from the 1950s through the 1970s. The Heavy Water Components Test Reactor (HWCTR), located in B Area, was used in the early 1960 s to test prototype fuels for a proposed heavy water power reactor. The other test reactors, located in $\mathbf{M}$ Area, were used from the mid 1950 s through the late 1970s. The Process Development Pile and the Lattice Test Reactor were used as zero-power mock-up facilities to test components for the production reactors. The Subcritical Experimental Pile also was used to test component designs. The Standard Pile provided neutrons for experiments such as neutron radiography and neutron activation.

\section{Spontaneous Fission}

Spontaneous fission is a radioactive decay mode that occurs in heavy elements such as uranium that produces neutrons and fission-product noble gases. Spontaneous fission is one of the mechanisms for the production of noble gases in nature. Occurrence of spontaneous fission ranges from rare to frequent. Uranium-238 is an example of a radionuclide in which spontaneous fission occurs infrequently.

Californium-252 is a valuable neutron source because it frequently undergoes spontaneous fission. Californium-252 was produced in SRS reactors by the irradiation of ${ }^{244} \mathrm{Cm}$ targets. From the mid $1960 \mathrm{~s}$ until 1987, the Savannah River Technology Center (SRTC) fabricated industrial and medical ${ }^{252} \mathrm{Cf}$ sources for offsite use. Some of the sources were retained at SRS for neutron calibrations in the ${ }^{252} \mathrm{Cf}$ fabrication facility and for two neutron activation facilities. One ${ }^{252} \mathrm{Cf}$ neutron activation facility was 
operated in M Area during the 1970s. The other has been operational at SRTC since the mid 1970s. Noble gases are produced during the spontaneous fission of ${ }^{252} \mathrm{Cf}$.

Other isotopes of uranium and isotopes of thorium, plutonium, and curium also fission spontaneously. One or more of the materials discussed in this subsection were used in M Area, the reactor areas, the chemical separation areas, the Naval Fuels Facility, TNX Semiworks, and SRTC.

\section{Neutron Activation Analysis}

Neutron activation analysis is a technique for measurement of elemental compositions in materials. The ${ }^{252} \mathrm{Cf}$ neutron activation facilities and the $\mathrm{C}$ and $\mathrm{K}$ production reactors were used for the analysis of low levels of ${ }^{129} \mathrm{I}$ and uranium. For example, from the late 1970 s to the mid $1980 \mathrm{~s}$, environmental samples were activated in $C$ Reactor to determine uranium content. Traces of fission-product noble gases were produced in the irradiated samples.

\section{Materials Originating Offsite}

Certain fuels irradiated at offsite, noncommercial facilities were shipped to SRS for reprocessing. While awaiting reprocessing, the fuel was stored in the Receiving Basin for Offsite Fuel (RBOF) located in $\mathrm{H}$ Area.

Noble gases also were purchased from commercial vendors. These isotopes. were used at SRS for purposes such as instrument calibration. The amounts are insignificant when compared to that produced in fúel and targets in SRS production reactors or produced in fuel offsite and shipped to SRS.

\section{Disposition of Noble Gases at SRS}

Noble gases produced outside the fuel or target elements were released rapidly through the ventilation system and exited a 61-meter stack in the reactor areas. Noble gases produced by fission in the fuel or targets remained in place (except for minor leaks) until processed in the separation facilities.

\section{Noble Gases in Fuel and Targets Irradiated in Production Reactors}

Under ideal operating conditions, noble gases were contained within the cladding of fuel and target elements during both irradiation and cooling. Cooling is the interval between the end of irradiation and the beginning of chemical separation. Irradiated materials are stored underwater in reactor basins for most of this time. Beginning in the 1970s, the cooling time was at least 200 days for most irradiated materials for control of radioiodine emissions. This cooling time had relatively little effect on the inventory of ${ }^{85} \mathrm{Kr}$ but allowed for almost complete decay of other noble gases.

Under normal operating conditions; it was possible for noble gases to escape from irradiated fuel and target elements to the reactor moderator or to the water in the cooling basins through small defects in the clädding. Air exiting the reactor stacks was monitored for such releases. Actual releases are described in greater detail in Chapter 3.
Occasionally, the small defects developed into holes or splits in the cladding. This was called failure of the element. When a failure occurred, the reactor was shut down and the failed element was transferred into a container called a "harp," which was stored underwater in the reactor basin and vented to the reactor stack. Failures occurred more frequently in the early years of operation than in later years.

After the cooling period, fuel and targets were treated in the chemical separation areas. During the chemical separation process, targets were treated by the Purex process in F Area to recover ${ }^{239} \mathrm{Pu},{ }^{237} \mathrm{~Np}$, and ${ }^{238} \mathrm{U}$ from irradiated ${ }^{238} \mathrm{U}$. The Purex process extracted plutonium and uranium into an organic solvent for separation and purification from waste products. Fuel was treated by the H Modified Purex (HM) process in $\mathrm{H}$ Area to recover ${ }^{235} \mathrm{U}$ and ${ }^{237} \mathrm{~Np}$ from irradiated ${ }^{235} \mathrm{U}$; until 1959, the Purex process was used in $\mathrm{H}$ Area. The principal difference was that the HMM process used mercuric nitrate as a catalyst to enhance the dissolution of the irradiated fuel. Also in H Area, ${ }^{238} \mathrm{Pu}$ was occasionally recovered from ${ }^{237} \mathrm{~Np}$ targets by the Frames process.

During the separation process, all of the remaining noble gases (predominantly ${ }^{85} \mathrm{Kr}$ ) were released through 61-meter stacks. Insignificant quantities may have remained in liquid and solid waste, but they do not warrant further consideration. Krypton-85 released through the stacks could be detected offsite with specially designed monitoring equipment. 


\section{Noble Gases in Certain Fuels Irradiated Offsite}

Irradiated fuels received from certain offsite facilities were stored underwater in RBOF until the fuel was ready for chemical separation. The fuel then entered the regular process stream in $\mathrm{H}$ Area. The disposition of noble gases became the same as described for fuel irradiated in SRS production reactors.

\section{Noble Gases in Fuel and Targets Irradiated in Test Reactors}

Fuels and targets from the various test reactors were sent primarily to the RBOF for cooling before chemical separation. Some were sent to SRTC for research or to reactor materials fabrication facilities, which only received fuel or targets that had not been irradiated. This material was blended into the standard fabrication process for targets and fuel to be used in the production reactors. Because only minute quantities of naturally produced noble gases occurred in the fabricated materials (such as ${ }^{238} \mathrm{U}$ ), no monitoring for noble gases was conducted at fabrication facilities 


\section{This page intentionally left blank.}




\section{Chapter 3. Releases of Noble Gases at SRS}

Routine operations at SRS facilities have released noble gases to the regional environment surrounding the Site. This chapter presents a discussion on noble gases at SRS facilities in terms of possible release pathways, emission control features, and annual releases to the atmospheric environment.

No single incident has resulted in a major acute release of noble gases to the environment. Releases that occurred were the result of normal operation of the reactors and separation facilities. Releases declined through the years as better controls were established and as production declined. 
This page intentionally left blank. 


\section{Reactor Facilities}

The five production reactors at SRS are identified by the letter designations $C, K, L, P$, and $R$. The reactors were designed to irradiate various targets to produce special nuclear materials (principally tritium and plutonium) for national defense purposes.

\section{Facility Operations}

When a nuclear reactor was operating, nuclear fission reactions occurred in the reactor core. The principal components of the core are the fuel, targets, control rods, and moderator. Control rods are neutron-absorbing materials positioned in the core to control the power level of a reactor.

The moderator in SRS reactors was heavy water, which was circulated around the fuel and target elements in the reactor core. The moderator decreased the kinetic energy (slowed the speed) of neutrons emitted in the fission process. Slow neutrons have a greater probability than fast neutrons for interaction with fuel and target materials.

The moderator also functioned as the primary coolant to remove heat from fuel and target elements. Heat then was transferred from the moderator by heat exchangers to the secondary coolant. SRS reactors used either river or pond water as the secondary coolant in the heat exchangers.

In reactors that used water from the Savannah River as the secondary coolant, the river water was passed through the shell side of the heat exchanger and discharged to a site stream that flowed to the Savannah River. Reactors that used pond water as the secondary coolant discharged the water from the heat exchanger to a canal that flowed to a series of cooling ponds. Cooled pond water was recirculated through the heat exchanger.

Under normal operating conditions, fuel and target elements were irradiated for a specified time, removed from the reactor core, and stored underwater in the Vertical Tube Storage (VTS) basin of the reactor building. Storage in VTS for the cooling period, usually at least 200 days, allowed short-lived radionuclides to decay to low levels before the reprocessing of the fuel and targets began. After cooling, the elements were . moved to the disassembly basin and prepared for transfer to the chemical separation areas.

The abnormal condition of a fuel or target failure was detected by sensors in the reactor core. When a failure occurred, the reactor was shut down and the failed element was transferred into a "harp," which was stored underwater in the reactor basin and vented to the reactor stack.

\section{Production of Noble Gases}

Most of the radioactive noble gases released from the reactors were formed by neutron activation. Stable isotopes of trace constituents in air passing near the reactor vessel were subjected to an intense neutron flux. Some of the neutrons were captured by the stable nuclei and formed radioactive nuclei, which were monitored as they left the stack In some instances, the quantities of radioactive materials released were calculated or estimated when they were not monitored.

The highest dose occurred from the release of ${ }^{41} \mathrm{Ar}$, which was created when the nucleus of stable ${ }^{40} \mathrm{Ar}$ captured a neutron. In a similar manner, the nuclei of ${ }^{84} \mathrm{Kr},{ }^{86} \mathrm{Kr},{ }^{132} \mathrm{Xe}$, and ${ }^{134} \mathrm{Xe}$ also captured neutrons and became radioactive. Xenon-135 also is a fission product that leaked into the moderator from exposed fuel and diffused in the helium blanket gas. It was then released through normal leakage and periodic purges of the blanket gas (Taylor, 1973).

Noble gases also were created from fission of heavy nuclei in the fuel and targets, and small amounts were released. The dose was insignificant in comparison with that from activation products.

\section{History of Measured and Calculated Releases.}

After 1973, reactor stack air was continuously monitored for ${ }^{41} \mathrm{Ar},{ }^{85} \mathrm{~m} \mathrm{Kr},{ }^{87} \mathrm{Kr},{ }^{88} \mathrm{Kr}$, ${ }^{133} \mathrm{Xe}$, and ${ }^{135} \mathrm{Xe}$ using a lithium-drifted germanium (Ge[Li]) detector mounted at the bottom of a 2.8liter sample cell through which stack gases were passed continuously. Earlier releases were calculated based on a grab-sampling system that provided comparable values (Wood and Randolph, 1975) and were reported in Cummins (1991). 


\section{Reactor}

C Reactor was operational from 1955 until it was shut down for extensive maintenance in 1985; as of 1995 it is permanently shut down. Releases are shown in Table 3-1 and Figures 3.1 through 3.6

\section{KReactor}

K Reactor was operational from 1954 until 1988. It also operated briefly in 1992; but as of 1995; it is in a standby condition. Releases are shown in Table 3-2 and Figures 3.7 through 3.12.

\section{Reactor}

L Reactor was operational from 1954 to 1968 , when it was placed in standby. It was refurbished beginning in the early 1980 s, restarted in 1985 , and operated until 1988; as of 1995, it is permanenttly shut down. Releases are shown in Table 3-3 and Figures 3.13 through 3.18.

\section{$P$ Reactor}

P Reactor was operational from 1954 until 1988; as of 1995 , it is permanently shut down. Releases are shown in Table 3-4 and Figures 3.19 through 3.24 .

\section{R Reactor}

R Reactor, the first operational production reactor at SRS, operated from late 1953 until 1964, when it was placed on inactive status; as of 1995 , it is permanently shut down. Releases are shown in Table 3-5 and Figures 3.25 through 3.29 .

\section{Separation Facilities}

Two chemical separation areas located near the center of the Site (Figure 3-1) are identified by the letter designations $\mathrm{F}$ and $\mathrm{H}$. In these areas, the products of interest such as ${ }^{239} \mathrm{Pu}$ were chemically separated and purified from waste products. Occasional special campaigns have occurred for the production of radionuclides such as ${ }^{238 \mathrm{Pu}}$ and ${ }^{252} \mathrm{CF}$.

\section{Facility Operations}

The two chemical separation facilities were used to reprocess irradiated fuel and targets in canyon buildings (221-F and 221-H).

Beginning in late $1954,{ }^{239} \mathrm{Pu},{ }^{237} \mathrm{~Np}$, and ${ }^{238} \mathrm{U}$ generally were recovered from irradiated ${ }^{238} \mathrm{U}$ targets in F Area, which used the Purex chemical extraction process. In $\mathrm{H}$ Area, ${ }^{239} \mathrm{Pu}$ and ${ }^{238} \mathrm{U}$ were recovered from ${ }^{238} \mathrm{U}$ targets by the Purex process during 1955-1959. The $\mathrm{H}$ Area facility then was modified to recover ${ }^{235} \mathrm{U}$ from irradiated enriched uranium fuel. A further modification in 1963 allowed the recovery of ${ }^{237} \mathrm{~Np}$ from the fuel; the HM process was used for chemical extraction of the uranium. Also in $\mathrm{H}$ Area, the Frames process was used occasionally to recover ${ }^{238} \mathrm{Pu}$ and ${ }^{237} \mathrm{~Np}$ from special target elements. This process used ion exchange for separation and purification.

\section{Production of Noble Gases}

Noble gases were produced in the fuel and targets as a result of fission of uranium and plutonium nuclei. Because the fuel and targets were encapsulated, the noble gases remained in place (except for minor leaks) until the chemical separation process removed the cladding, and dissolving occurred. Essentially all of the noble gases were vented through one of the 61-meter stacks in $\mathrm{F}$ and $\mathrm{H}$ Areas.

\section{History of Calculated Releases}

Noble gases were not routinely monitored in $F$ and $\mathrm{H}$ Areas because it was more accurate to calculate the quantities produced during the fission process and released during dissolving. An early report (Arnett, 1955) discussed the comparison of SRS calculations with Hanford methods for ${ }^{85} \mathrm{Kr}$, ${ }^{131 m X e}$, and ${ }^{133} \mathrm{Xe}$. Few details of the calculation were reported, but the results were in agreement with Hanford within $3.3 \%$, and the differences were in the decay schemes and fission yields used. 
The release of ${ }^{85} \mathrm{Kr}$ occurred rapidly beginning 0.5 hours after fuel was loaded into a hot dissolver in 221-H; 60\% was released after 4 hours and essentially $100 \%$ after 14 hours (Perkins, 1975). Xenon-131m and ${ }^{133}$ Xe were released at the same time.
Releases of ${ }^{85} \mathrm{Kr}$ prior to 1971 are not available in the open literature; so for purposes of dose calculation, they are estimated by assuming that each year's release was equal to the 1971-86 average (Figure 3.30)

\section{References}

Arnett, L. M., 1955, "Operation Bluenose," DPST-55-356, E. I. du Pont de Nemours and Company, Aiken, SC.

Cummins, C. L., C. S. Hetrick, and D. K. Martin, 1991, "Radioactive Releases at the Savannah River Site 1954-1989," WSRC-RP91-684, Westinghouse Savannah River Company, Aiken, SC.

Perkins, W. C., 1975, ${ }^{855} \mathrm{Kr}$ Release from $221-\mathrm{H}$ Dissolvers," DPST-75-208, E. I. du Pont de Nemours and Company, Aiken, SC.
Taylor, R. W., 1973, "Atmospheric Detection and Measurement of Radioactive Noble Gases," DPST-73-459, E. I. du Pont de Nemours and Company, Aiken, SC.

Wood, M. B., and H. W. Randolph, 1975, "Continuous Monitoring of Noble Gases in Reactor Stack Exhausts," in Proceedings of the Thirteenth Air Cleaning Conference, CONF740807, UC-70, National Technical Information Service, Springfield, VA. 
Table 3-1. C-Area Atmospheric Releases

Activity Released (Curies)

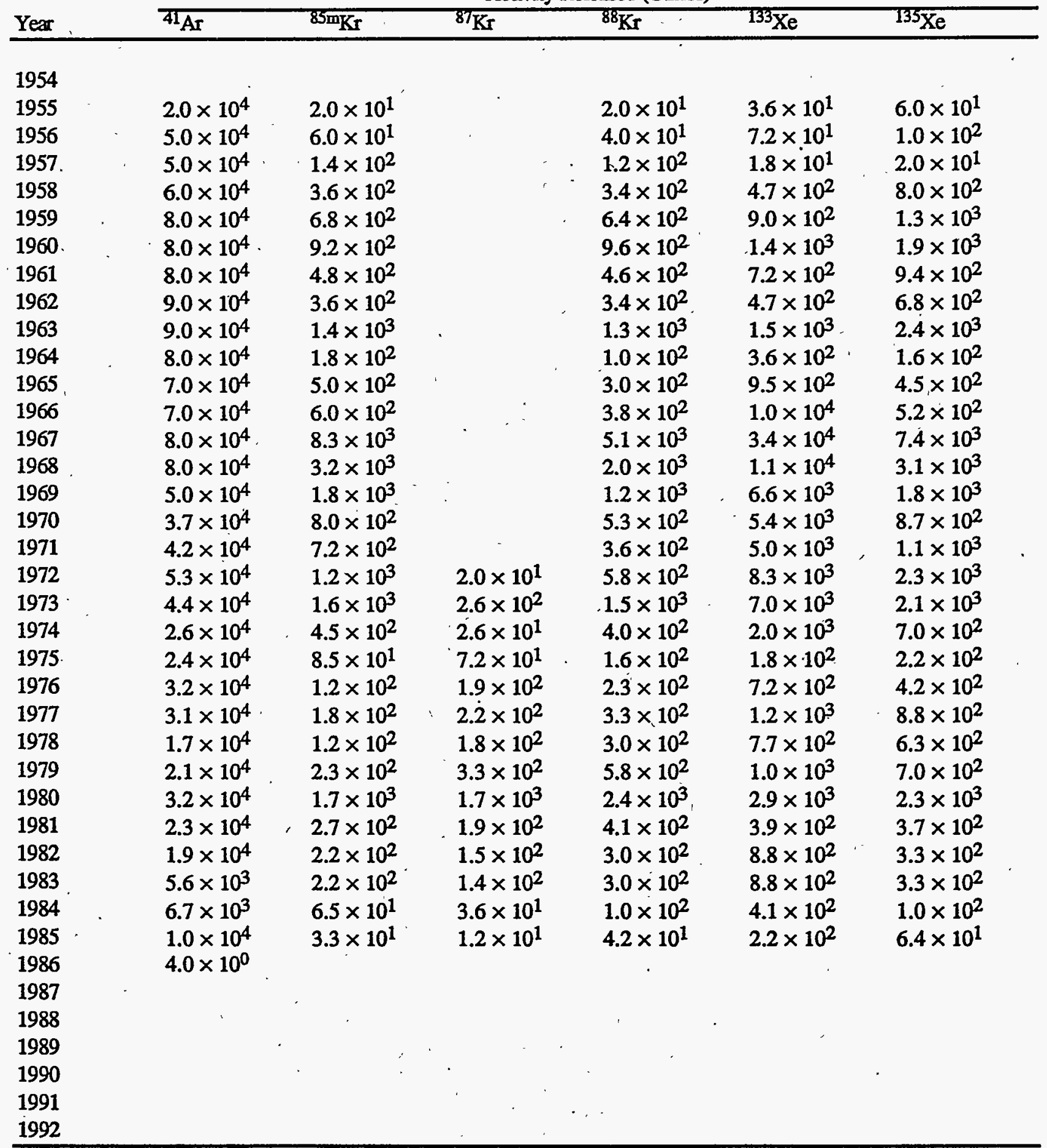

1954-89 release data from Cummins, Hetrick, and Martin, 1991

1990-92 release data from annual environmental reports 
Table 3-2. K-Area Atmospheric Releases

Activity Released (Curies)

\begin{tabular}{|c|c|c|c|c|c|c|}
\hline Year & $41 \overline{\mathrm{Ar}}$ & $85 m_{\mathrm{Kr}}$ & ${ }^{87} \mathrm{Kr}$ & ${ }^{88} \mathbf{K r}$ & ${ }^{133} \mathrm{Xe}$ & $35 \mathrm{Xe}$ \\
\hline 1954 & & & & & & \\
\hline 1955 & $3.0 \times 10^{4}$ & $2.0 \times 10^{1}$ & & $2.0 \times 10^{1}$ & $3.6 \times 10^{1}$ & $6.0 \times 10^{1}$ \\
\hline 1956 & $5.0 \times 10^{4}$ & $6.0 \times 10^{1}$ & & $4.0 \times 10^{1}$ & $7.2 \times 10^{1}$ & $1.0 \times 10^{2}$ \\
\hline 1957 & $6.0 \times 10^{4}$ & $1.4 \times 10^{2}$ & & $1.2 \times 10^{2}$ & $1.8 \times 10^{1}$ & $2.0 \times 10^{1}$ \\
\hline 1958 & $7.0 \times 10^{4}$ & $3.6 \times 10^{2}$ & & $3.4 \times 10^{2}$ & $4.7 \times 10^{2}$ & $8.0 \times 10^{2}$ \\
\hline 1959 & $9.0 \times 10^{4}$ & $6.8 \times 10^{2}$ & & $6.4 \times 10^{2}$ & $9.0 \times 10^{2}$ & $1.3 \times 10^{3}$ \\
\hline 1960 & $8.0 \times 10^{4}$ & $9.2 \times 10^{2}$ & & $9.6 \times 10^{2}$ & $1.4 \times 10^{3}$ & $1.9 \times 10^{3}$ \\
\hline 1961 & $8.0 \times 10^{4}$ & $4.8 \times 10^{2}$ & & $4.6 \times 10^{2}$ & $7.2 \times 10^{2}$ & $9.4 \times 10^{2}$ \\
\hline 1962 & $.8 .0 \times 10^{4}$ & $3.6 \times 10^{2}$ & & $3.4 \times 10^{2}$ & $4.7 \times 10^{2}$ & $6.8 \times 10^{2}$ \\
\hline 1963 & $9.0 \times 10^{4}$ & $1.4 \times 10^{3}$ & & $1.3 \times 10^{3}$ & $1.5 \times 10^{3}$ & $2.4 \times 10^{3}$ \\
\hline 1964 & $7.0 \times 10^{4}$ & $1.8 \times 10^{2}$ & ' & $1.0 \times 10^{2}$ & $3.6 \times 10^{2}$ & $1.6 \times 10^{2}$ \\
\hline 1965 & $7.0 \times 10^{4}$ & $5.0 \times 10^{2}$ & & $3.0 \times 10^{2}$ & $9.5 \times 10^{2}$ & $4.5 \times 10^{2}$ \\
\hline 1966 & $7.0 \times 10^{4}$ & $6.0 \times 10^{2}$ & & $3.8 \times 10^{2}$ & $1.0 \times 10^{4}$ & $5.2 \times 10^{2}$ \\
\hline 1967 & $8.0 \times 10^{4}$ & $8.3 \times 10^{3}$ & & $5.1 \times 10^{3}$ & $3.4 \times 10^{4}$ & $7.4 \times 10^{3}$ \\
\hline 1968 & $7.0 \times 10^{4}$ & $3.2 \times 10^{3}$ & & $2.0 \times 10^{3}$ & $1.1 \times 10^{4}$ & $3.1 \times 10^{3}$ \\
\hline 1969 & $5.0 \times 10^{4}$ & $1.8 \times 10^{3}$ & & $1.2 \times 10^{3}$ & $6.6 \times 10^{3}$ & $1.8 \times 10^{3}$ \\
\hline 1970 & $3.7 \times 10^{4}$ & $8.0 \times 10^{2}$ & & $5.3 \times 10^{2}$ & $5.4 \times 10^{3}$ & $8.7 \times 10^{2}$ \\
\hline 1971 & $4.0 \times 10^{4}$ & $8.4 \times 10^{2}$ & & $2.7 \times 10^{2}$ & $3.5 \times 10^{3}$ & $7.1 \times 10^{2}$ \\
\hline 1972 & $5.8 \times 10^{4}$ & $4.5 \times 10^{3}$ & $2.2 \times 10^{3}$ & $2.8 \times 10^{3}$ & $1.8 \times 10^{4}$ & $7.2 \times 10^{3}$ \\
\hline 1973 & $7.1 \times 10^{4}$ & $3.1 \times 10^{3}$ & $1.4 \times 10^{3}$ & $3.8 \times 10^{3}$ & $9.8 \times 10^{3}$ & $4.5 \times 10^{3}$ \\
\hline 1974 & $3.0 \times 10^{4}$ & $8.9 \times 10^{2}$ & $3.1 \times 10^{2}$ & $9.5 \times 10^{2}$ & $3.3 \times 10^{3}$ & $1.4 \times 10^{3}$ \\
\hline 1975 & $1.8 \times 10^{4}$ & $2.2 \times 10^{2}$ & $2.7 \times 10^{2}$ & $4.4 \times 10^{2}$ & $6.8 \times 10^{2}$ & $3.9 \times 10^{2}$ \\
\hline 1976 & $2.4 \times 10^{4}$ & $8.8 \times 10^{1}$ & $1.2 \times 10^{2}$ & $1.5 \times 10^{2}$ & $4.2 \times 10^{2}$ & $1.5 \times 10^{2}$ \\
\hline 1977 & $1.6 \times 10^{4}$ & $4.9 \times 10^{1}$ & $6.4 \times 10^{1}$ & $7.2 \times 10^{1}$ & $2.4 \times 10^{2}$ & $1.1 \times 10^{2}$ \\
\hline 1978 & $1.8 \times 10^{4}$ & $1.1 \times 10^{2}$ & $1.5 \times 10^{2}$ & $1.9 \times 10^{2}$ & $5.1 \times 10^{2}$ & $2.7 \times 10^{2}$ \\
\hline 1979 & $1.6 \times 10^{4}$ & $1.0 \times 10^{2}$ & $1.1 \times 10^{2}$ & $1.5 \times 10^{2}$ & $7.0 \times 10^{2}$ & $2.8 \times 10^{2}$ \\
\hline 1980 & $1.6 \times 10^{4}$ & $1.9 \times 10^{2}$ & $1.7 \times 10^{2}$ & $2.6 \times 10^{2}$ & $1.0 \times 10^{3}$ & $4.9 \times 10^{2}$ \\
\hline 1981 & $2.0 \times 10^{4}$ & $3.3 \times 10^{2}$ & $4.3 \times 10^{2}$ & $6.1 \times 10^{2}$ & $1.1 \times 10^{3}$ & $9.1 \times 10^{2}$ \\
\hline 1982 & $1.7 \times 10^{4}$ & $2.6 \times 10^{2}$ & $3.0 \times 10^{2}$ & $5.0 \times 10^{2}$ & $8.4 \times 10^{2}$ & $7.6 \times 10^{2}$ \\
\hline 1983 & $1.1 \times 10^{4}$ & $1.9 \times 10^{2}$ & $2.0 \times 10^{2}$ & $3.5 \times 10^{2}$ & $5.0 \times 10^{2}$ & $4.0 \times 10^{2}$ \\
\hline 1984 & $5.8 \times 10^{3}$ & $6.3 \times 10^{1}$ & $7.7 \times 10^{1}$ & $8.6 \times 10^{1}$ & $1.2 \times 10^{2}$ & $1.2 \times 10^{2}$ \\
\hline 1985 & $1.0 \times 10^{4}$ & $1.9 \times 10^{2}$ & $5.2 \times 10^{2}$ & $3.5 \times 10^{2}$ & $1.2 \times 10^{3}$ & $1.4 \times 10^{2}$ \\
\hline 1986 & $1.6 \times 10^{4}$ & $3.5 \times 10^{2}$ & $5.6 \times 10^{2}$ & $6.1 \times 10^{2}$ & $5.7 \times 10^{3}$ & $1.7 \times 10^{2}$ \\
\hline 1987 & $4.1 \times 10^{4}$ & $2.0 \times 10^{0}$ & $2.1 \times 10^{2}$ & $4.0 \times 10^{2}$ & $1.8 \times 10^{3}$ & $2.3 \times 10^{1}$ \\
\hline 1988 & $1.0 \times 10^{4}$ & $7.8 \times 10^{1}$ & $1.2 \times 10^{2}$ & $4.5 \times 10^{2}$ & $1.5 \times 10^{3}$ & $5.4 \times 10^{1}$ \\
\hline 1989 & & & & & & \\
\hline 1990 & & & & & & \\
\hline 1991 & & & & & & \\
\hline 1992 & $2.5 \times 10^{2}$ & & & & & \\
\hline
\end{tabular}

1954-89 release data from Cummins, Hetrick, and Martin, 1991 1990-92 release data from annual environmental reports 
Table 3-3: L-Area Atmospheric Releases

\begin{tabular}{|c|c|c|c|c|c|c|}
\hline \multirow[b]{2}{*}{ Year } & \multicolumn{6}{|c|}{ Activity Released (Curies) } \\
\hline & ${ }^{41} \mathrm{Ar}$ & $85 m_{\mathrm{Kr}}$ & ${ }^{87} \mathrm{Kr}$ & ${ }^{88} \mathrm{Kr}$ & ${ }^{133} \mathrm{Xe}$ & ${ }^{135} \mathrm{Xe}$ \\
\hline 1954 & . & & & & & \\
\hline 1955 & $3.0 \times 10^{4}$ & $2.0 \times 10^{1}$ & - & $2.0 \times 10^{1}$ & $3.6 \times 10^{1}$ & $6.0 \times 10^{1}$ \\
\hline 1956 & $5.0 \times 10^{4}$ & $6.0 \times 10^{1}$ & & $4.0 \times 10^{1}$ & $7.2 \times 10^{1}$ & $1.0 \times 10^{2}$ \\
\hline 1957 & $6.0 \times 10^{4}$ & $1.4 \times 10^{2}$ & & $1.2 \times 10^{2}$ & $1.8 \times 10^{1}$ & $2.0 \times 10^{1}$ \\
\hline 1958 & $7.0 \times 10^{4}$ & $3.6 \times 10^{2}$ & & $3.4 \times 10^{2}$ & $4.7 \times 10^{2}$ & $8.0 \times 10^{2}$ \\
\hline 1959 & $9.0 \times 10^{4}$ & $6.8 \times 10^{2}$ & & $6.4 \times 10^{2}$ & $9.0 \times 10^{2}$ & $1.3 \times 10^{3}$ \\
\hline 1960 & $8.0 \times 10^{4}$ & $9.2 \times 10^{2}$ & & $9.6 \times 10^{2}$ & $1.4 \times 10^{3}$ & $1.9 \times 10^{3}$ \\
\hline 1961 & $8.0 \times 10^{4}$ & $4.8 \times 10^{2}$ & & $4.6 \times 10^{2}$ & $7.2 \times 10^{2}$ & $9.4 \times 10^{2}$ \\
\hline 1962 & $8.0 \times 10^{4}$ & $3.6 \times 10^{2} \times$ & & $3.4 \times 10^{2}$ & $4.7 \times 10^{2}$ & $6.8 \times 10^{2}$ \\
\hline 1963 & $9.0 \times 10^{4}$ & $1.4 \times 10^{3}$ & & $1.3 \times 10^{3}$ & $1.5 \times 10^{3}$ & $2.4 \times 10^{3}$ \\
\hline 1964 & $7.0 \times 10^{4}$ & $1.8 \times 10^{2}$ & & $1.0 \times 10^{2}$ & $3.6 \times 10^{2}$ & $1.6 \times 10^{2}$ \\
\hline 1965 & $7.0 \times 10^{4}$ & $5.0 \times 10^{2}$ & & $3.0 \times 10^{2}$ & $9.5 \times 10^{2}$ & $4.5 \times 10^{2}$ \\
\hline 1966 & $7.0 \times 10^{4}$ & $6.0 \times 10^{2}$ & , & $3.8 \times 10^{2}$ & $1.0 \times 10^{4}$ & $5.2 \times 10^{2}$ \\
\hline 1967 & $8.0 \times 10^{4}$ & $8.3 \times 10^{3}$ & & $5.1 \times 10^{3}$ & $3.4 \times 10^{4}$ & $7.4 \times 10^{3}$ \\
\hline 1968 & & $3.2 \times 10^{3}$ & & $2.0 \times 10^{3}$ & $1.1 \times 10^{4}$ & $3.1 \times 10^{3}$ \\
\hline 1969 & & & · & & & \\
\hline 1970 & & & ( & & & \\
\hline 1971. & & & & & & \\
\hline 1972 & . & & & & & \\
\hline 1973 & & & & & & \\
\hline 1974 & & & & & & \\
\hline 1975 & & & & & & \\
\hline 1976 & . & & . & & & - \\
\hline 1977 & & & & & & \\
\hline 1978 & & & & & & \\
\hline 1979 & & & - & . & & $\therefore$ \\
\hline 1980 & 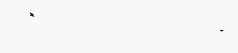 & & & , & & \\
\hline 1981 & & . & . & & & \\
\hline 1982 & & & & & & \\
\hline 1983 & & & & & & \\
\hline 1984 & & & & & & \\
\hline 1985 & $1.3 \times 10^{1}$ & & & & $1.0 \times 10^{2}$ & \\
\hline 1986 & $1.4 \times 10^{4}$ & $1.8 \times 10^{2}$ & $2.0 \times 10^{2}$ & $3.9 \times 10^{2}$ & $4.0 \times 10^{2}$ & $2.9 \times 10^{2}$ \\
\hline 1987 & $8.0 \times 10^{3}$ & $6.7 \times 10^{1}$ & $8.6 \times 10^{1}$ & $1.5 \times 10^{2}$ & $4.6 \times 10^{2}$ & $1.4 \times 10^{2}$ \\
\hline 1988 & $1.6 \times 10^{3}$ & $1.2 \times 10^{1}$ & $7.1 \times 10^{2}$ & $6.0 \times 10^{0}$ & & $2.4 \times 10^{2}$ \\
\hline 1989 & & & & & & \\
\hline 1990 & & & - & & . & \\
\hline 1991 & & & & & & \\
\hline 1992 & & & & & & \\
\hline
\end{tabular}

1954-89 release data from Cummins, Hetrick, and Martin, 1991 1990-92 release data from annual environmental reports 
Table 3-4. P-Area Atmospheric Releases

Activity Released (Curies)

\begin{tabular}{|c|c|c|c|c|c|c|}
\hline Year & $\overline{{ }^{41} \mathrm{Ar}}$ & $85 \mathrm{mKr}$ & ${ }^{87} \mathrm{Kr}$ & ${ }^{88} \mathrm{Kr}$ & ${ }^{133} \mathrm{Xe}$ & ${ }^{135} \mathrm{Xe}$ \\
\hline 1954 & $2.5 \times 10^{4}$ & $2.0 \times 10^{1}$ & & $2.0 \times 10^{1}$ & $2.7 \times 10^{1}$ & $4.0 \times 10^{1}$ \\
\hline 1955 & $3.0 \times 10^{4}$ & $2.0 \times 10^{1}$ & , & $2.0 \times 10^{1}$ & $3.6 \times 10^{1}$ & $6.0 \times 10^{1}$ \\
\hline 1956 & $5.0 \times 10^{4}$ & $6.0 \times 10^{1}$ & & $4.0 \times 10^{1}$ & $7.2 \times 10^{1}$ & $1.0 \times 10^{2}$ \\
\hline 1957 & $6.0 \times 10^{4}$ & $1.4 \times 10^{2}$ & & $1.2 \times 10^{2}$ & $1.8 \times 10^{1}$ & $2.0 \times 10^{1}$ \\
\hline 1958 & $7.0 \times 10^{4}$ & $3.6 \times 10^{2}$ & & $3.4 \times 10^{2}$ & $4.7 \times 10^{2}$ & $8.0 \times 10^{2}$ \\
\hline 1959 & $9.0 \times 10^{4}$ & $6.8 \times 10^{2}$ & & $6.4 \times 10^{2}$ & $9.0 \times 10^{2}$ & $1.3 \times 10^{3}$ \\
\hline 1960 & $8.0 \times 10^{4}$ & $9.2 \times 10^{2}$ & & $9.6 \times 10^{2}$ & $1.4 \times 10^{3}$ & $1.9 \times 10^{3}$ \\
\hline 1961 & $9.0 \times 10^{4}$ & $4.8 \times 10^{2}$ & & $4.6 \times 10^{2}$ & $7.2 \times 10^{2}$ & $9.4 \times 10^{2}$ \\
\hline 1962 & $9.0 \times 10^{4}$ & $3.6 \times 10^{2}$ & & $3.4 \times 10^{2}$ & $4.7 \times 10^{2}$ & $6.8 \times 10^{2}$ \\
\hline 1963 & $9.0 \times 10^{4}$ & $1.4 \times 10^{3}$ & & $1.3 \times 10^{3}$ & $1.5 \times 10^{3}$ & $2.4 \times 10^{3}$ \\
\hline 1964 & $7.0 \times 10^{4}$ & $1.8 \times 10^{2}$ & & $1.0 \times 10^{2}$ & $3.6 \times 10^{2}$ & $1.6 \times 10^{2}$ \\
\hline 1965 & $6.0 \times 10^{4}$ & $5.0 \times 10^{2}$ & $\cdot$ & $3.0 \times 10^{2}$ & $9.5 \times 10^{2}$ & $4.5 \times 10^{2}$ \\
\hline 1966 & $7.0 \times 10^{4}$ & $6.0 \times 10^{2}$ & : & $3.8 \times 10^{2}$ & $1.0 \times 10^{4}$ & $5.2 \times 10^{2}$ \\
\hline 1967 & $8.0 \times 10^{4}$ & $8.3 \times 10^{3}$ & & $5.1 \times 10^{3}$ & $3.4 \times 10^{4}$ & $7.4 \times 10^{3}$ \\
\hline 1968 & $7.0 \times 10^{4}$ & $3.2 \times 10^{3}$ & . & $2.0 \times 10^{3}$ & $1.1 \times 10^{4}$ & $3.1 \times 10^{3}$ \\
\hline 1969 & $4.0 \times 10^{4}$ & $1.8 \times 10^{3}$ & & $1.2 \times 10^{3}$ & $6.6 \times 10^{3}$ & $1.8 \times 10^{3}$ \\
\hline 1970 & $3.7 \times 10^{4}$ & $8.0 \times 10^{2}$ & & $5.3 \times 10^{2}$ & $5.4 \times 10^{3}$ & $8.7 \times 10^{2}$ \\
\hline 1971 & $5.9 \times 10^{4}$ & $1.5 \times 10^{3}$ & & $1.1 \times 10^{3}$ & $1.4 \times 10^{4}$ & $2.9 \times 10^{3}$ \\
\hline 1972 & $5.6 \times 10^{4}$ & $1.7 \times 10^{3}$ & $2.8 \times 10^{2}$ & $8.6 \times 10^{2}$ & $1.2 \times 10^{4}$ & $2.3 \times 10^{3}$ \\
\hline 1973 & $7.0 \times 10^{4}$ & $1.9 \times 10^{3}$ & $3.4 \times 10^{2}$ & $2.1 \times 10^{3}$ & $5.6 \times 10^{3}$ & $2.7 \times 10^{3}$ \\
\hline 1974 & $5.2 \times 10^{4}$ & $9.0 \times 10^{0}$ & $3.0 \times 10^{2}$ & $5.6 \times 10^{1}$ & $3.2 \times 10^{1}$ & $2.6 \times 10^{1}$ \\
\hline 1975 & $2.3 \times 10^{4}$ & $6.7 \times 10^{1}$ & $8.3 \times 10^{2}$ & $2.6 \times 10^{2}$ & $2.2 \times 10^{2}$ & $1.2 \times 10^{2}$ \\
\hline 1976 & $2.7 \times 10^{4}$ & $1.7 \times 10^{2}$ & $1.2 \times 10^{2}$ & $1.3 \times 10^{2}$ & $4.4 \times 10^{2}$ & $1.6 \times 10^{2}$ \\
\hline 1977 & $1.8 \times 10^{4}$ & $6.1 \times 10^{2}$ & $3.2 \times 10^{2}$ & $2.7 \times 10^{2}$ & $9.0 \times 10^{2}$ & $6.6 \times 10^{2}$ \\
\hline 1978 & $1.7 \times 10^{4}$ & $6.7 \times 10^{2}$ & $2.2 \times 10^{2}$ & $3.5 \times 10^{2}$ & $9.0 \times 10^{2}$ & $7.8 \times 10^{2}$ \\
\hline 1979 & $1.7 \times 10^{4}$ & $1.5 \times 10^{3}$ & $1.1 \times 10^{3}$ & $1.5 \times 10^{3}$ & $3.6 \times 10^{3}$ & $3.5 \times 10^{3}$ \\
\hline 1980 & $2.2 \times 10^{4}$ & $1.3 \times 10^{3}$ & $9.2 \times 10^{2}$ & $1.3 \times 10^{3}$ & $3.9 \times 10^{3}$ & $3.6 \times 10^{3}$ \\
\hline 1981 & $2.0 \times 10^{4}$ & $7.0 \times 10^{2}$ & $2.6 \times 10^{2}$ & $4.6 \times 10^{2}$ & $2.4 \times 10^{3}$ & $1.3 \times 10^{3}$ \\
\hline 1982 & $2.4 \times 10^{4}$ & $7.8 \times 10^{2}$ & $2.4 \times 10^{2}$ & $3.9 \times 10^{2}$ & $2.5 \times 10^{3}$ & $1.3 \times 10^{3}$ \\
\hline 1983 & $2.5 \times 10^{4}$ & $8.2 \times 10^{2}$ & $4.6 \times 10^{2}$ & $6.3 \times 10^{2}$ & $2.0 \times 10^{3}$ & $1.6 \times 10^{3}$ \\
\hline 1984 & $2.3 \times 10^{4}$ & $1.1 \times 10^{3}$ & $4.9 \times 10^{2}$ & $7.3 \times 10^{2}$ & $3.2 \times 10^{3}$ & $2.2 \times 10^{3}$ \\
\hline 1985 & $3.1 \times 10^{4}$ & $1.1 \times 10^{3}$ & $5.2 \times 10^{2}$ & $8.8 \times 10^{2}$ & $3.3 \times 10^{3}$ & $1.6 \times 10^{3}$ \\
\hline 1986 & $5.3 \times 10^{4}$ & $1.5 \times 10^{3}$ & $6.3 \times 10^{2}$ & $1.4 \times 10^{3}$ & $4.5 \times 10^{3}$ & $2.1 \times 10^{3}$ \\
\hline 1987 & $3.9 \times 10^{4}$ & $1.4 \times 10^{3}$ & $7.1 \times 10^{2}$ & $1.5 \times 10^{3}$ & $3.1 \times 10^{3}$ & $3.3 \times 10^{3}$ \\
\hline 1988 & $1.8 \times 10^{4}$ & $9.3 \times 10^{1}$ & $5.3 \times 10^{2}$ & $1.1 \times 10^{3}$ & $2.0 \times 10^{3}$ & $2.7 \times 10^{3}$ \\
\hline 1989 & 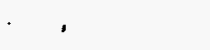 & & & & & \\
\hline 1990 & & & & & & \\
\hline 1991 & & & & & & \\
\hline 1992 & & & & & & \\
\hline
\end{tabular}

1954-89 release data from Cummins, Hetrick, and Martin, 1991 1990-92 release data from annual environmental reports 
Table 3-5. R-Area Atmospheric Releases

\begin{tabular}{|c|c|c|c|c|c|c|c|}
\hline \multirow[b]{2}{*}{ Year } & \multicolumn{7}{|c|}{ Activity Released (Curies) } \\
\hline & ${ }^{41} \mathrm{Ar}$ & $85 \mathrm{mKr}$ & $\sqrt[87]{\mathbf{K r}}$ & & ${ }^{88} \mathrm{Kr}$ & ${ }^{133} \mathrm{Xe}$ & ${ }^{135 X e}$ \\
\hline 1954 & $2.5 \times 10^{4}$ & $2.0 \times 10^{1}$ & & & $2.0 \times 10^{1}$ & $2.7 \times 10^{1}$ & $4.0 \times 10^{1}$ \\
\hline 1955 & $3.0 \times 10^{4}$ & $2.0 \times 10^{1}$ & & & $2.0 \times 10^{1}$ & $3.6 \times 10^{1}$ & $6.0 \times 10^{1}$ \\
\hline 1956 & $5.0 \times 10^{4}$ & $6.0 \times 10^{1}$ & & & $4.0 \times 10^{1}$ & $7.2 \times 10^{1}$ & $1.0 \times 10^{2}$ \\
\hline 1957 & $6.0 \times 10^{4}$ & $1.4 \times 10^{2}$ & & & $1.2 \times 10^{2}$ & $1.8 \times 10^{1}$ & $2.0 \times 10^{1}$ \\
\hline 1958 & $7.0 \times 10^{4}$ & $3.6 \times 10^{2}$ & & & $3.4 \times 10^{2}$ & $4.7 \times 10^{2}$ & $8.0 \times 10^{2}$ \\
\hline 1959 & $9.0 \times 10^{4}$ & $6.8 \times 10^{2}$ & & & $6.4 \times 10^{2}$ & $9.0 \times 10^{2}$ & $1.3 \times 10^{3}$ \\
\hline 1960 & $8.0 \times 10^{4}$ & $9.2 \times 10^{2}$ & & & $9.6 \times 10^{2}$ & $1.4 \times 10^{3}$ & $1.9 \times 10^{3}$ \\
\hline 1961 & $9.0 \times 10^{4}$ & $4.8 \times 10^{2}$ & & & $4.6 \times 10^{2}$ & $7.2 \times 10^{2}$ & $9.4 \times 10^{2}$ \\
\hline 1962 & $9.0 \times 10^{4}$ & $3.6 \times 10^{2}$ & & & $3.4 \times 10^{2}$ & $4.7 \times 10^{2}$ & $6.8 \times 10^{2}$ \\
\hline 1963 & $9.0 \times 10^{4}$ & $1.4 \times 10^{3}$ & & : & $1.3 \times 10^{3}$ & $1.5 \times 10^{3}$ & $2.4 \times 10^{3}$ \\
\hline 1964 & $8.0 \times 10^{4}$ & $1.8 \times 10^{2}$ & & & $1.0 \times 10^{2}$ & $3.6 \times 10^{2}$ & $1.6 \times 10^{2}$ \\
\hline 1965 & & 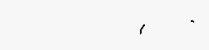 & & & & & \\
\hline 1966 & & & & & & - & $\because$ \\
\hline 1967 & . & & & & & & \\
\hline 1968 & & & & & . & & \\
\hline 1969 & . & & & & & & ' \\
\hline 1970 & & & & & & & \\
\hline 1971 & & & . & & & ' & \\
\hline 1972 & & & & & & & \\
\hline 1973 & - & & & & & & \\
\hline 1974 & & & & & & & \\
\hline 1975 & & & & & & & \\
\hline 1976 & 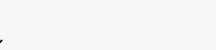 & & & & & & \\
\hline 1977 & & & & & & & . \\
\hline 1978 & & $\cdot$ & & & & & \\
\hline 1979 & & & & & & & \\
\hline 1980 & & & . & & & & \\
\hline 1981 & & & & & & & \\
\hline 1982 & & & & & . & & \\
\hline 1983 & & . & & & . & & \\
\hline 1984 & & & & & & - & \\
\hline 1985 & $\cdot$ & & & & & & \\
\hline 1986 & & & . & & & & \\
\hline 1987 & & & & & & & \\
\hline 1988 & & , & & & ' & & \\
\hline 1989 & & & & & & & \\
\hline 1990 & & & & & , & & \\
\hline 1991 & & & & & & $\therefore$ & \\
\hline 1992 & & & & & & & \\
\hline
\end{tabular}

1954-89 release data from Cummins, Hetrick, and Martin, 1991 1990-92 release data from annual environmental reports 
Table 3-6. F-Area and H-Area Atmospheric Releases

\begin{tabular}{|c|c|c|c|c|c|}
\hline \multirow[b]{2}{*}{ Year } & \multicolumn{5}{|c|}{ Activity Released (Curies) } \\
\hline & $\overline{85} \mathrm{Kr}$ & & $131 \mathrm{mXe}$ & & ${ }^{133} \mathrm{Xe}$ \\
\hline 1954 & & & & & $6.0 \times 10^{0}$ \\
\hline 1955 & $6.2 \times 10^{5}$ & & & & $2.0 \times 10^{1}$ \\
\hline 1956 & $6.2 \times 10^{5}$ & & & & $4.0 \times 10^{1}$ \\
\hline 1957 & $6.2 \times 10^{5}$ & & & & $1.0 \times 10^{1}$ \\
\hline 1958 & $6.2 \times 10^{5}$ & & & & $2.6 \times 10^{2}$ \\
\hline 1959 & $6.2 \times 10^{5}$ & & & & $5.0 \times 10^{2}$ \\
\hline 1960 & $6.2 \times 10^{5}$ & & $6.9 \times 10^{2}$ & & $4.1 \times 10^{2}$ \\
\hline 1961 & $6.2 \times 10^{5}$ & & $5.0 \times 10^{2}$ & & $4.2 \times 10^{2}$ \\
\hline 1962 & $6.2 \times 10^{5}$ & & $2.9 \times 10^{2}$ & & $2.6 \times 10^{2}$ \\
\hline 1963 & $6.2 \times 10^{5}$ & & $1.4 \times 10^{2}$ & & $8.5 \times 10^{2}$ \\
\hline 1964 & $6.2 \times 10^{5}$ & & $1.7 \times 10^{2}$ & & $2.0 \times 10^{2}$ \\
\hline 1965. & $6.2 \times 10^{5}$ & & $6.1 \times 10^{2}$ & $\cdot$ & $4.2 \times 10^{2}$ \\
\hline 1966 & $6.2 \times 10^{5}$ & & $2.6 \times 10^{2}$ & & $4.3 \times 10^{3}$ \\
\hline 1967 & $6.2 \times 10^{5}$ & & $1.9 \times 10^{3}$ & & $1.4 \times 10^{4}$ \\
\hline 1968 & $6.2 \times 10^{5}$ & & $9.3 \times 10^{2}$ & & $5.2 \times 10^{3}$ \\
\hline 1969 & $6.2 \times 10^{5}$ & & $8.5 \times 10^{2}$ & & $2.2 \times 10^{3}$ \\
\hline 1970 & $6.2 \times 10^{5}$ & & $1.0 \times 10^{3}$ & & $1.8 \times 10^{3}$ \\
\hline 1971 & $6.4 \times 10^{5}$ & & $1.1 \times 10^{3}$ & & $2.7 \times 10^{3}$ \\
\hline 1972 & $6.0 \times 10^{5}$ & & $2.9 \times 10^{2}$ & & $8.0 \times 10^{0}$ \\
\hline 1973 & $7.6 \times 10^{5}$ & & $5.1 \times 10^{2}$ & & $3.7 \times 10^{1}$ \\
\hline 1974 & $5.0 \times 10^{5}$ & & $1.4 \times 10^{2}$ & & $1.3 \times 10^{2}$ \\
\hline 1975 & $5.2 \times 10^{5}$ & & $6.0 \times 10^{0}$ & & \\
\hline 1976 & $7.4 \times 10^{5}$ & & $6.3 \times 10^{2}$ & & $9.0 \times 10^{2}$ \\
\hline 1977 & $4.4 \times 10^{5}$ & & $1.2 \times 10^{1}$ & & $1.0 \times 10^{-2}$ \\
\hline 1978 & $5.3 \times 10^{5}$ & & $7.0 \times 10^{0}$ & & $6.4 \times 10^{-1}$ \\
\hline 1979 & $4.8 \times 10^{5}$ & & $9.0 \times 10^{2}$ & & $2.9 \times 10^{-1}$ \\
\hline 1980 & $5.8 \times 10^{5}$ & & $2.0 \times 10^{-1}$ & & \\
\hline 1981 & $8.4 \times 10^{5}$ & & $6.0 \times 10^{0}$ & & \\
\hline 1982 & $5.1 \times 10^{5}$ & & $5.9 \times 10^{1}$ & & \\
\hline 1983 & $5.7 \times 10^{5}$ & & $2.0 \times 10^{1}$ & & $3.0 \times 10^{-3}$ \\
\hline 1984 & $8.4 \times 10^{5}$ & & $1.8 \times 10^{1}$ & & \\
\hline 1985 & $6.5 \times 10^{5}$ & & $5.0 \times 10^{0}$ & & \\
\hline 1986 & $7.1 \times 10^{5}$ & & $3.0 \times 10^{-1}$ & 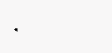 & \\
\hline 1987 & $4.0 \times 10^{5}$ & & & & \\
\hline 1988 & $2.4 \times 10^{5}$ & & & & 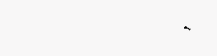 \\
\hline 1989 & $4.2 \times 10^{4}$ & & & & \\
\hline 1990 & $3.0 \times 10^{3}$ & & & & \\
\hline 1991 & $1.0 \times 10^{4}$ & & & & \\
\hline 1992 & $5.0 \times 10^{1}$ & & & & \\
\hline
\end{tabular}

1954-89 release data from Cummins, Hetrick, and Martin, 1991 1990-92 release data from annual environmental reports

A blank entry indicates no release or no measurement 
Figure 3.1. ${ }^{41} \mathrm{Ar}$, C-Area Atmospheric Releases

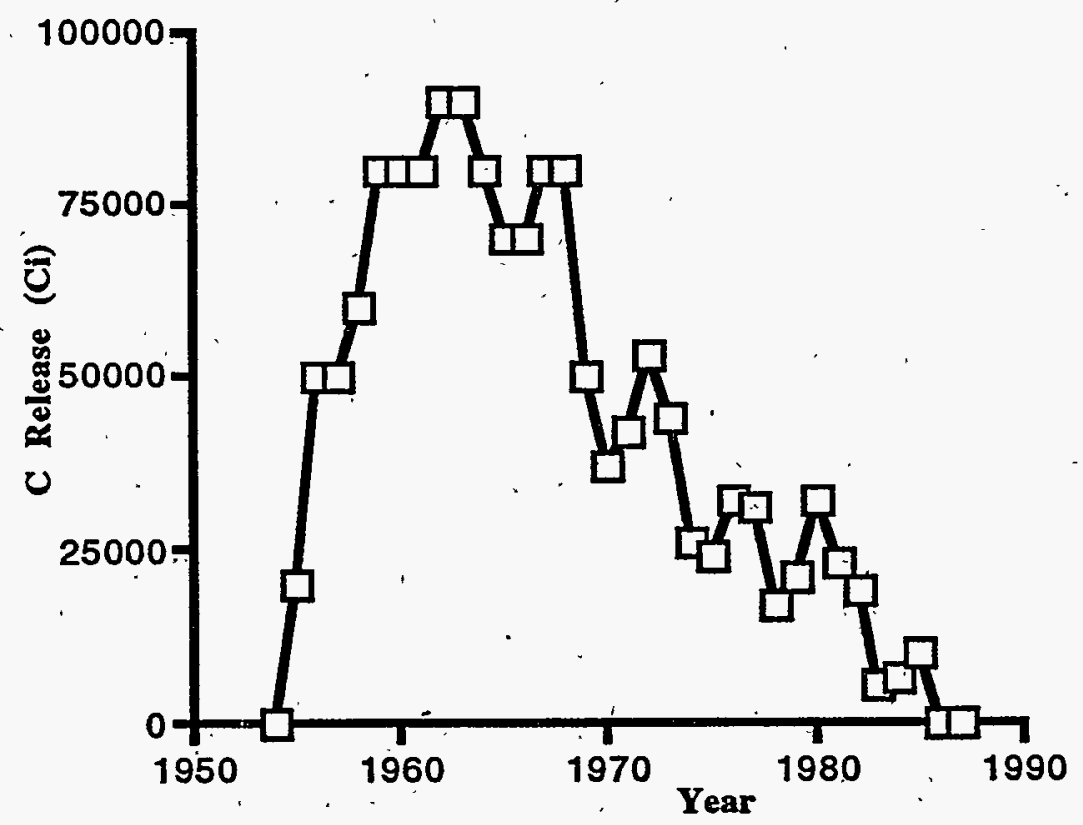

Figure 3.2. $85 \mathrm{~m}_{\mathrm{Kr}}$, C-Area Atmospheric Releases

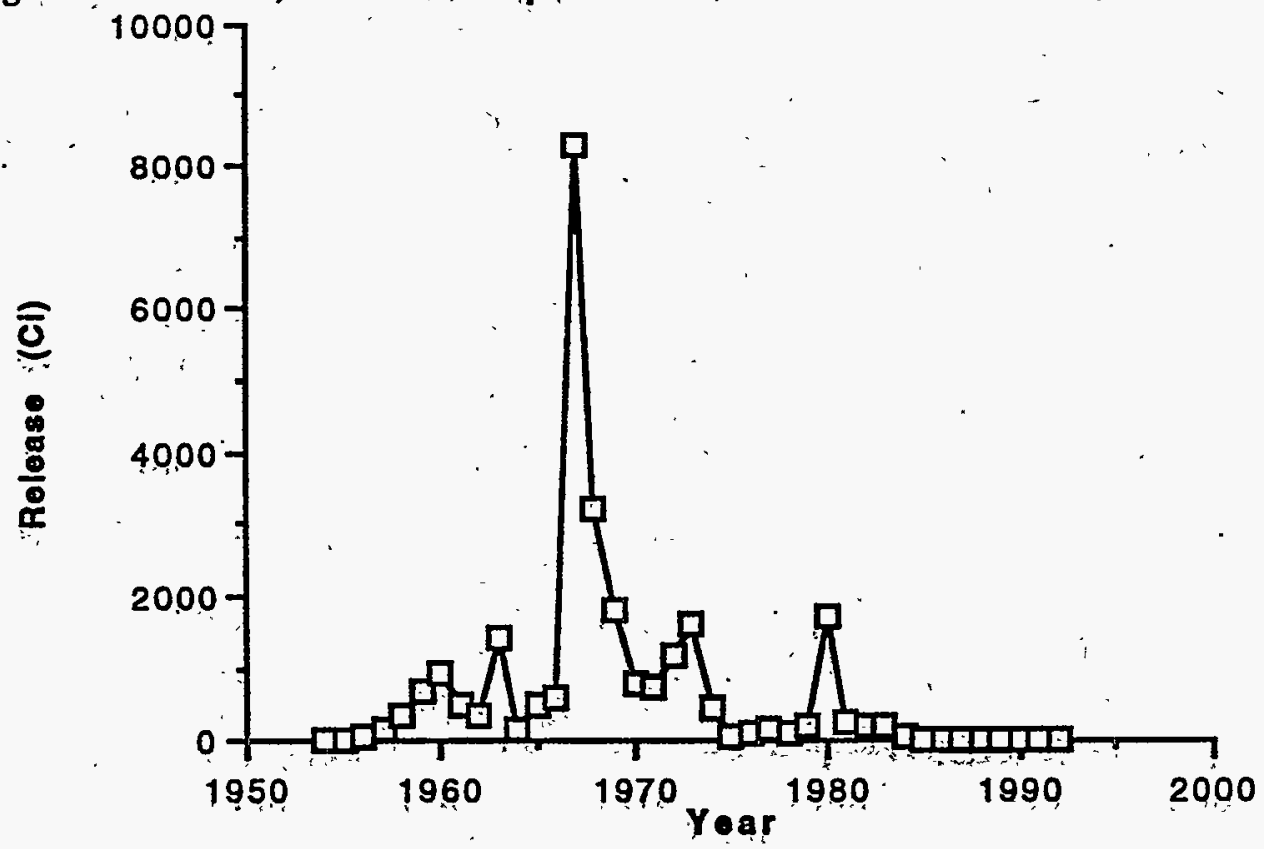


Chapter 3. Releases of Noble Gases at SRS

Figure 3.3. ${ }^{87} \mathrm{Kr}$, C-Area Atmospheric Releases

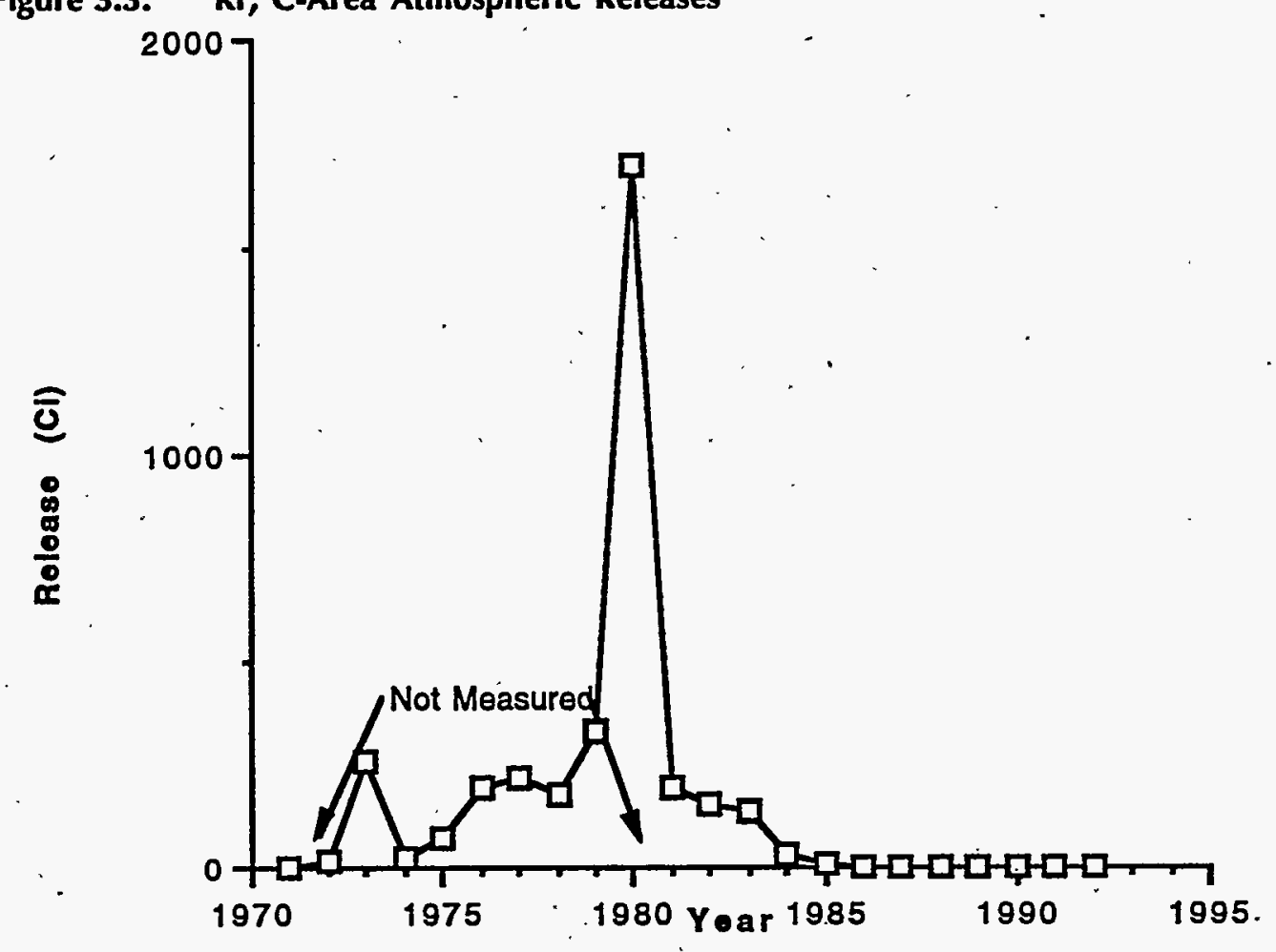

Figure 3.4. ${ }^{88} \mathrm{Kr}, \mathrm{C}$-Area Atmospheric Releases

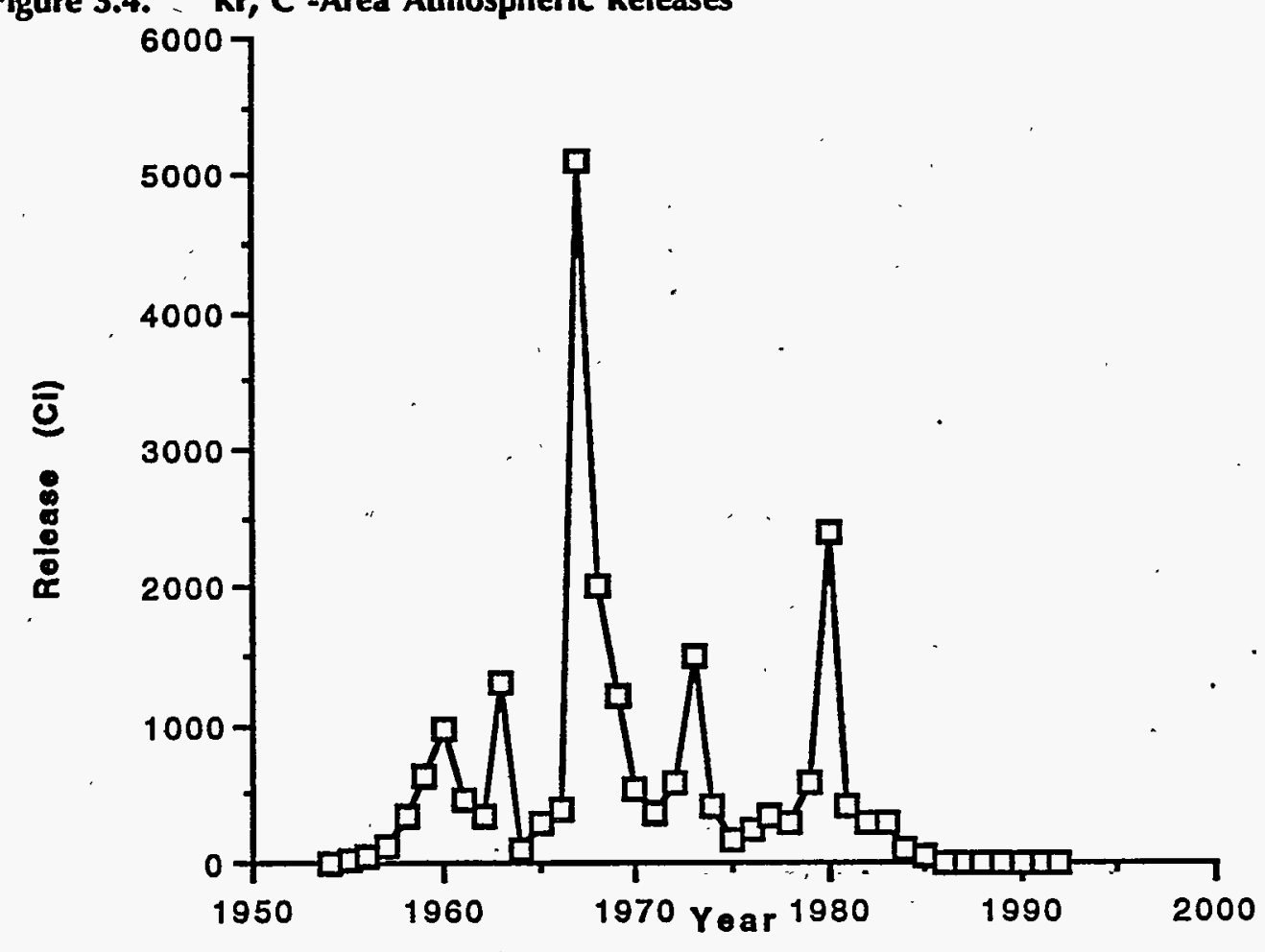

95X00700.MWO

3-13 
Assessment of Noble Gases in the Savannah River Site Environment

Figure 3.5. ${ }^{133} \mathrm{Xe}$, C-Area Atmospheric Releases

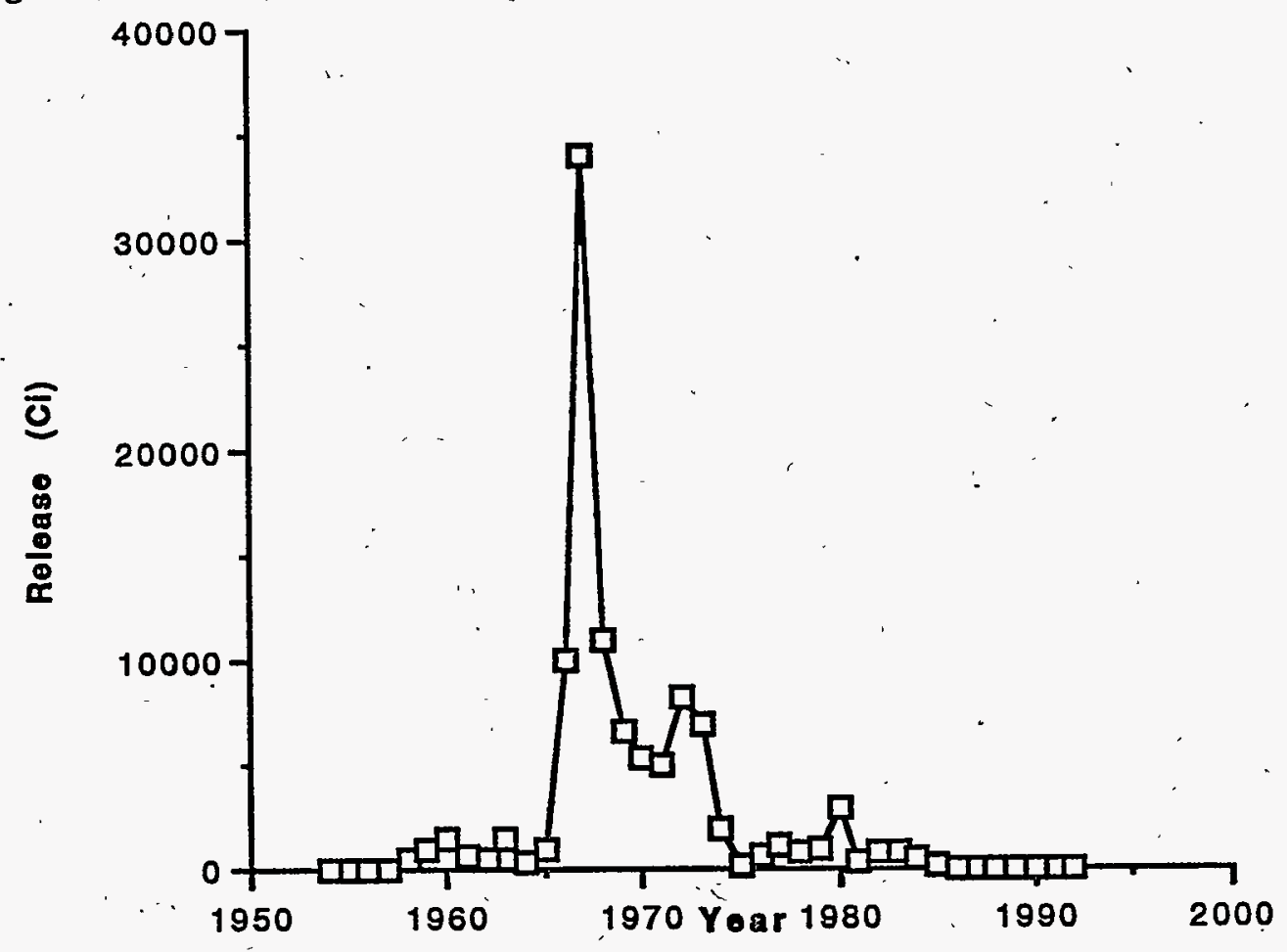

Figure 3.6. ${ }^{135} \mathrm{Xe}$, C-Area Atmospheric Releases

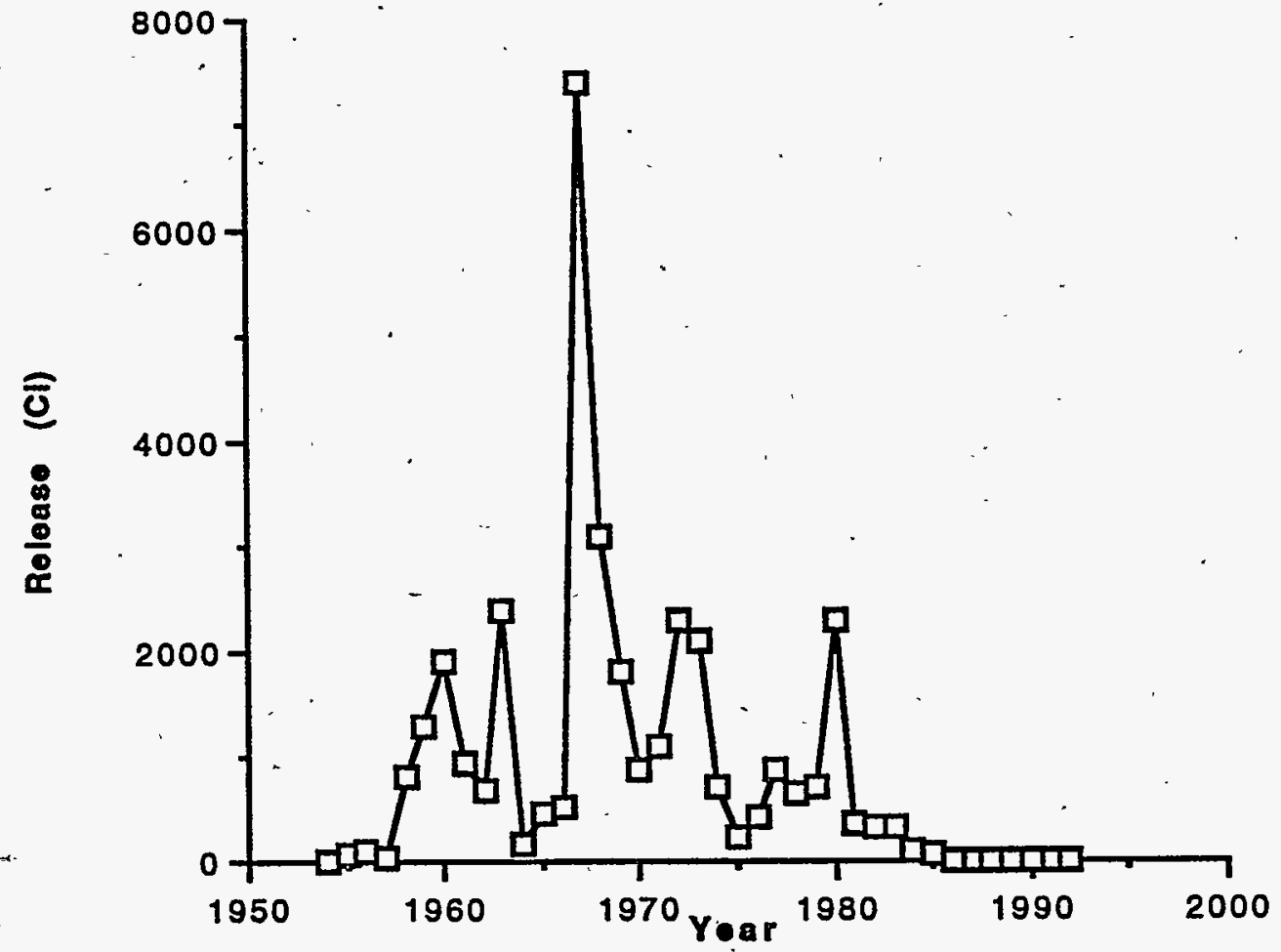

3-14

95x00700.MWO

5 
Chapter 3. Releases of Noble Gases at SRS

Figure 3.7. ${ }^{41}$ As, K-Area Atmospheric Releases

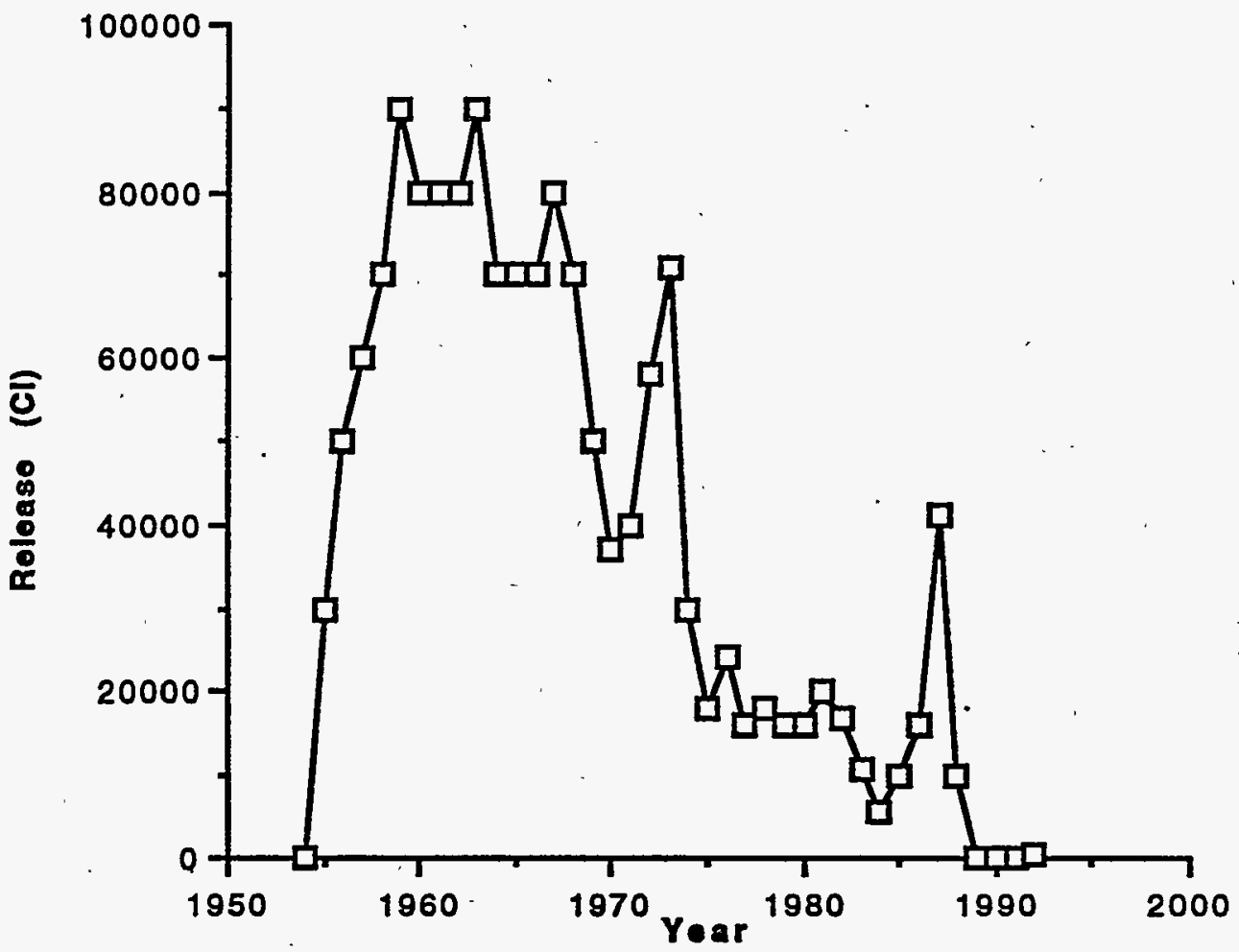

1

Figure 3.8. ${ }^{85} \mathrm{~m}_{\mathrm{Kr}}$, K-Area Atmospheric Releases

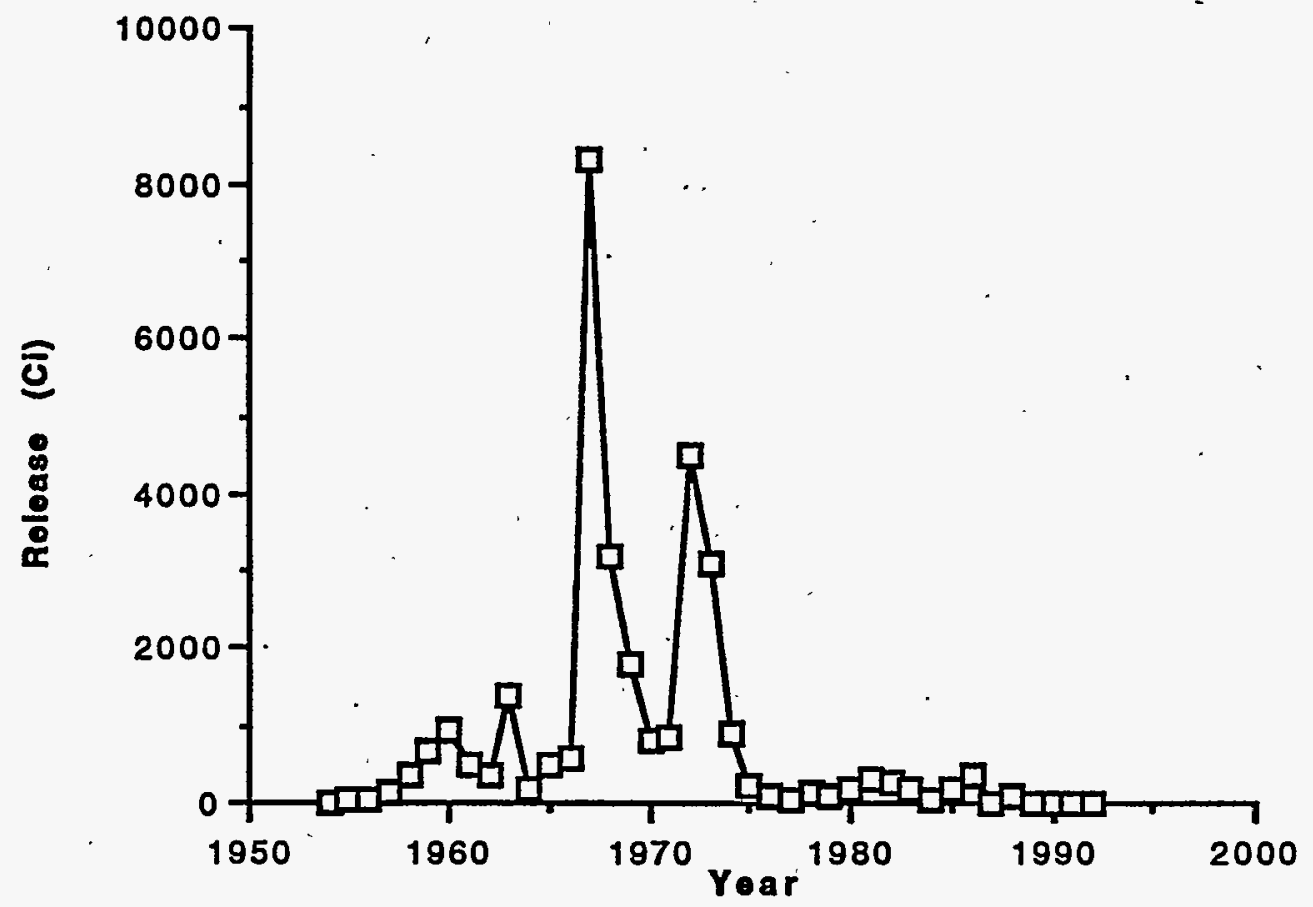

95X00700.MWO

3-15 


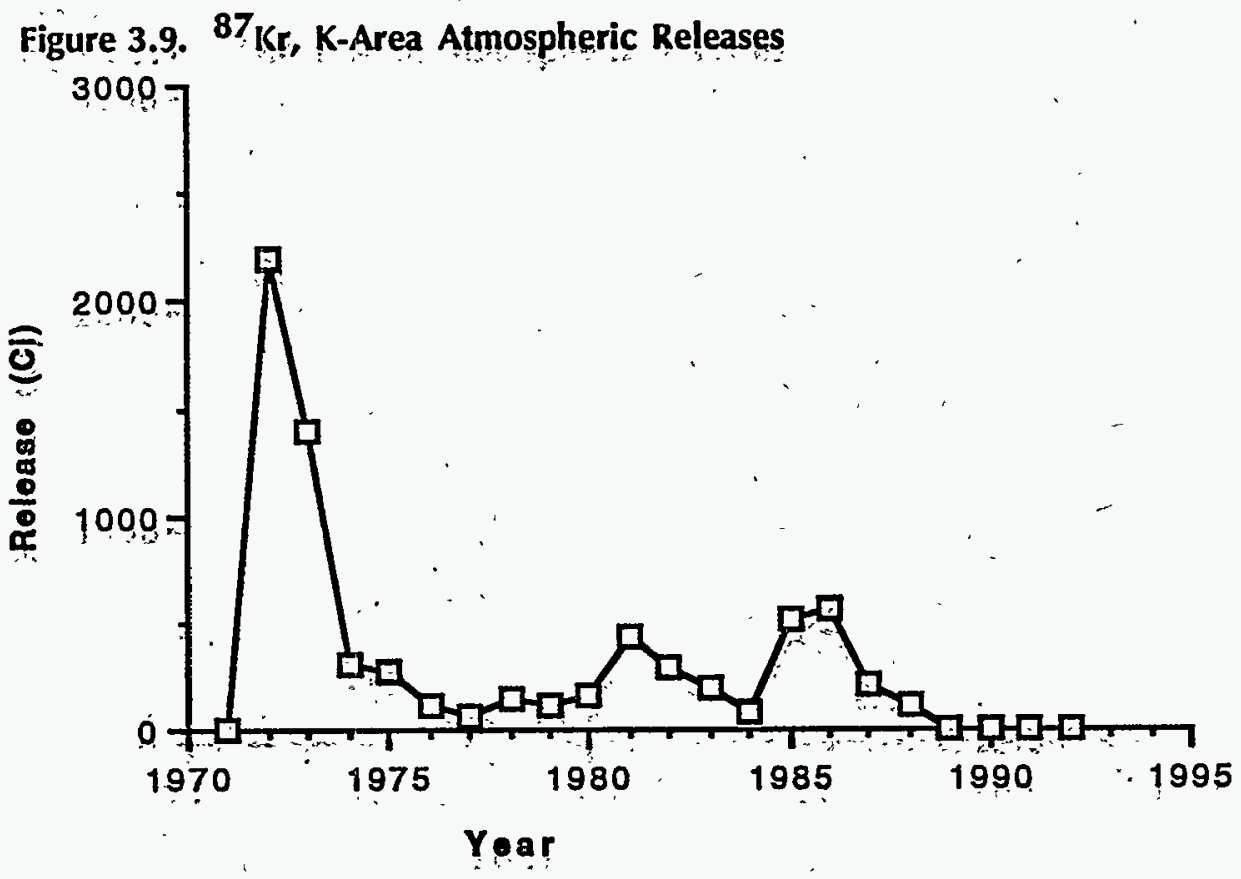

Figure 3.10. ${ }^{88} \mathbf{K r}, \mathrm{K}$-Area Atmospheric Releases

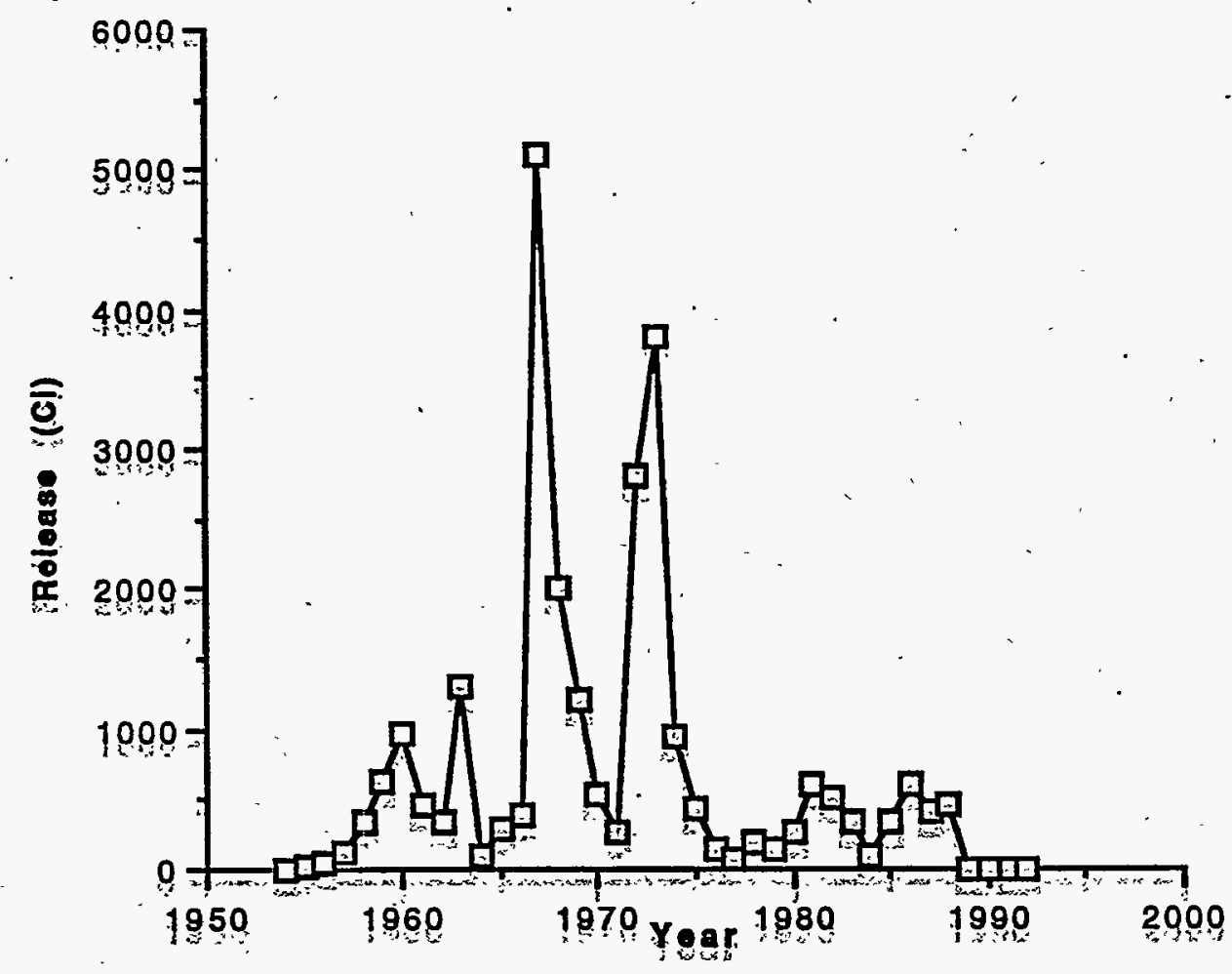


Chapter 3. Releases of Noble Gases at SRS

Figure 3.11. ${ }^{133} \mathrm{Xe}$, K-Area Atmospheric Releases

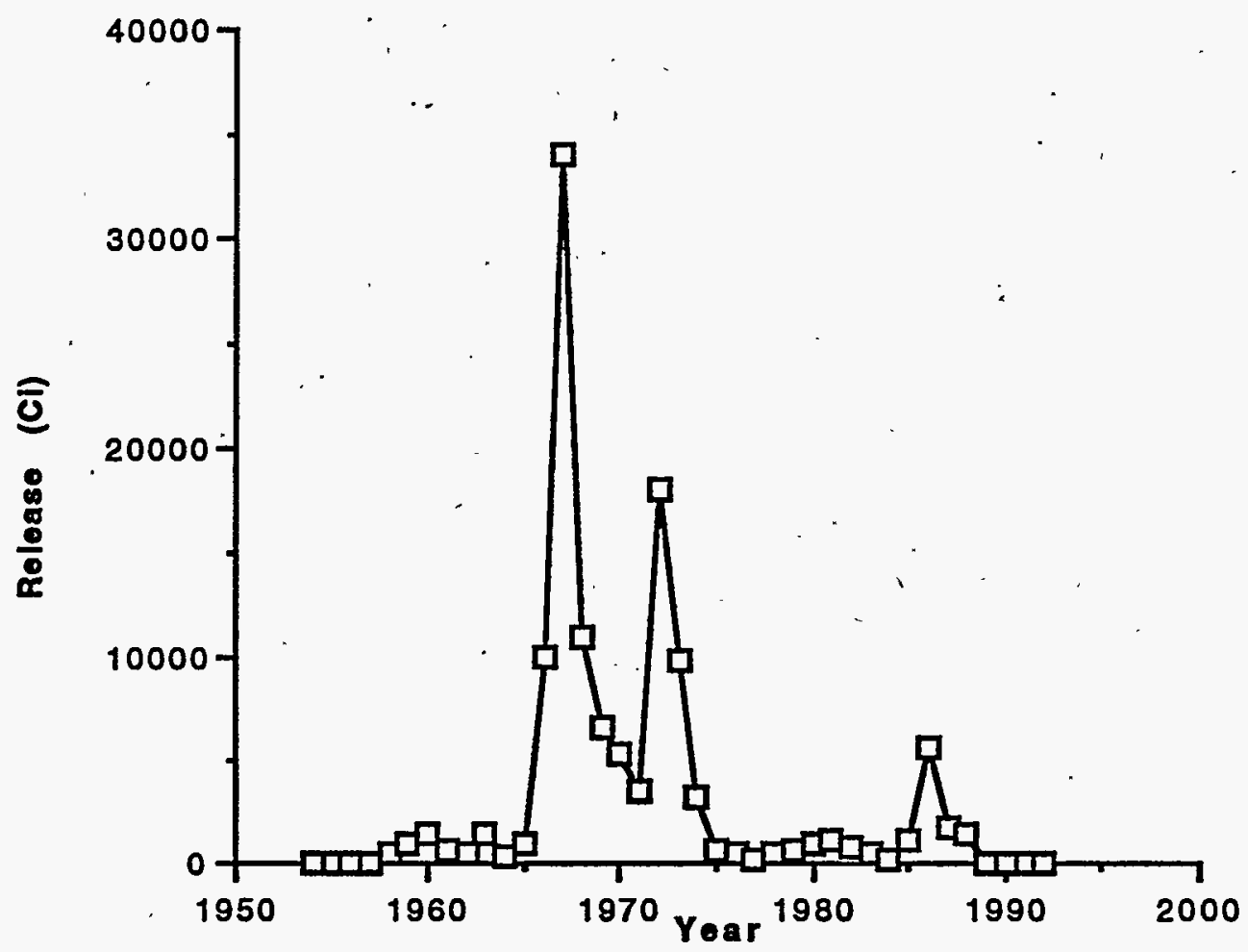

Figure 3.12. ${ }^{135} \mathrm{Xe}$, K-Area Atmospheric Releases

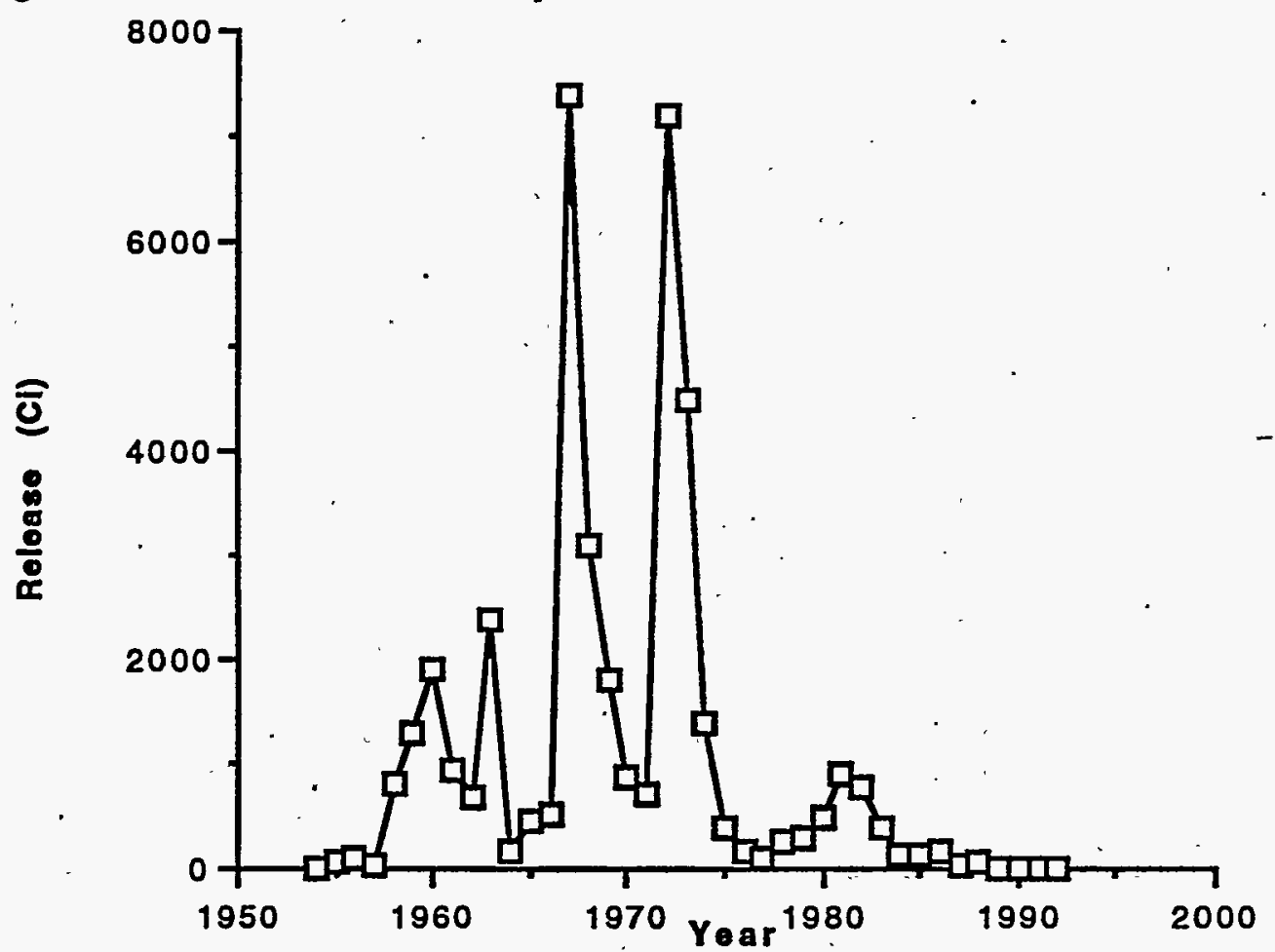

95X00700.MWO

3-17 
Assessment of Noble Gases in the Savannah River Site Environment

Figure 3.13. 41 Ar, L-Area Atmospheric Releases

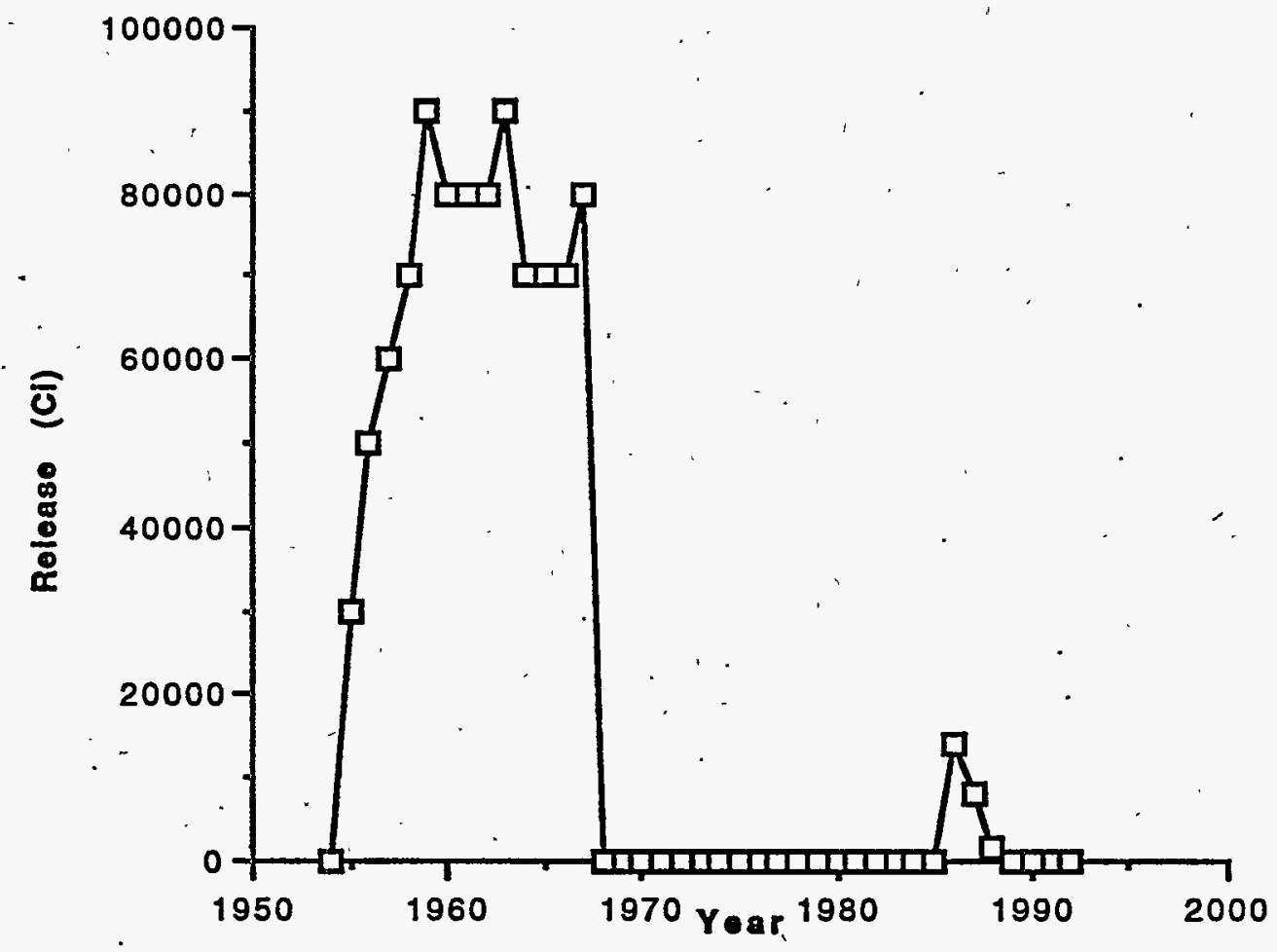

Figure 3.14. ${ }^{85} \mathrm{~m}_{\mathrm{Kr}}$, L-Area Atmospheric Releases

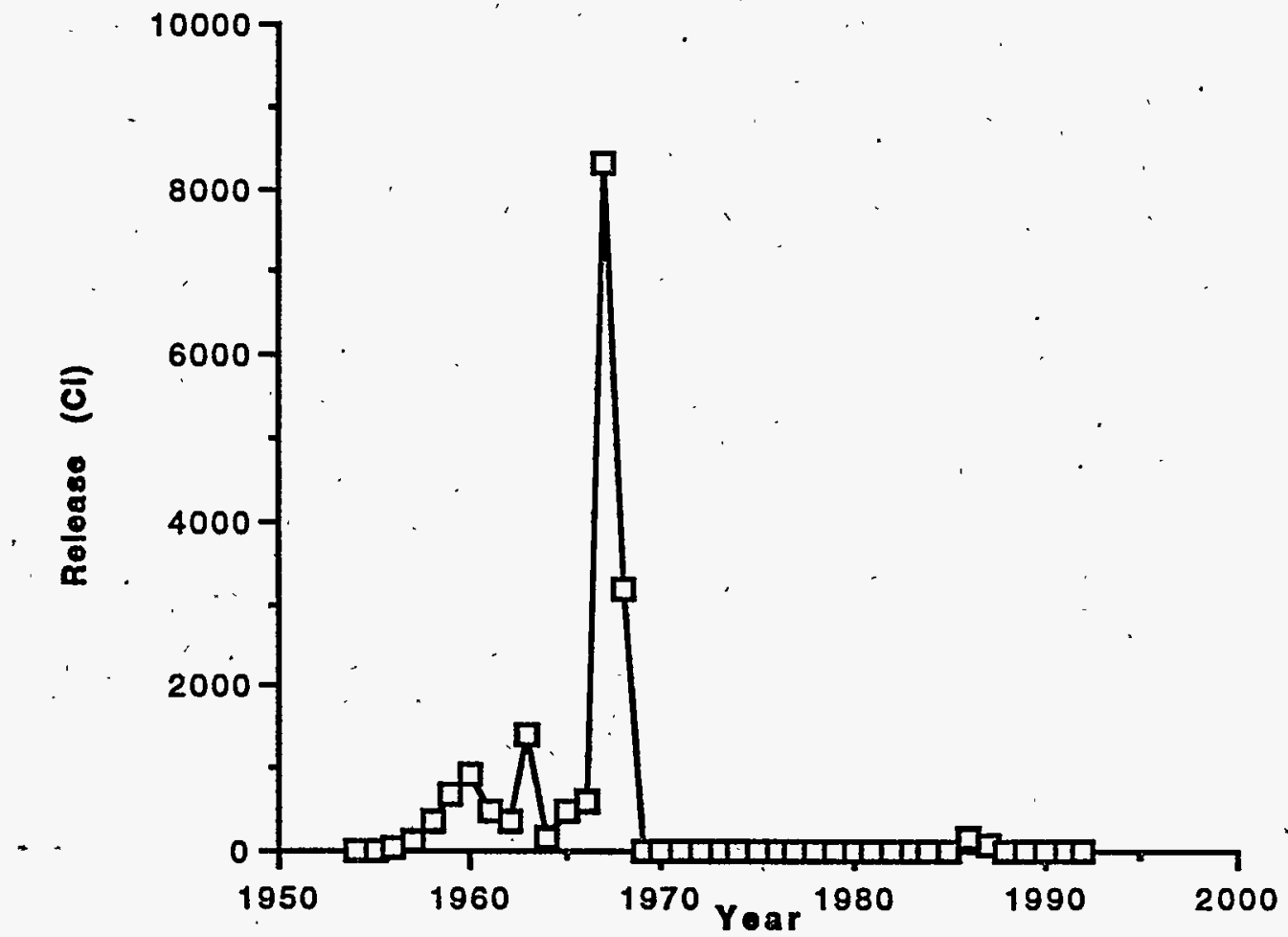

3-18

95X00700.MWO 
Figure 3.15. ${ }^{87} \mathrm{Kr}$, L-Area Atmospheric Releases

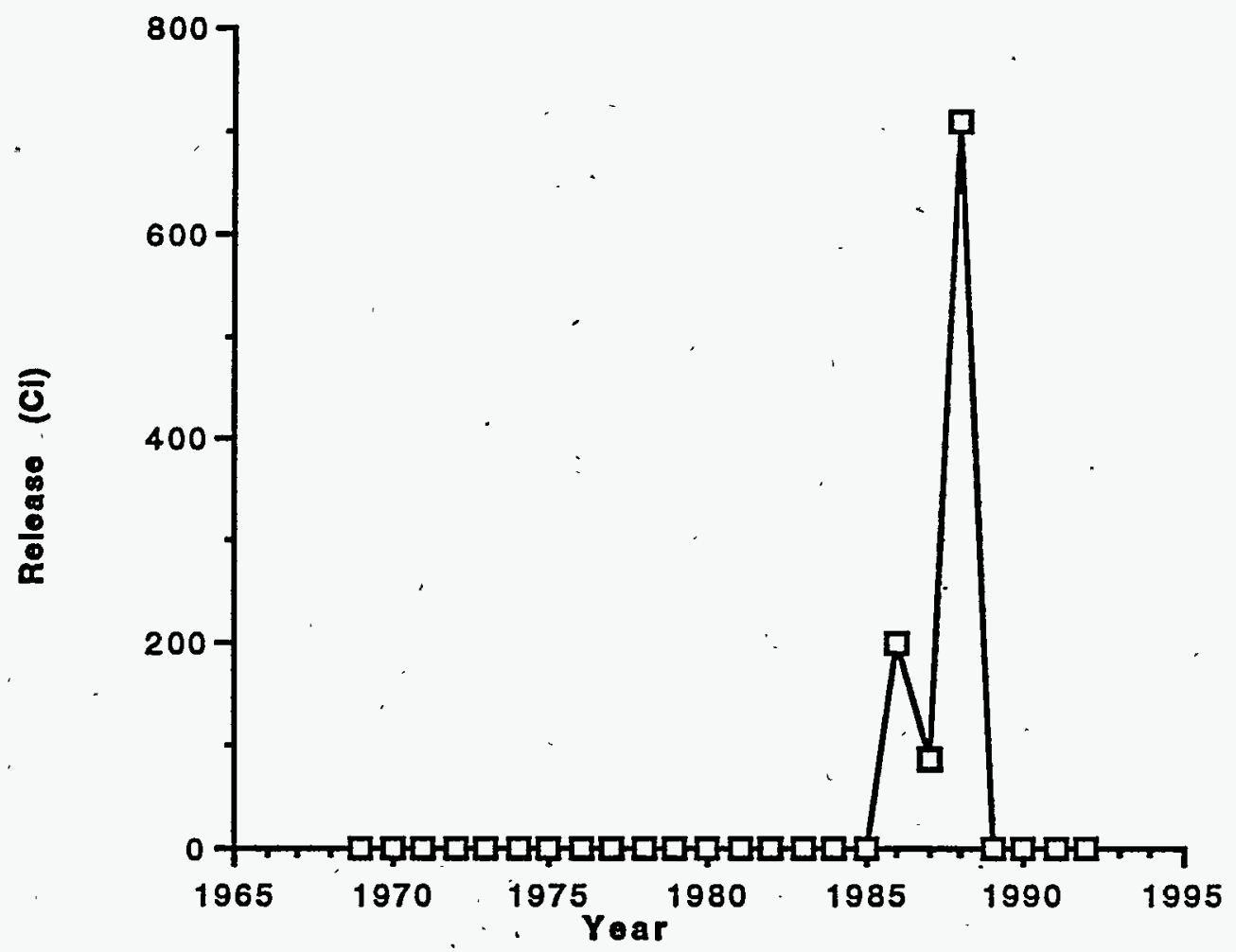

Figure 3.16. ${ }^{88} \mathrm{Kr}$, L-Area Atmospheric Releases

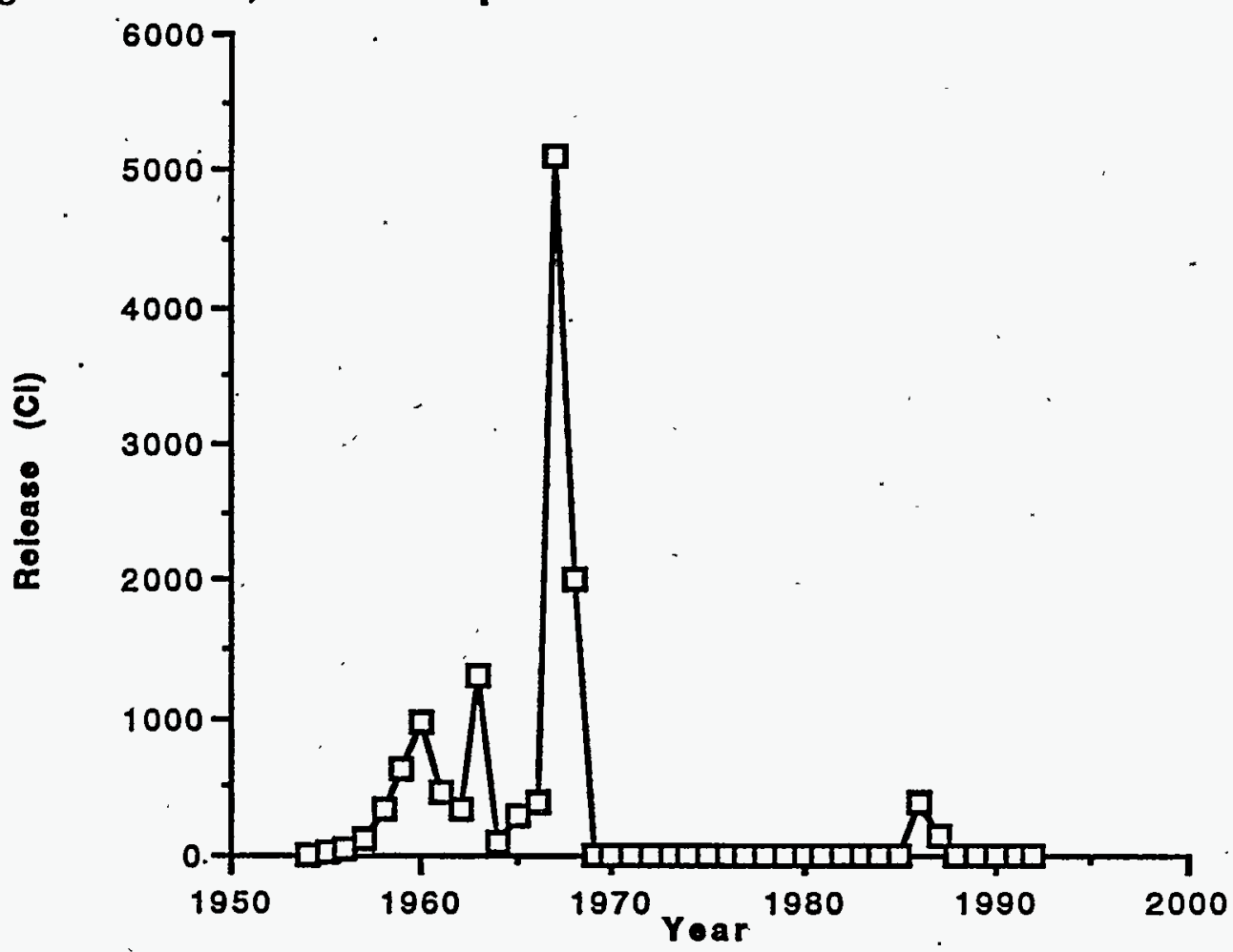


Figure 3.17. ${ }^{133} \mathrm{Xe}$, L-Area Atmoșpheric Releases

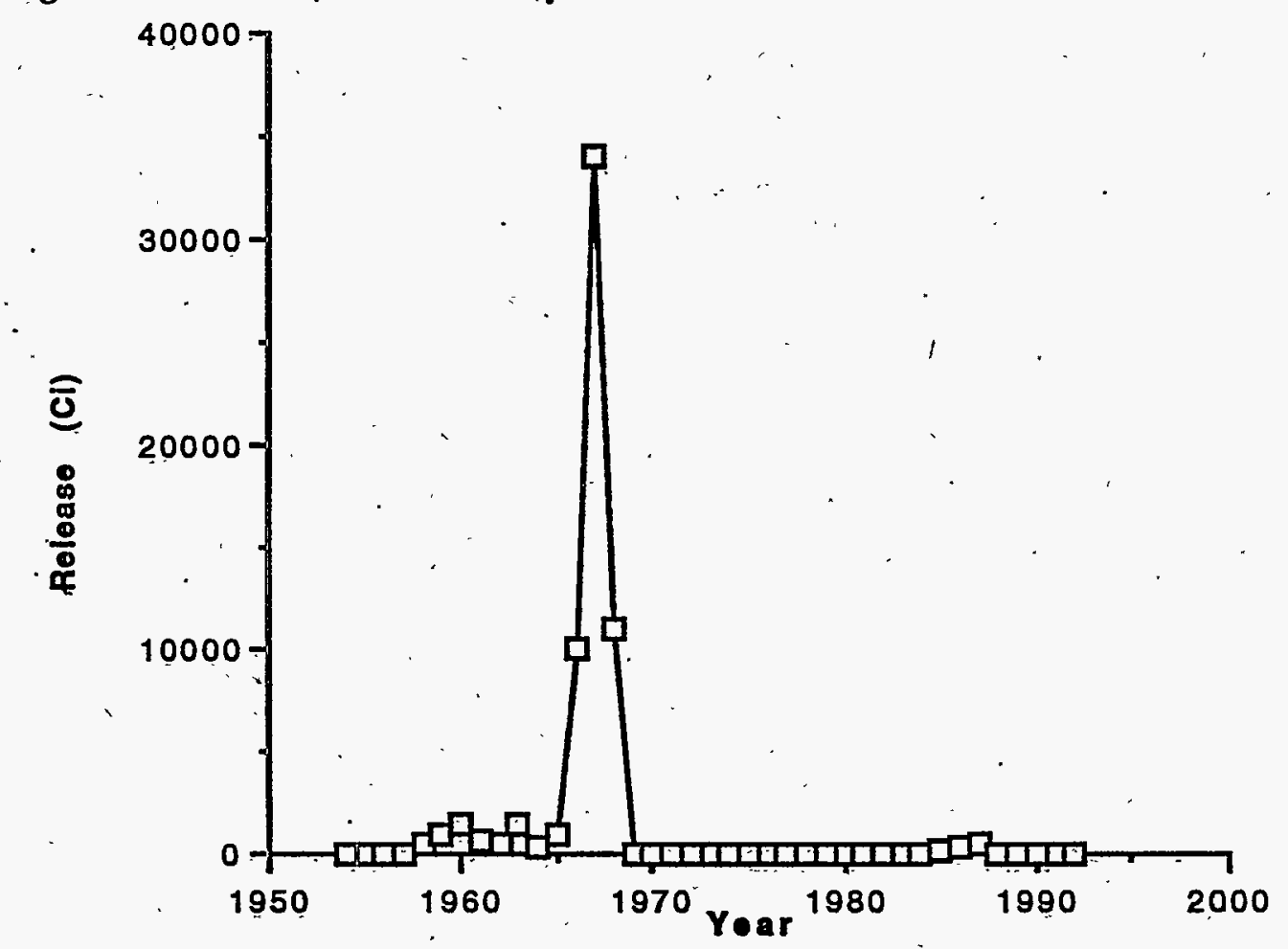

Figure 3.18. ${ }^{135}$ Xe, L-Area Atmospheric Releases

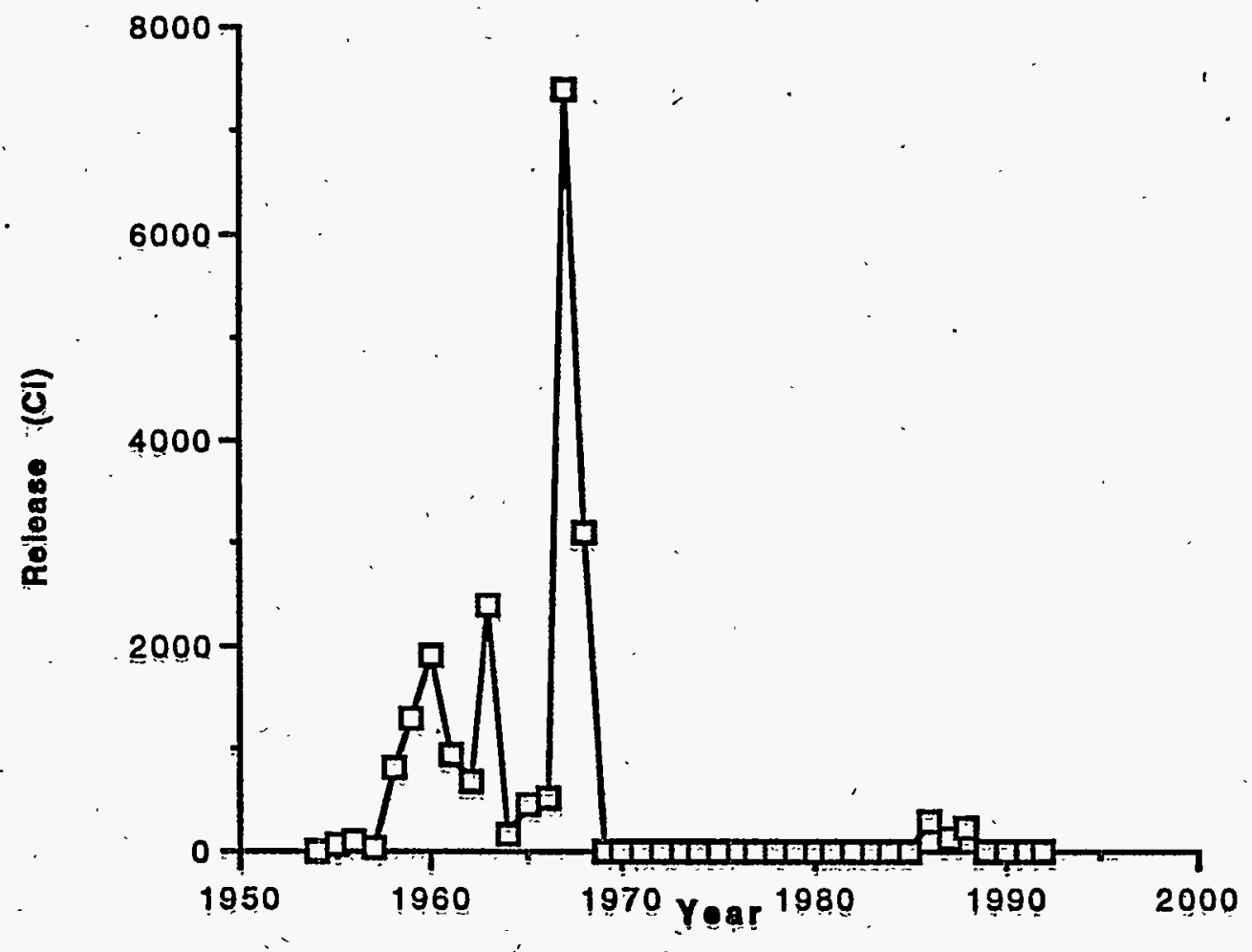




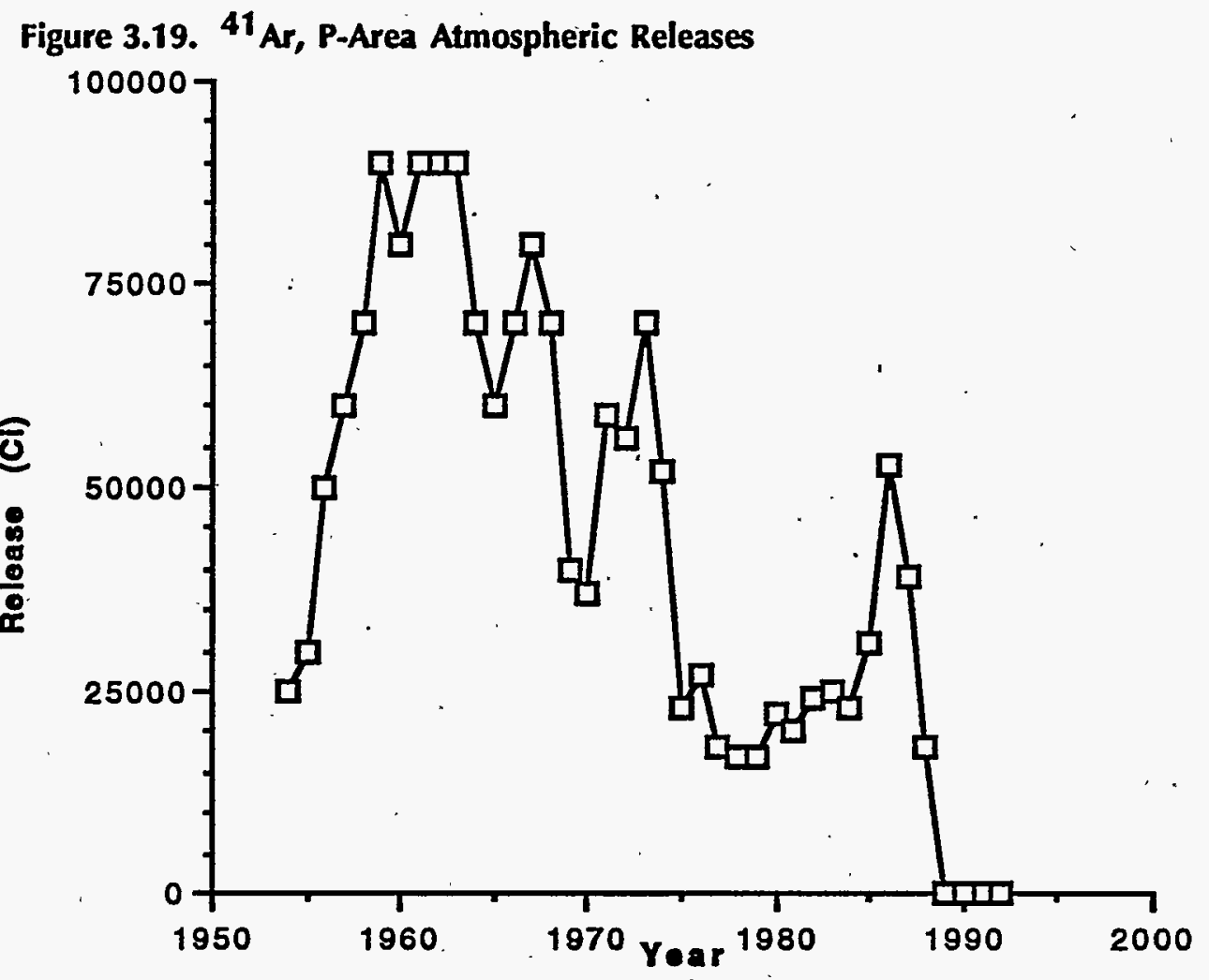


Figure 3.20. ${ }^{85} \mathrm{~m}_{\mathrm{Kr}}, \mathrm{P}$-Area Atmospheric Releases

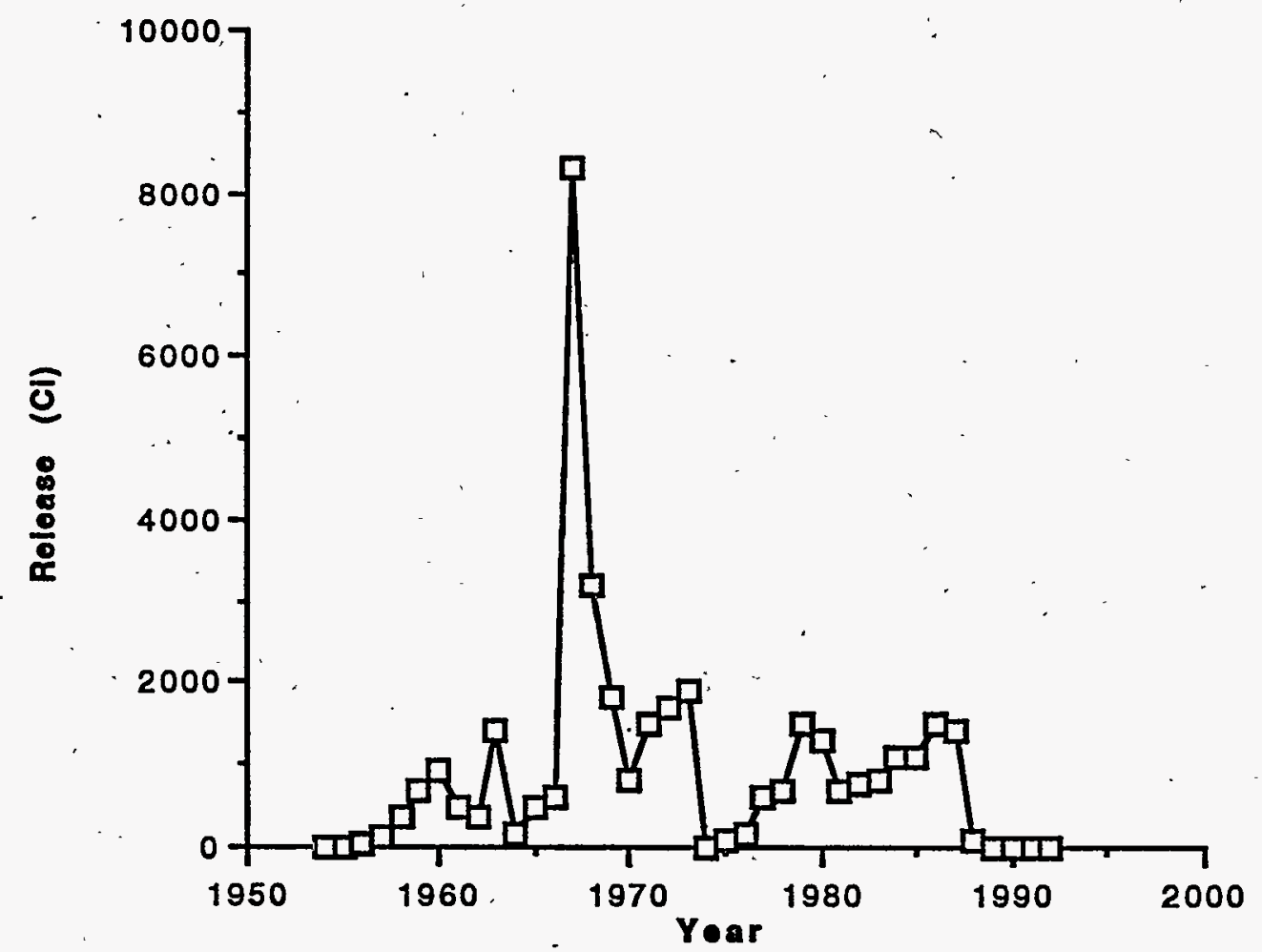

Figure 3.21. ${ }^{87} \mathrm{Kr}$, P-Area Atmospheric Releases

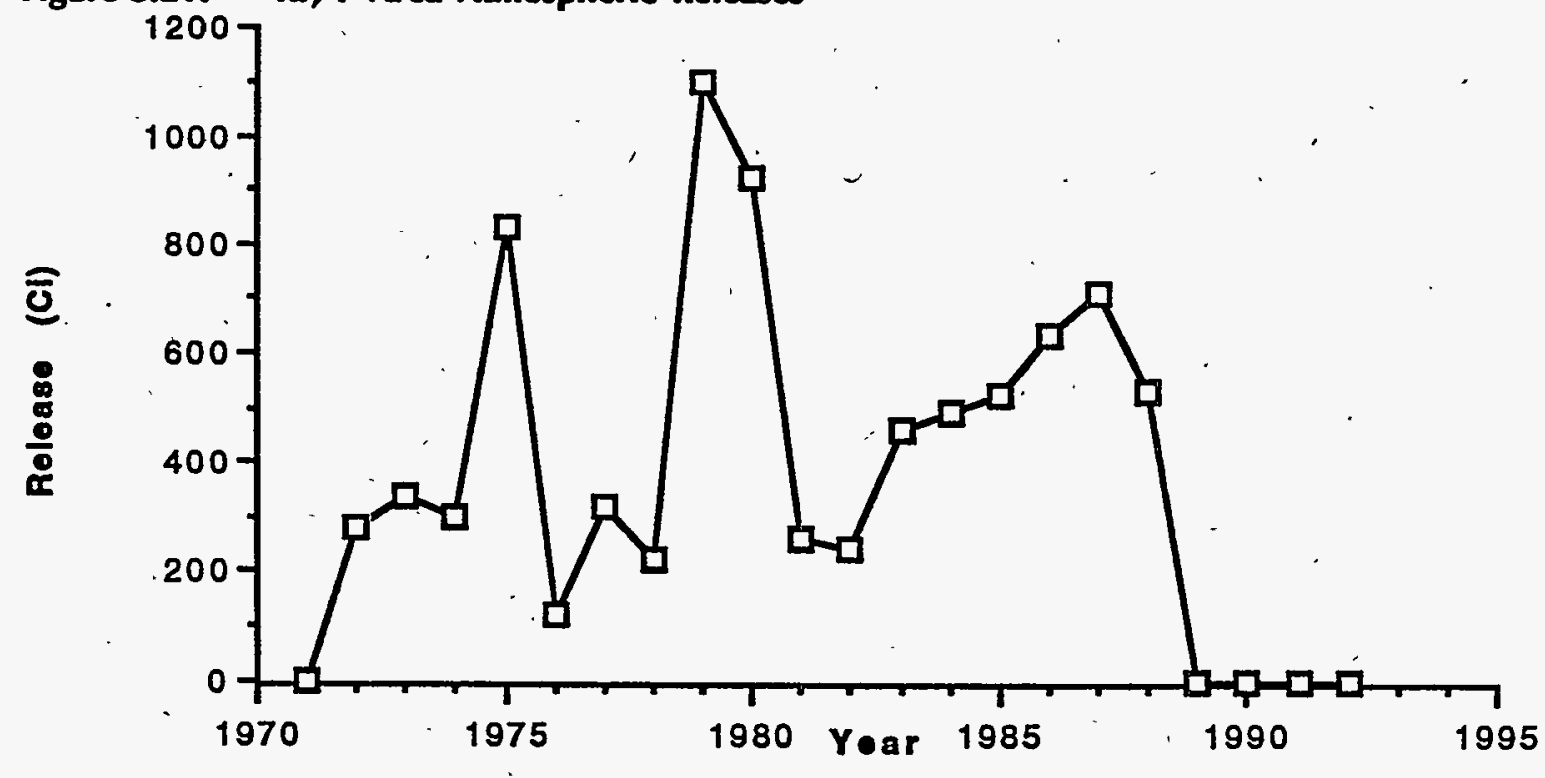


Chapter 3. Releases of Noble Gases at SRS

Figure 3.22. ${ }^{88} \mathrm{Kr}$, P-Area Atmospheric Releases

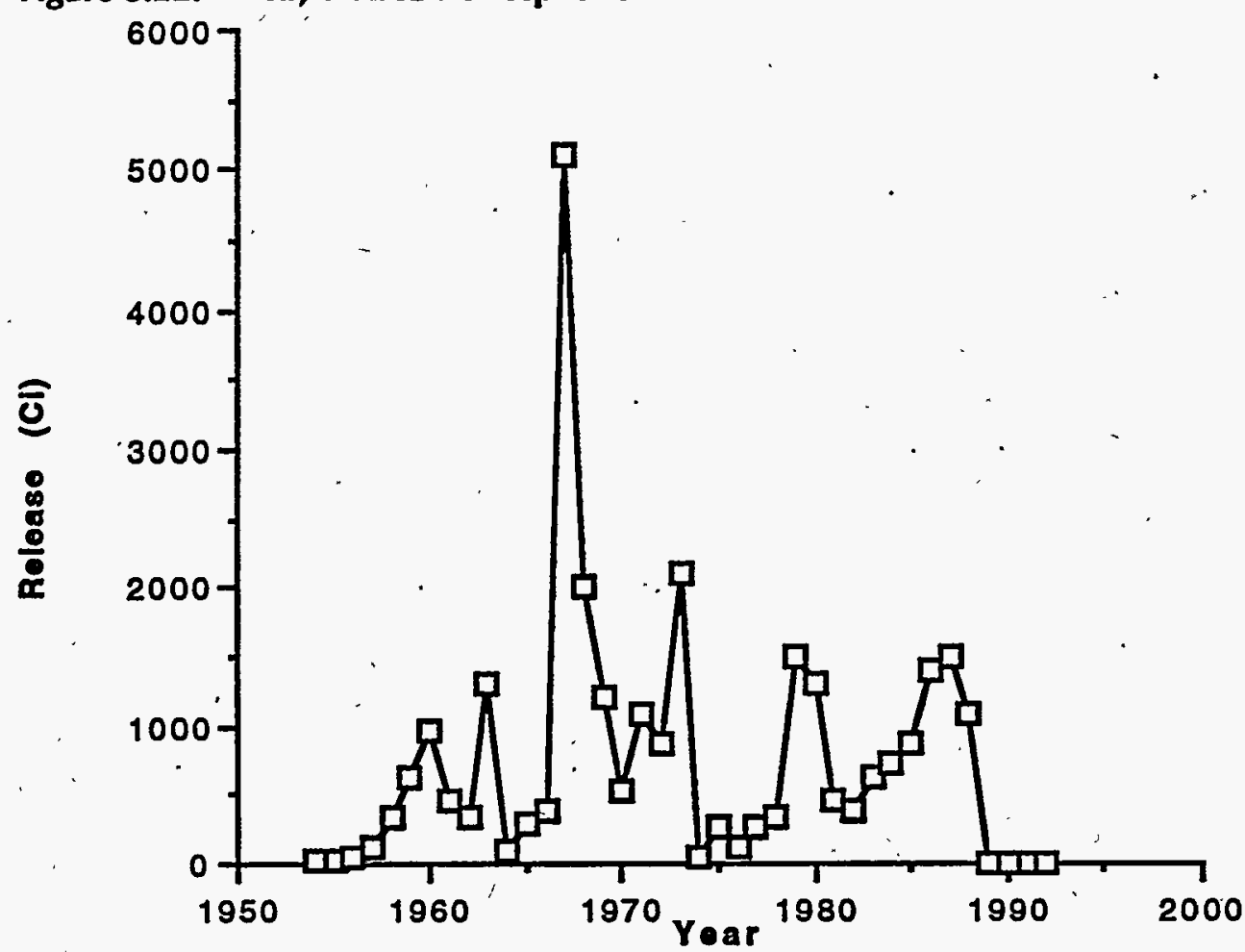

Figure 3.23. ${ }^{133} \mathrm{Xe}, \mathrm{P}$-Area Atmospheric Releases

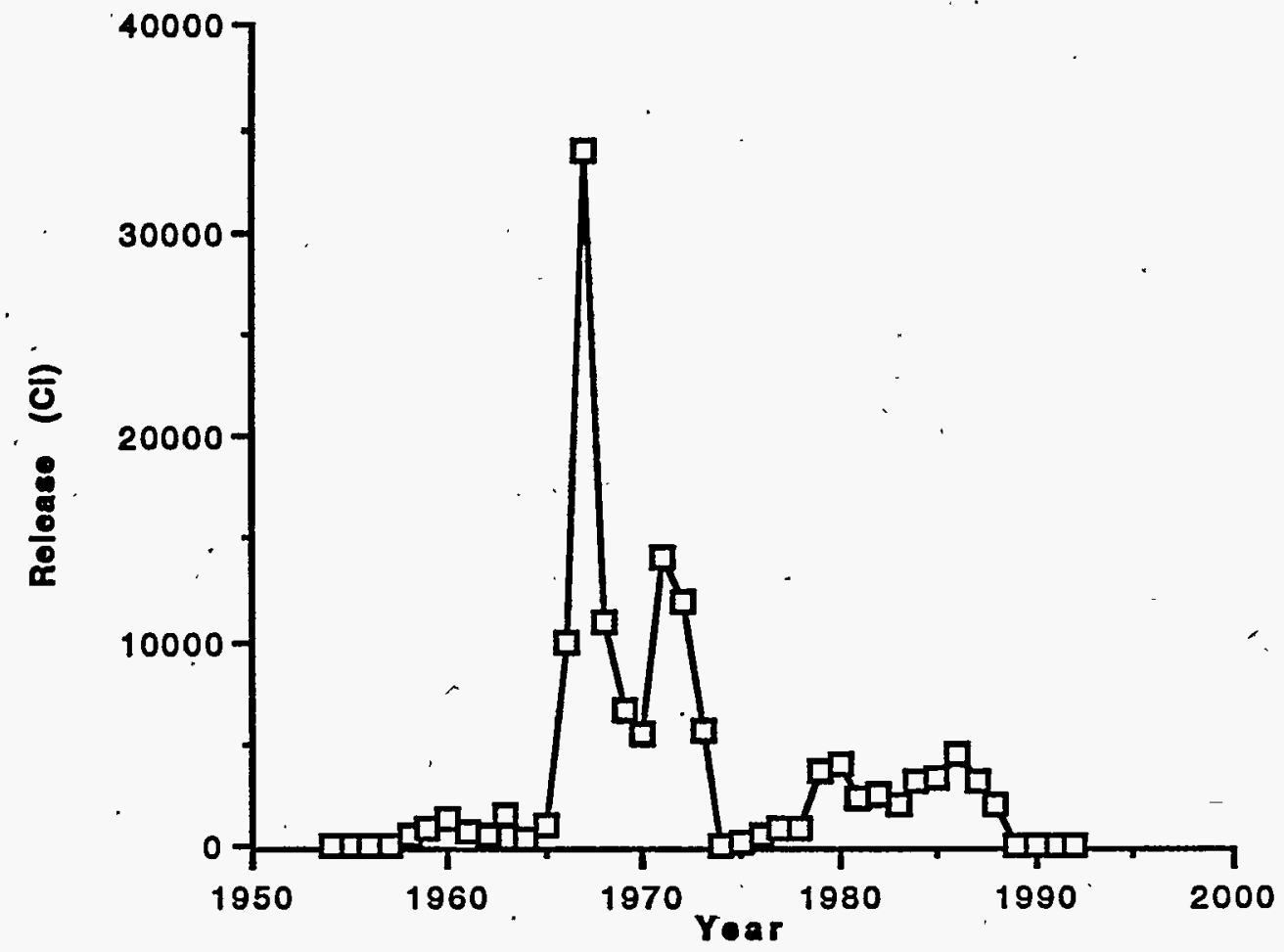

95X00700.MWO

$3-23$ 
Figure 3.24. ${ }^{135} \mathrm{Xe}, \mathrm{P}$-Area Atmospheric Releases

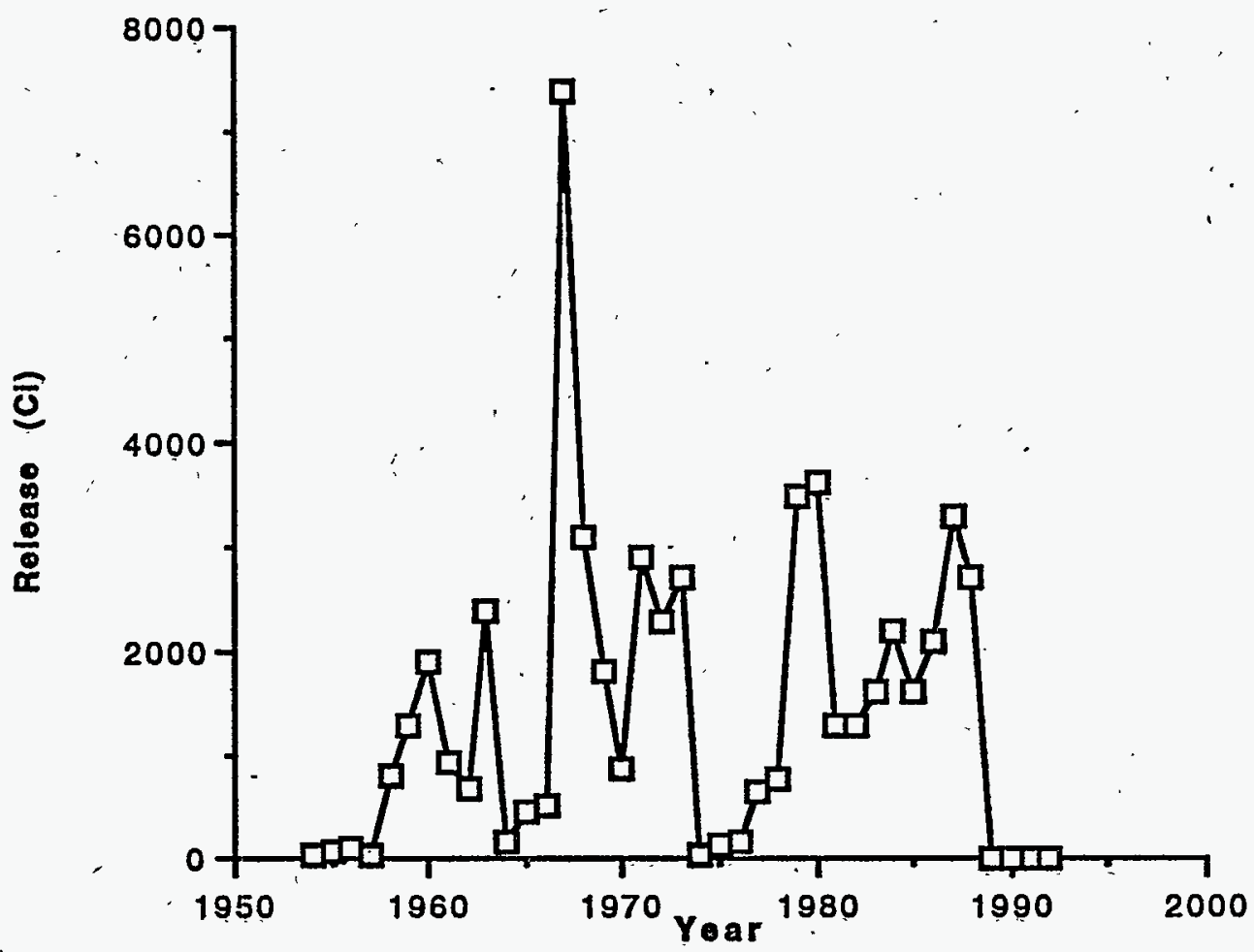

Figure 3.25. ${ }^{41} \mathrm{Ar}$, R-Area Atmospheric Releases

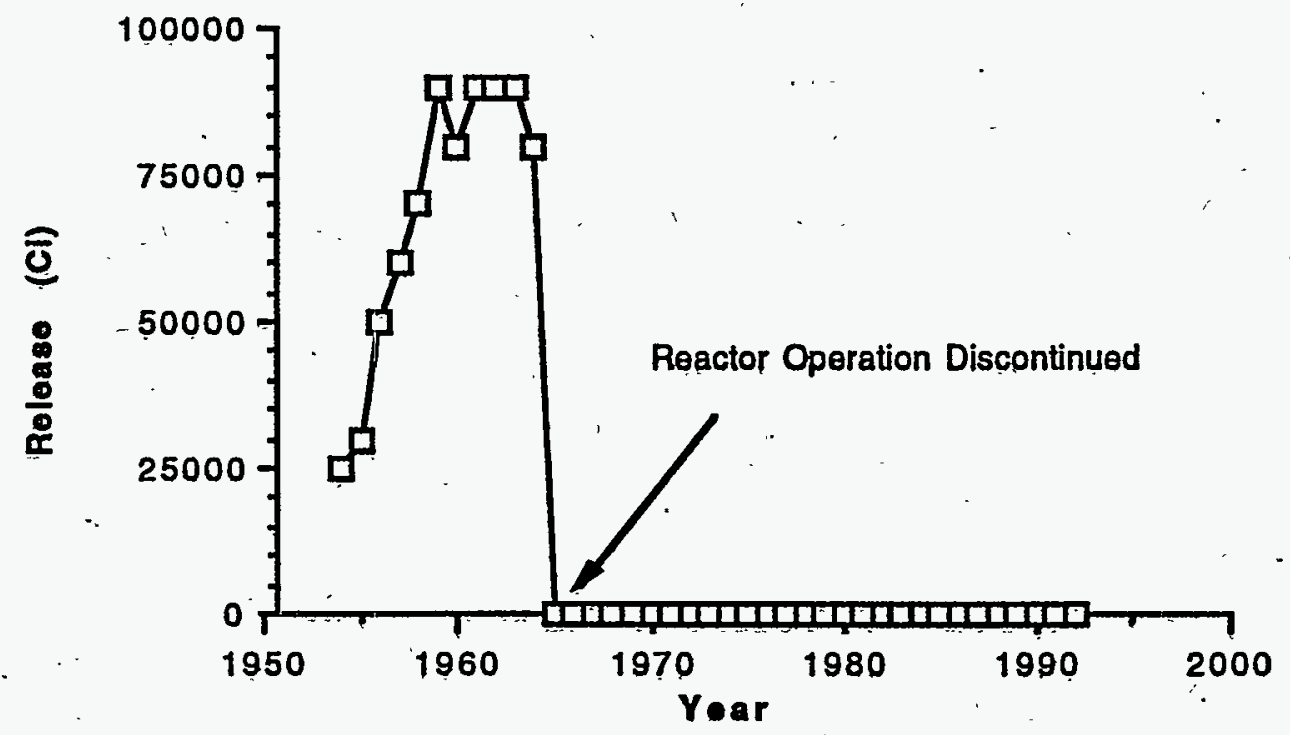




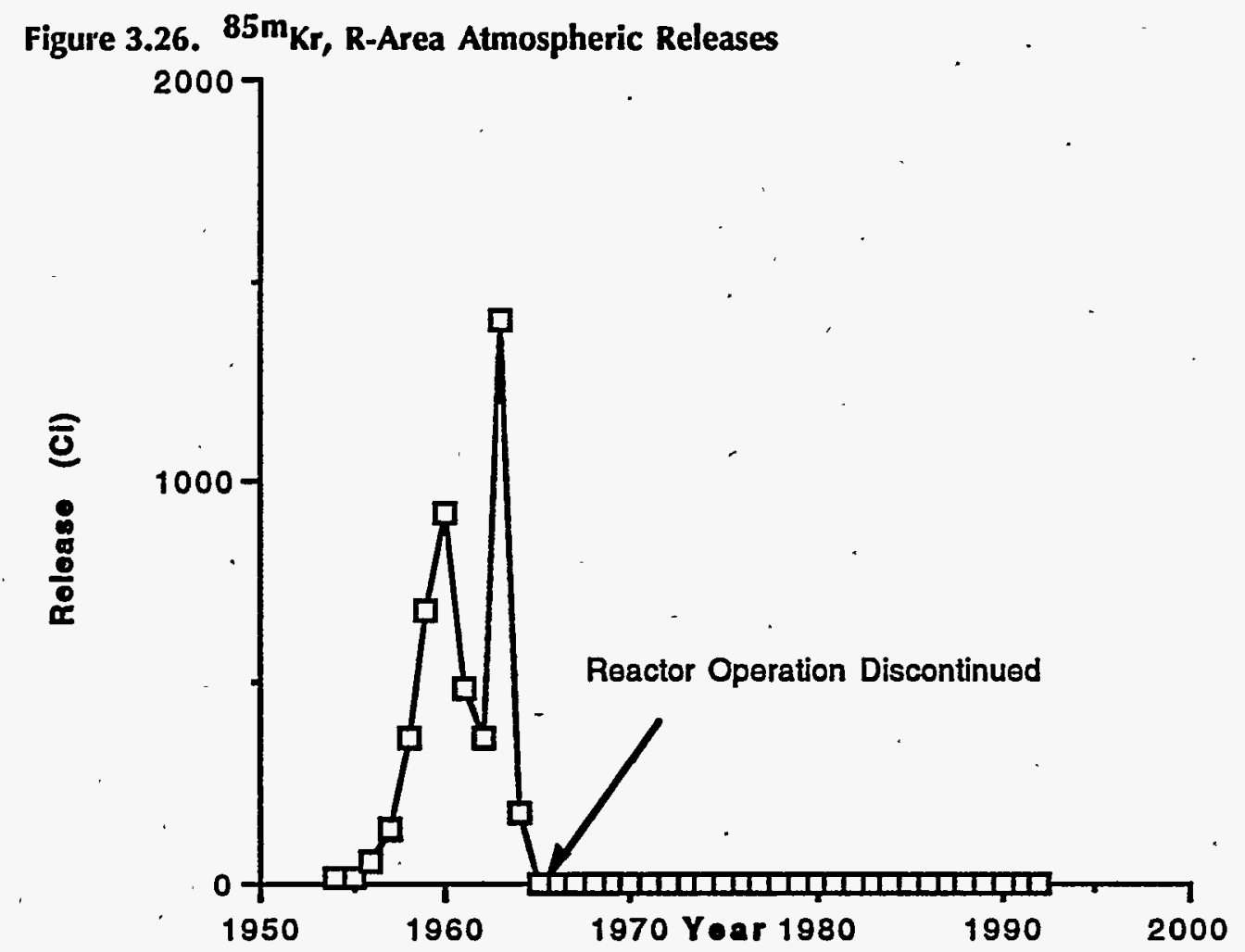

Figure $3.27 .{ }^{88} \mathrm{Kr}$, R-Area Atmospheric Releases

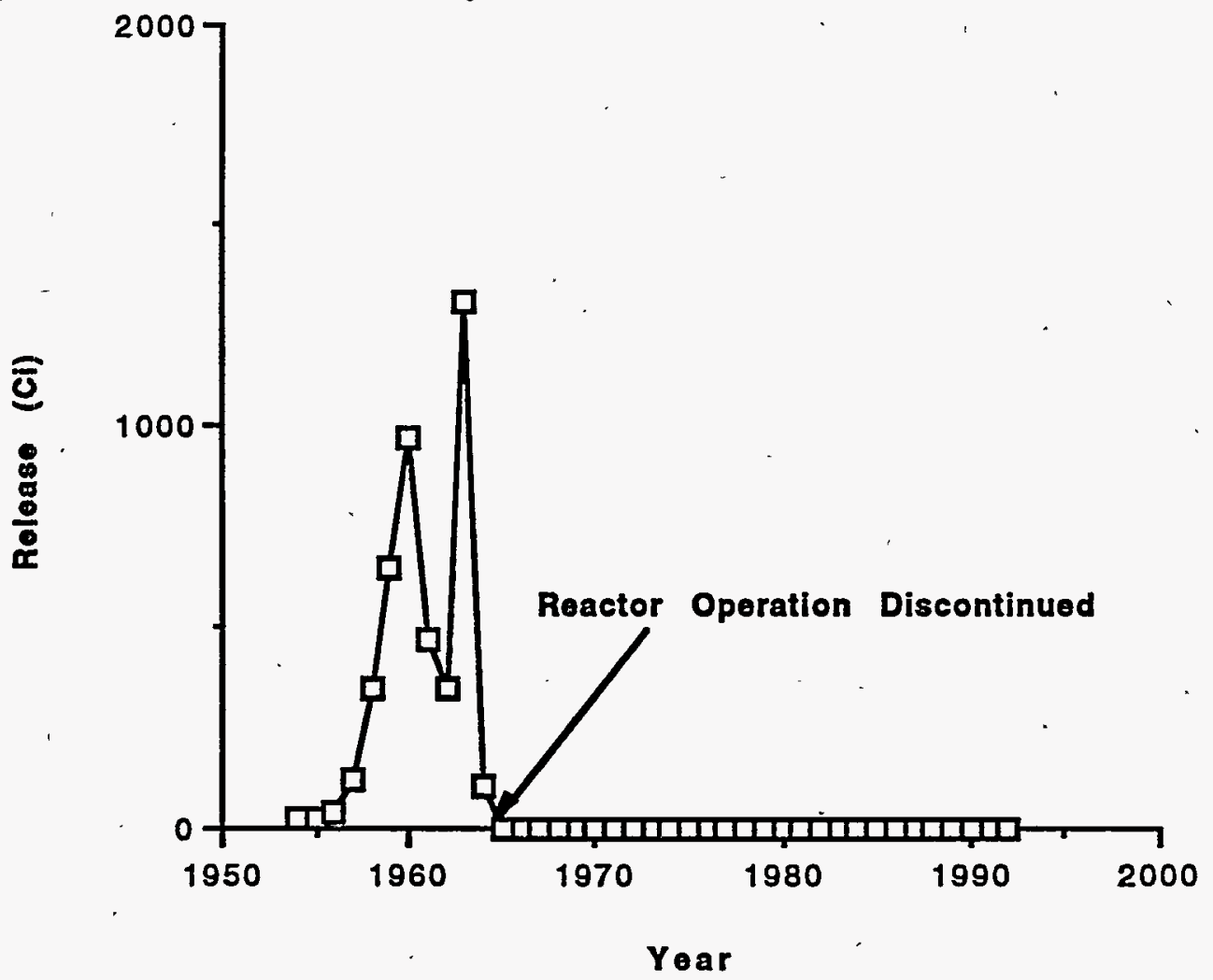




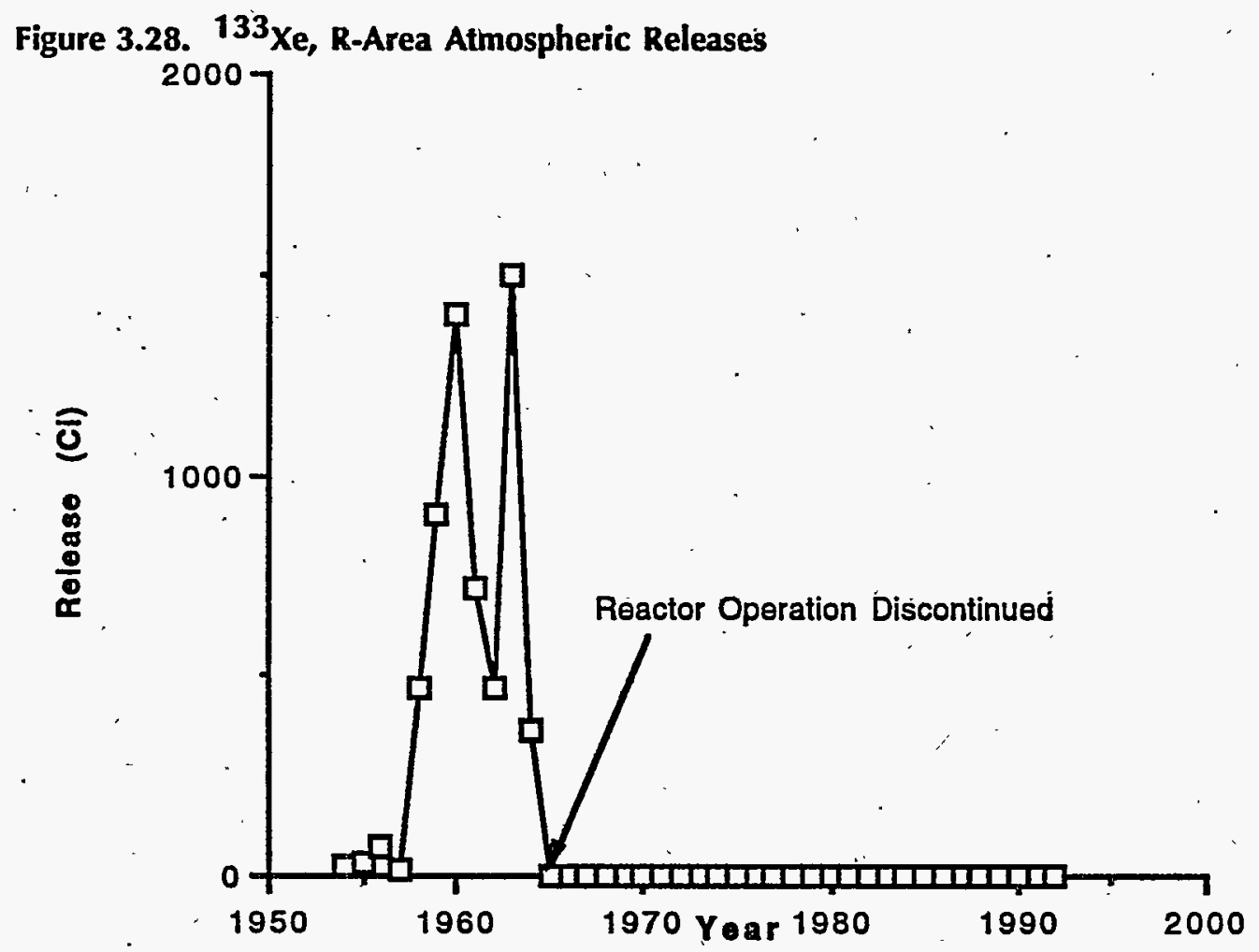

Figure 3.29. ${ }^{135} \mathrm{Xe}$, R-Area Atmospheric Releases

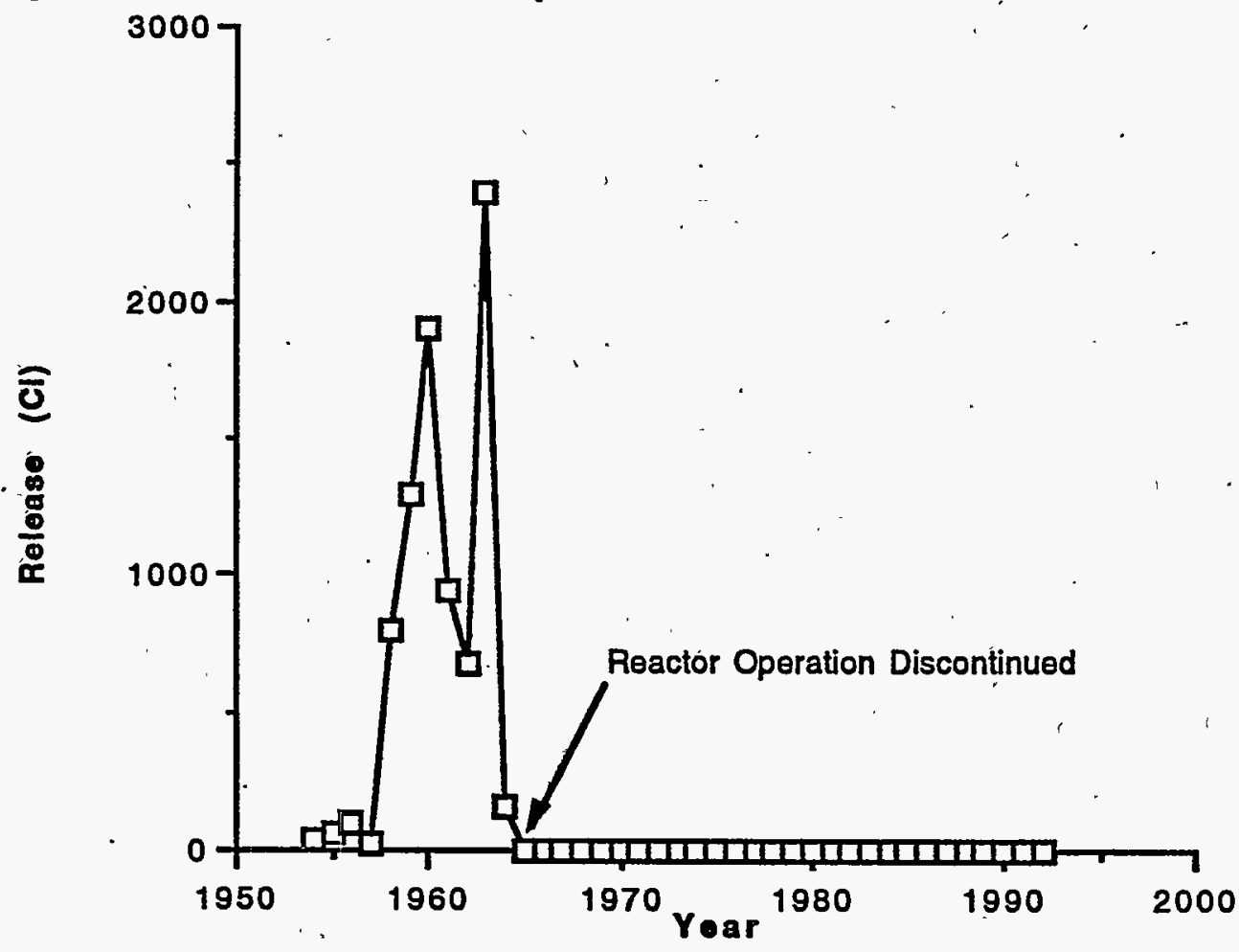


Figure 3.30. ${ }^{85} \mathrm{Kr}$, F-Area and H-Area Atmospheric Releases

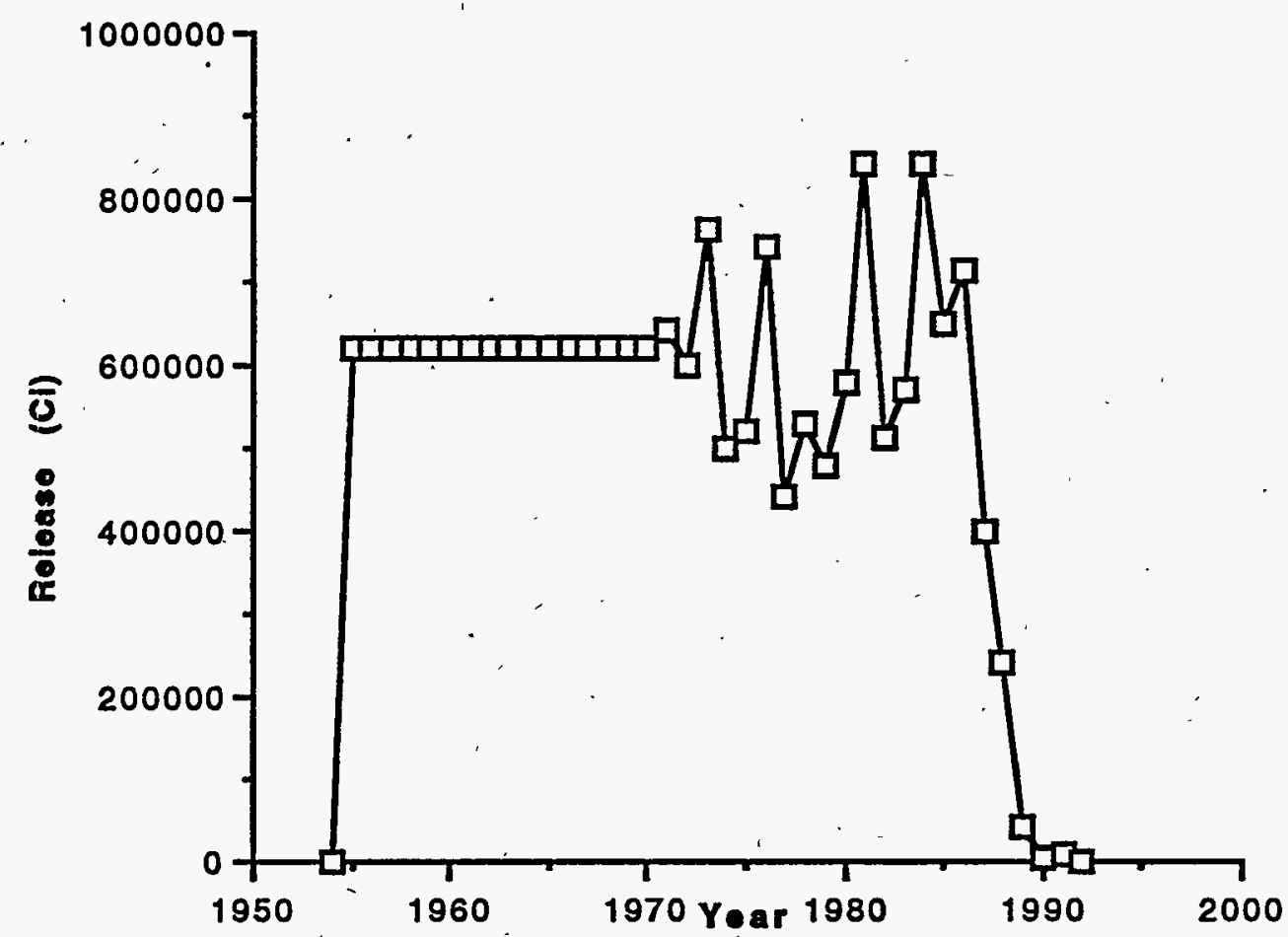

Figure 3.31. ${ }^{131 \mathrm{~m}} \mathrm{Xe}$, F-Area and H-Area Atmospheric Releases

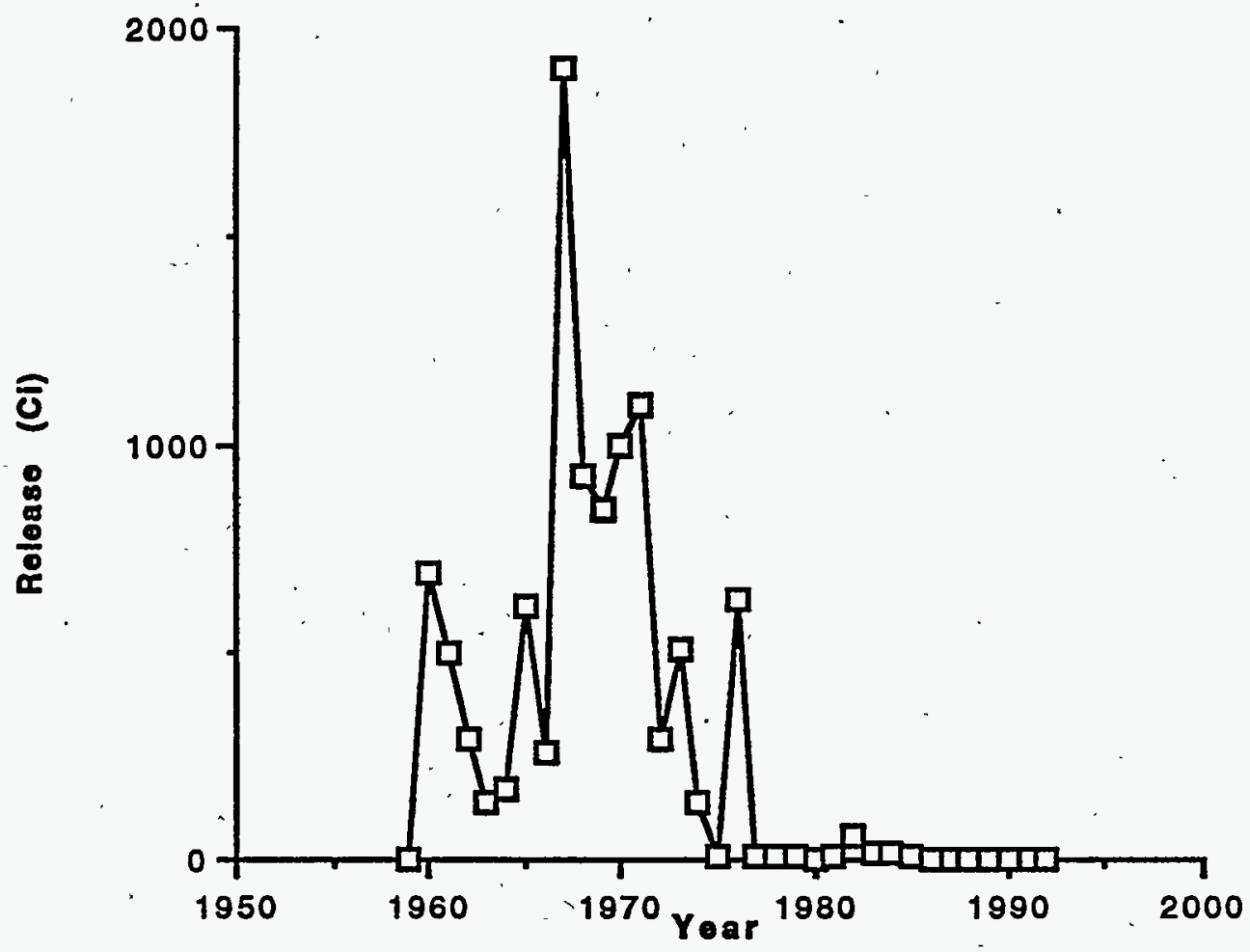


Figure 3.32. ${ }^{133} \mathrm{Xe}, \mathrm{F}$-Area and H-Area Atmospheric Releases

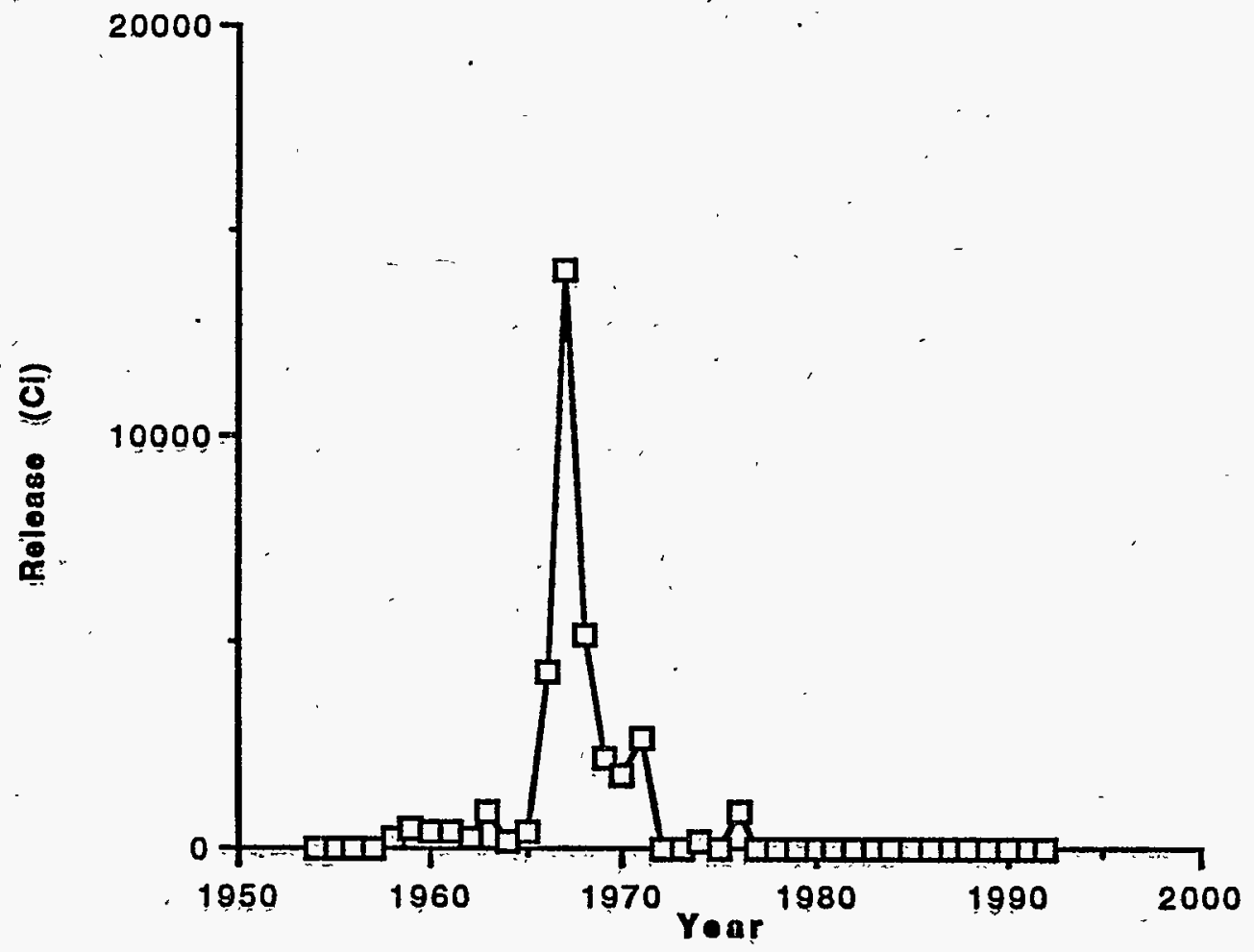




\section{Chapter 4. Noble Gas Concentration and Transport Mechanisms}

Most radionuclides have been released to the environment by SRS operations through atmospheric, surface water, and groundwater pathways. However, the unusual chemical nature of the noble gases, discussed in Chapter 1, precluded their release to surface water and groundwater. In this chapter, only atmospheric transport mechanisms will be considered. 
This page intentionally left blank. 


\section{Atmospheric Transport of Noble Gases}

Routine air concentration measurements are not made of noble gases released by SRS operations $\left({ }^{41} \mathrm{Ar}\right.$, ${ }^{85} \mathrm{Kr},{ }^{85} \mathrm{~m} \mathrm{Kr},{ }^{87} \mathrm{Kr},{ }^{88} \mathrm{Kr},{ }^{131} \mathrm{mXe},{ }^{133} \mathrm{Xe}$, and ${ }^{135} \mathrm{Xe}$ ). However, studies have been conducted in which the noble gases released from SRS facilities were traced in the atmosphere. The most intensive of these studies was a cooperative program between the Air Resources Laboratory of NOAA, Argonne National Laboratory, and SRS (Telegadas et al., 1978; Pendergast et al., 1979; Telegadas et al., 1980; and Gogolak et al., 1981). Measurements of ${ }^{85} \mathrm{Kr}$ and ${ }^{41} \mathrm{Ar}$ also were made as part of a cooperative equipment test with EPA (Garrett, 1983), and ${ }^{85} \mathrm{Kr}$ measurements of long-distance transport were made in cooperation with Air Resources Laboratory of NOAA (Schubert, 1983).

These studies provide some information about air concentrations for short time periods of a few hours and about infrequent detection of SRS releases at distances up to $1000 \mathrm{~km}$. However, only the first of , the aforementioned studies provides enough information to evaluate doses to the surrounding public -and that one only for the period from March
1975 to September 1977. As will be discussed later in this document, atmospheric models using detailed local environmental data are the basis for the doses to the population in the vicinity of SRS. These models have been validated by comparing their predicted air concentrations to measured tritium (HTO) concentrations (Murphy et al., 1993).

From the data reported in Telegadas et al. (1978), it is possible to compare the air concentrations of ${ }^{85} \mathrm{Kr}$ and tritium for 1976 and test the method of using an atmospheric diffusion model validated with tritium data for calculation of noble gas air concentrations. Figure 4.1 shows the annual average ${ }^{85} \mathrm{Kr}$ air concentration (minus background) for each of the sampling locations plotted against the distance from the fuel reprocessing areas at SRS for the calendar year 1976. As expected from theory, the data can be fit reasonably well by a straight line in logarithmic coordinates.

To compare the ${ }^{85} \mathrm{Kr}$ concentration to the tritium concentration, the concentrations are normalized by dividing each by the release during 1976 . The best

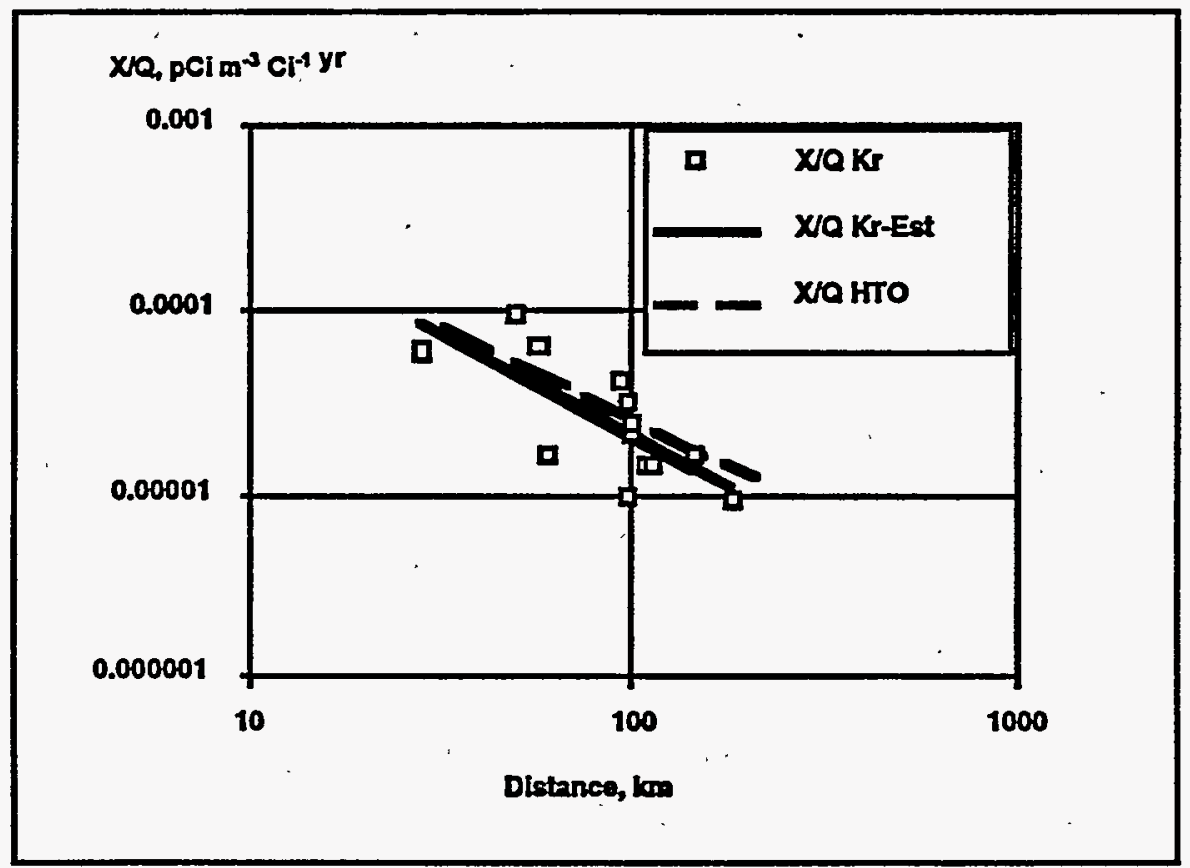

Figure 4.1. The Air Concentration of ${ }^{85} \mathrm{Kr}$ and a Comparison of the Best-Fit Straight Line of the ${ }^{85} \mathrm{Kr}$ and Tritium Air Concentration Samples in 1976 


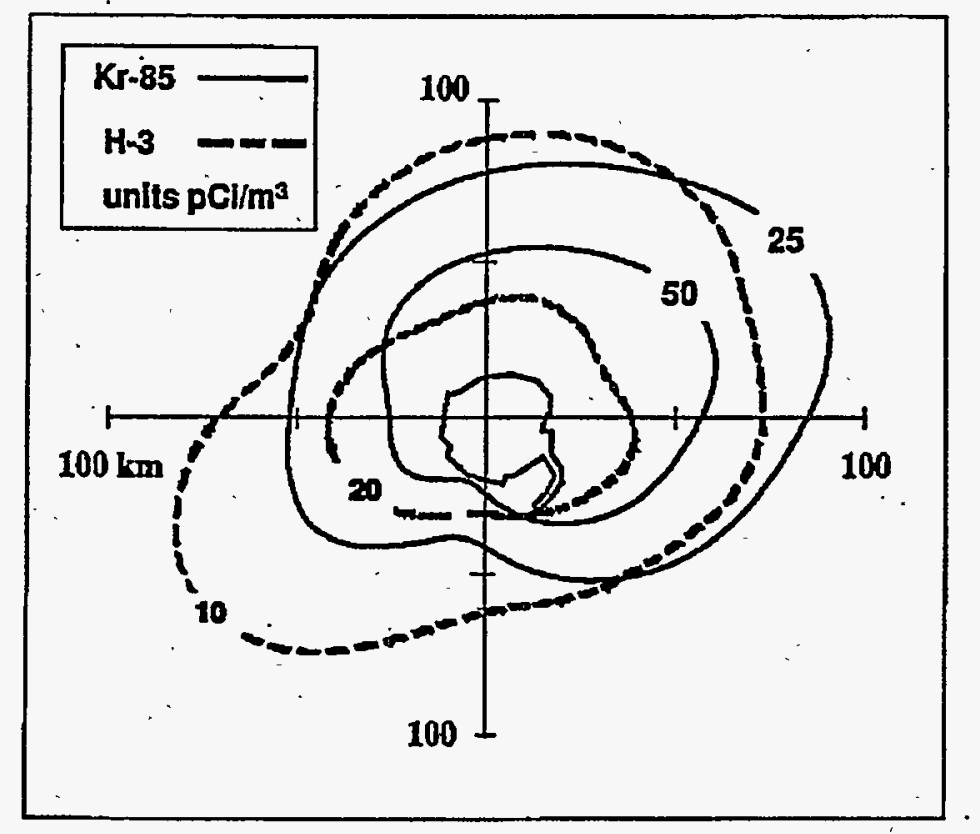

Figure 4.2. Comparison of the Contours of ${ }^{85} \mathrm{Kr}$ and Tritium Air Concentrations in the Vicinity of SRS

straight-line fit of the data for each radionuclide, indicates agreement between slopes of the two lines and suggests that the atmospheric diffusion of the two radionuclides is similar.

The agreement of the absolute values indicates that the reported release rates are consistent with the measured air concentrations. In 1976, the tritium releases to the atmosphere were about $40 \%$ of the ${ }^{85} \mathrm{Kr}$ releases.

The air concentration contours of ${ }^{85} \mathrm{Kr}$ and tritium are compared in Figure 4.2. The contours do not agree as well as might have been expected, based on the analysis shown in Figure 4.1. This is not altogether surprising. Figure 4.1 suggests that air concentrations averaged over a year are similar for the two radionuclides when normalized on the basis of releases. The contours show shorter term variability because of differences in the timing of releases. All of the ${ }^{85} \mathrm{Kr}$ releases took place in discrete puffs, depending on the manufacturing processes taking place in the SRS facilities. However; about half of the tritium releases were continuous throughout the year. Also, the releases of ${ }^{85} \mathrm{Kr}$ and tritium are from different manufacturing facilities and are not connected in such a way that the releases take place simultaneously. For instance, the extension of the tritium profiles in the west-southwest direction may be attributable to the chance release of tritium when wind conditions favored transport in that direction. On the other hand, the decreased transport to the south of SRS for both radionuclides is consistent with the annual distribution of wind direction observed at SRS for many years. 


\section{References}

Garrett, A. J., 1983, "SRL Calculations of Surface Concentration of Tritium and Argon Near $\mathrm{H}$ and $\mathrm{P}$ Areas on December 14 and 15, 1982," DPST-83396, E. I. du Pont de Nemours and Company, Aiken, SC.

Gogolak, C. V., H. L. Beck, and M. M. Pendergast, 1981, "Calculated and Observed ${ }^{85} \mathrm{Kr}$ Concentrations within $10 \mathrm{~km}$ of the Savannah River Plant Chemical Separations Facility," Atmospheric Environment 15:497-507.

Murphy, C. E., Jr., W. H. Cariton, L. R. Bauer, D. W. Hayes, W. L. Marter, C. C. Zeigler, R. L. Nichols, R. N. Strom, B. R. del Carmen, D. M. Hamby, D. D. Hoel, and D. E. Stephenson, 1993, "Assessment of Tritium in the Savannah River Site Environment," WSRC-TR-93-214, Westinghouse Savannah River Company, Aiken, SC.

Pendergast, M. M., A. L. Boni, G. J. Ferber, and K Telegadas, 1979, "Measured Weekly ${ }^{85} \mathrm{Kr}$ Concentrations within $150 \mathrm{~km}$ of the Savannah River Plant (March 1975 through August 1976), " DP-1486, E. I. du Pont de Nemours and Company, Aiken, SC.
Schubert, J. F., 1983, "Empirical Observations of Diffusion Rates Out to Distances of $1000 \mathrm{~km}$ over the Eastern U.S. Based on Krypton-85 Measurements," Air Pollution Control Association Conference on the Meteorology of Long-Range Transport, Hartford, Conn., October 16-19, 1983.

Telegadas, K., G. J. Ferber, J. L. Heffter, and R. R. Draxler, 1978, "Calculated and Observed Seasonal and Annual Krypton-85 Concentrations at $30-150 \mathrm{~km}$ from a Point Source," Atmospheric Environment 12:1769-1775.

Telegadas, K., G. J. Ferber, R. R. Draxler, M. M. Pendergast, A. L. Boni, J. P. Hughes, and J. Gray, 1980, "Measured Weekly and Twice-Daily Krypton85 Surface Air Concentrations within $150 \mathrm{~km}$ of the Savannah River Plant (March 1975 through September 1977) - Final Report," NOAA Technical Memorandum ERL ARL-80, Air Resources Laboratories, Silver Springs, MD. 
This page intentionally left blank. 


\section{Chapter 5. Assessment of Dose/Risk from SRS Noble Gas Releases}

This chapter describes the methodology used to produce dose estimates. The results of a dose assessment for noble gas releases during the 1954-1992 period are presented, and. the health impacts associated with exposure to noble gases are discussed. 
This page intentionally lefț blank. 


\section{Relationship of Dose to Risk and Health Effects}

\section{Ionizing Radiation}

Ionizing radiation is that radiation that has enough energy to remove electrons from the atoms through which it passes. The interaction of ionizing radiation with biological systems can induce a series of chemical reactions that can cause permanent changes in the genetic material of cells. These changes (mutations) may cause abnormal functioning within the cell or may lead to cell death.

The nature of radiation-induced cellular changes depends on the magnitude of the dose and the rate at which it is received. For the low doses and dose rates encountered in the environment from SRS releases, the most significant effect is cancer induction. This is believed to be a stochastic effect (i.e., an increase in dose increases the probability of the effect but the severity of the effect is independent of dose).

A characteristic of stochastic risks is the absence of a threshold. In other words, it is conceivable that any dose of radiation, no matter how small, might give rise to a cancer. On the other hand, there is no way to be certain that a given dose, no matter how large, will cause a cancer in an individual.

\section{Cancer Risk Estimates}

The most comprehensive estimates of cancer induction by exposure to ionizing radiation come from studies of the atomic bomb survivors at Hiroshima and Nagasaki. Less definitive studies include those of medical patients exposed to therapeutic and diagnostic radiation. Studies of laboratory animals have increased the understanding of dose-effect relationships. The International Commission on Radiological Protection (ICRP) has evaluated all these studies and concluded that the best estimate of lifetime risk of fatal cancer for members of the general population is approximately 500 cases per 1,000,000 person-rem (ICRP, 1991). This is equivalent to one case per 2000 person-rem.

\section{Noble Gas Exposure and Dose to Man}

\section{Distribution and Retention of Noble Gases in the Human Body}

Noble gases typically enter the human body through inhalation and are rapidly exhaled when exposure to airborne activity ceases. The noble gases do not react chemically but are dissolved in various components of the body. A study of total body retention of ${ }^{79} \mathrm{Kr}$ indicated that after 10 minutes of exposure, $90 \%$ of the activity in the chest region was exhaled in approximately 3 minutes (Ellis, 1977). Susskind (1977) studied the retention of ${ }^{127} \mathrm{Xe}$ and found a five-compartment model. Compartment 1, half-time 22 seconds, was gas clearance directly from the air spaces of the lungs. Compartment 2, half-time 3.1 minutes, was associated with xenon attached to hemoglobin molecules in the blood. Compartment 3 , half-time 0.4 hours, was xenon in resting muscle and lean body tissues. Compartments 4 and 5, half-times 2.7 and 10 hours respectively, represented xenon in fat, and the long clearance times represent xenon's preferential solubility in fat versus other body tissues.

\section{Noble Gas Dosimetry}

The ICRP (ICRP, 1979) has concluded that the radiation dose from inhalation of noble gases is insignificant when compared to the dose from. submersion in a radioactive cloud of noble gases. Most of the dose delivered is from high-energy betas and gammas originating outside the human body.

The U.S. Department of Energy (DOE) issued internal dose conversion factors in 1988 to ensure that doses are calculated consistently at all DOE facilities (DOE, 1988). The factors are based on ICRP recommendations (ICRP, 1981). These dose factors are used, in conjunction with the models described in the subsection on models of noble gas transport and dose, to calculate all the doses reported in this document.

Future changes are anticipated in the dose calculation methodology. The ICRP (ICRP, 1989) has issued age-specific dose factors for ingestion of some of the more common isotopes and is developing agespecific dose factors for inhalation of radioisotopes. 


\section{Models of Noble Gas Transport and Dose}

With the exception of tritium, most of the radioactive materials released from SRS have such low concentrations in the offsite environment that they are not detectable by conventional monitoring techniques. Therefore, radiation doses to offsite individuals and populations are calculated with mathematical models. These models use known transport mechanisms for atmospheric and liquid releases and known major pathways of exposure to man. Modeled atmospheric and aqueous dispersion are verified periodically through the use of environmental tritium measurements. Tritium is released during normal SRS operations.

The first models used at SRS for calculating offsite doses were developed by SRTC (Cooper, 1975). These models, MREM (atmospheric releases) and RIVDOSE (liquid releases), were used first in 1972. In 1982, MREM and RIVDOSE were replaced with the more technologically advanced models now in use.

SRS annual offsite doses from atmospheric releases are calculated with the transport and dose models developed for the commercial nuclear industry (NRC, $1977 \mathrm{a}$; NRC, 1977b). The models are implemented at SRS in the following computer programs:

- MAXIGASP-calculates marimum and average doses to offsite individuals

- POPGASP-calculates offsite population collective dose

The programs MAXIGASP and POPGASP are SRTC-modified versions of the Nuclear Regulatory Commission (NRC) programs XOQDOQ (Sagendorf et al., 1982) and GASPAR (Eckerman et al., 1980). The modifications were made to meet the requirements for input of physical and biological data specific to SRS. The basic calculations in the XOQDOQ and GASPAR programs have not been modified.

\section{Modeling Atmospheric Dispersion of Radioactive Releases}

The routine atmospheric transport of radioactive materials from SRS is evaluated on the basis of meteorological conditions measured continuously at seven onsite towers. The towers relay wind speed, direction, and atmospheric stability information at 1.5-second intervals to SRTC via the WIND (Weather INformation and Display) system. A database of this information containing the 60-minute average values for the period 1987-1991 is accessed by dispersion codes to estimate downwind concentrations of released radionuclides.

Offsite doses from atmospheric releases have been calculated using H-Area meteorology and assuming the releases occurred at the geographic center of the site. It has been demonstrated that using data from one of the other onsite meteorological towers has little effect on the maximum individual dose and no effect on the $80-\mathrm{km}$ population dose (Hamby and Parker, 1991). Essentially all releases of noble gases occurred from C, F, H, K, L, P, and R Areas, all of which are located within three miles of the center of the 20-mile diameter site. Using the center of the Site as the release point simplifies the calculation of dose with no significant introduction of error.

The dispersion of an atmospheric release from $\mathrm{SRS}$ is modeled using $X O Q D O Q$, which computes concentrations in the plume as a function of downwind distance and compass sector. The plume is depleted by dry deposition and radioactive decay. At the user's option, plume concentrations can be reduced by taking into account the upward displacement of the effluent resulting from thermal buoyancy and/or momentum effects. This option is not used at SRS (i.e., no credit is taken for plume rise). The program XOQDOQ has undergone a comprehensive review in association with Westinghouse Savannah River Company (WSRC) quality assurance requirements for software (Bauer, 1991).

The plume concentration information generated by XOQDOQ is used by the dose modeling program GASPAR to estimate doses to offsite individuals and populations. GASPAR estimates doses from a number of pathways, which are illustrated in a general sense in Figure 5.1.

The doses estimated by GASPAR are reported on a pathway-specific basis as follows:

- Plume-external dose from radioactive materials suspended in the atmosphere

- Ground - external dose from radioactive materials deposited on the ground

- Inhalation - internal dose from inhalation of radioactive materials present in the plume

- Vegetation - internal dose from consumption of contaminated crops

- Milk - internal dose from milk produced in a contaminated area

- Meat - internal dose from consumption of meat produced in a contaminated area. 


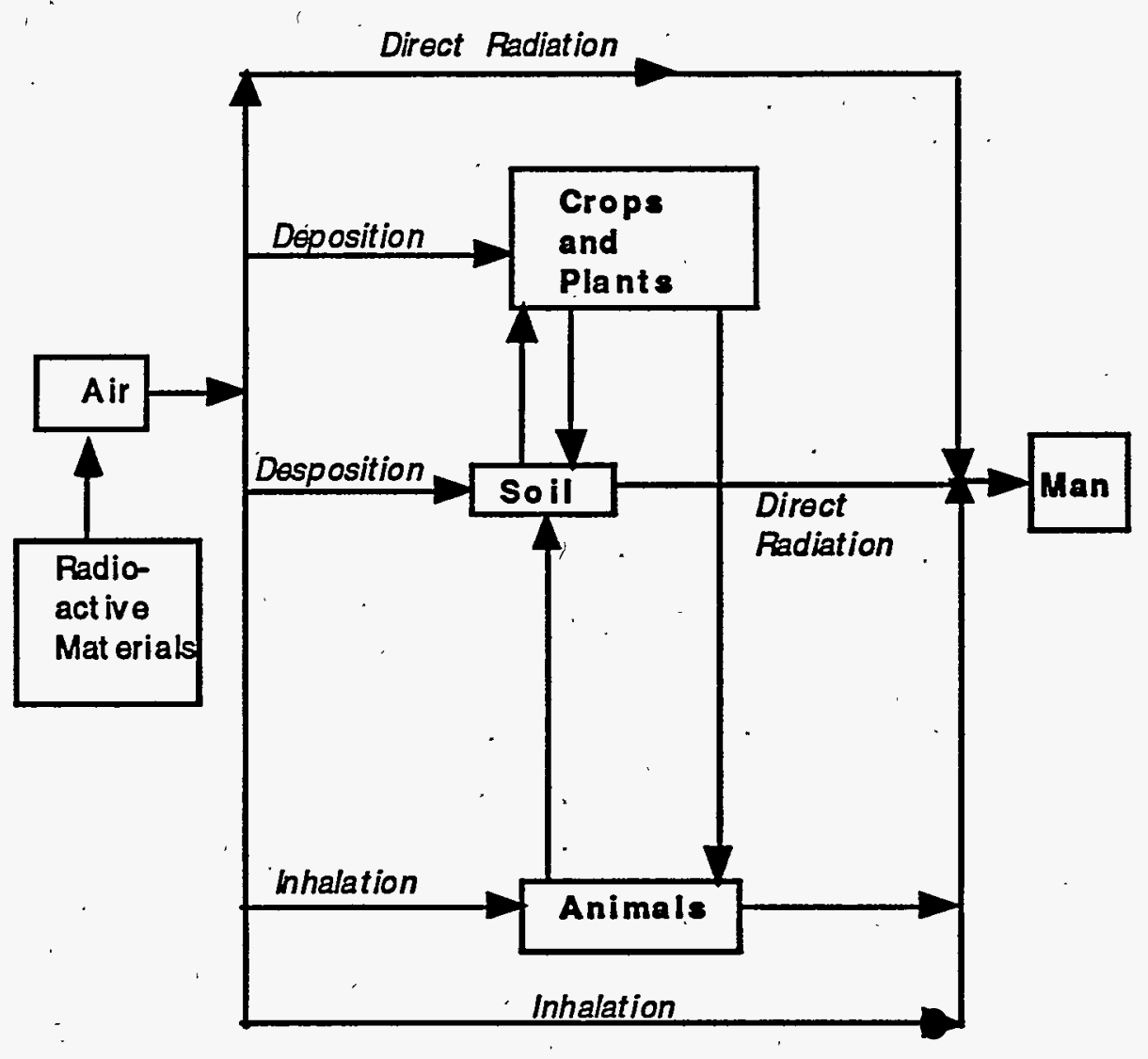

Figure 5.1. Simplified Pathways between Radioactive Materials Released to the Atmosphere and Man

\section{MAXIGASP}

The calculations required by XOQDOQ and GASPAR to estimate maximum and average individual doses are performed at SRS using the computer program MAXIGASP. MAXIGASP calculates annual average ground-level air concentrations and 50-year committed doses at a number of points along the site boundary in each of 16 compass sectors.

The main output from the program is the maximum dose equivalent to an individual along the SRS perimeter. The maximally exposed individual is assumed to reside continuously at the location of highest exposure and to have living and eating habits that maximize dose. These assumptions provide a ceiling on dose from atmospheric releases because no such individual is believed to exist.

\section{POPGASP}

Calculations required by XOQDOQ and GASPAR to estimate population doses from atmospheric releases are performed at SRS using POPGASP, which calculates annual average ground-level air concentrations and annual doses for each of 160 regions (16 wind direction sectors at 10 distances per sector) within an 80-kilometer radius of the release location.

In addition to compass sector-specific meteorological information, POPGASP uses sector-specific data on population distribution and composition. Comparable data on milk, meat, and vegetable production and consumption also are used in the code. These databases are quite extensive and are available for review in the annual SRS Environmental Report. The site-specific parameters (Hamby, 1991) used to calculate doses with MAXIGASP and POPGASP are presented in Table 5-1.

\section{Modeling Doses from Liquid Releases}

Noble gases cannot be released in liquid form from SRS facilities. Therefore, this release mechanism will not be discussed 


\section{Verification of Atmospheric Transport Models using Monitoring Data}

The radionuclide ' concentrations predicted by XOQDOQ are compared routinely with measured values of tritium concentrations in air to evaluate the performance of the code. (Tritium is the only radionuclide released by SRS that can be detected routinely offsite using conventional measuring techniques.) Predicted values tend to exceed observed values, but not to a degree that would indicate an excessively conservative approach.
Other comparisons of predicted and measured concentrations have been made (Marter, 1984) and have exhibited similar results. The available data suggest that calculated concentrations of tritium in air generally are conservative estimates of actual offsite values.

\section{Impact of SRS Noble Gas Releases on the Offsite Population}

The computer codes MAXIGASP and POPGASP have been used to calculate effective dose equivalents (EDE) that have been received by segments of the offsite population from noble gases released during site operations. The site total releases are listed in Table 5-2.

The EDE received by the "maximum" adult during the 1954-1992 time period at the site perimeter was 8.3 mrem (Table 5-3).

"Maximum" individuals are hypothetical persons who live at the SRS boundary and subsisted on, diets of locally produced milk, meat, and vegetables; no such individuals are known to exist. This theoretical dose is the upper bounding case and would make a minor contribution to the overall dose received during that time period.

A person living in the Central Savannah River Area (CSRA) would have received an effective dose of approximately $11,000 \mathrm{mrem}$ from exposure to natural . sources of radioactivity and an additional $2500 \mathrm{mrem}$ from medical practices and various consumer products during the 39-year period (Cummins et al., 1990). Therefore, the cumulative dose contribution to this individual from SRS atmospheric noble gas releases can be estimated as $0.06 \%$.

Because the contribution of SRS noble gas releases to any one individual's total radiation does was so small, it is necessary to pool the radiation exposures for a given population to assess potential health risks. The population dose within an 80-kilometer radius is the figure of merit frequently used to make such an assessment.

The population doses reported in Table 5-4 were based on 1980 census data (555,100 people within 80 km), 1987-91 meteorology and current dose factor data (DOE, 1988). If it is assumed that this population has lived in the SRS vicinity throughout the period of site operation, the total collective effective dose received by that population through 1992 would be 220 person-rem.

The risks associated with this collective dose are quite small. The risk estimate using the ICRP factor for the number of excess fatal cancers potentially induced by a collective dose of 220 person-rem is 0.11. Conversely, in that same population, at the current fatal cancer frequency of 16\% (EPA, 1989), about 90,000 fatal cancers will occur from all other causes. Therefore, it is impossible to demonstrate that a relationship exists between any of the cancer deaths occurring in this population and the release of noble gases to the atmosphere from SRS.

\section{Comparisons of Noble Gas Doses near SRS with Applicable Regulations}

The hypothetical dose received by the maximally exposed individual from atmospheric releases of noble gases from SRS over 39 years was $8.3 \mathrm{mrem}$ (Table 5-4). The current EPA annual limit on doses to members of the public from atmospheric releases of all radioisotopes is $10 \mathrm{mrem}$.

\section{Summary of Dosimetric Impacts}

The overall radiological impact of SRS noble gas releases (1954-1992) on the offsite "maximum" individual can be characterized by a total dose of 8.3 mrem. During this same period, however, such an individual received a dose of $13,500 \mathrm{mrem}$ from nonSRS sources of ionizing radiation present in the - environment.

The impact of SRS noble gas releases on offsite populations also has been evaluated. The total collective dose from atmospheric releases (1954- 
1992) was estimated as 220 person-rem distributed among 555,100 individuals.
Noble gas releases from SRS present a negligible risk to the offsite environment and the population it supports.

Table 5-1. Site-Specific Parameters for Atmospheric Releases

\section{Population Group}

80-km radius

555,100

Maximum Individual (MAXIGASP)

\section{Exposure Pathway}

Inhalation $\left(\mathrm{m}^{3} / \mathrm{yr}\right)$

Ingestion

Cow's milk (L/yr)

Meat (kg/yr)

Leafy vegetables (kg/yr)

Fruits, grains, and other vegetables $(\mathrm{kg} / \mathrm{yr})$

External exposure

Transmission factor for

shielding from buildings
8,000

230

81

43

276

0.7

General Population (POPGASP)

\section{Exposure Pathway}

Inhalation $\left(\mathrm{m}^{3} / \mathrm{yr}\right)$

Ingestion

Cow's milk (L/yr)

Meat (kg/yr)

Leafy vegetables (kg/yr)

21

Fruits, grains, and other

vegetables (kg/yr)

External exposure

Transmission factor for

0.5 
Table 5-2. Sum of Atmospheric Releases from SRS

Site Total Releases (Curies)

\begin{tabular}{|c|c|c|c|c|c|c|c|c|}
\hline ear & $41 \cdot \mathrm{Ar}$ & ${ }^{85} \overline{\mathrm{Kr}}$ & $35 \mathrm{~m} \mathbf{K r}$ & ${ }^{87} \mathrm{Kr}$ & ${ }^{88} \mathrm{Kr}$ & $31 \mathrm{~m} \times e^{-2}$ & $133 \mathrm{Xe}$ & ${ }^{135} \mathrm{Xe}$ \\
\hline & $\times 10^{4}$ & $9 \times 10$ & $4.0 \times 10^{1}$ & & $4.0 \times 10^{1}$ & & $6.0 \times 10^{1}$ & $8.0 \times 10$ \\
\hline & & $2 \times 10^{5}$ & $0 x$ & & $0 x$ & & $0 \times 10^{2}$ & $0 \times 10^{2}$ \\
\hline & $\times 10^{5}$ & $2 \times 10^{5}$ & $3.0 \times 10^{2}$ & & $0 \times 10^{2}$ & & $.0 \times 10^{2}$ & $5.0 \times 10^{2}$ \\
\hline & $\times 10^{5}$ & $6.2 \times 10^{5}$ & $7.0 \times 10^{2}$ & & $6.0 \times 10^{2}$ & & $.0 \times 10^{2}$ & $1.0 \times 10^{2}$ \\
\hline & $4 \times 10^{5}$ & $6.2 \times 10^{5}$ & $1.8 \times 10^{3}$ & & $1.7 \times 10^{3}$ & & $6 \times 10^{3}$ & $4.0 \times 10^{3}$ \\
\hline & $4 \times 10^{5}$ & $6.2 \times 10^{5}$ & $3.4 \times 10^{3}$ & & $3.2 \times 10^{3}$ & & $0 \times 10^{3}$ & $6.5 \times 10^{3}$ \\
\hline & $0 \times 10^{5}$ & $6.2 \times 10^{5}$ & $4.6 \times 10^{3}$ & & $4.8 \times 10^{3}$ & $\times 10^{2}$ & $4 \times 10^{3}$ & $9.5 \times 10^{3}$ \\
\hline & $2 \times 10^{5}$ & $6.2 \times 10^{5}$ & $2.4 \times 10^{3}$ & & $2.3 \times 10^{3}$ & $10^{2}$ & $1.0 \times 10^{3}$ & $4.7 \times 10^{3}$ \\
\hline & $3 \times 10^{5}$ & $6.2 \times 10^{5}$ & $1.8 \times 10^{3}$ & & $1.7 \times 10^{3}$ & $10^{2}$ & $.6 \times 10^{3}$ & $3.4 \times 10^{3}$ \\
\hline & $5 \times 10^{5}$ & $6.2 \times 10^{5}$ & $7.0 \times 10^{3}$ & & $6.5 \times 10^{3}$ & $10^{2}$ & $4 \times 10^{3}$ & $7.0 \times 10^{4}$ \\
\hline & $7 \times 10^{5}$ & $6.2 \times 10^{5}$ & $9.0 \times 10^{2}$ & & $5.0 \times 10^{2}$ & $10^{2}$ & $.0 \times 10^{3}$ & $8.0 \times 10^{2}$ \\
\hline & $7 \times 10^{5}$ & $6.2 \times 10^{5}$ & $2.0 \times 10^{3}$ & & $1.2 \times 10^{3}$ & $10^{2}$ & $4.2 \times 10^{3}$ & $8 \times 10^{3}$ \\
\hline & $8 \times 10^{5}$ & $6.2 \times 10^{5}$ & $2.4 \times 10^{3}$ & & $1.5 \times 10^{3}$ & $10^{2}$ & $7.0 \times 10^{4}$ & $2.1 \times 10^{3}$ \\
\hline & $2 \times 10^{5}$ & $6.2 \times 10^{5}$ & $7.0 \times 10^{4}$ & & $7.0 \times 10^{4}$ & $10^{3}$ & $1.5 \times 10^{5}$ & $7.0 \times 10^{4}$ \\
\hline & $2 \times 10^{5}$ & $6.2 \times 10^{5}$ & $7.0 \times 10^{4}$ & & $8.0 \times 10^{3}$ & $10^{2}$ & $7.0 \times 10^{4}$ & $7.0 \times 10^{4}$ \\
\hline & $4 \times 10^{5}$ & $2 \times 10^{5}$ & $5.4 \times 10^{3}$ & & $3.6 \times 10^{3}$ & $10^{2}$ & $7.0 \times 10^{4}$ & $5.4 \times 10^{3}$ \\
\hline & $1 \times 10^{5}$ & $2 \times 10^{5}$ & $2.4 \times 10^{3}$ & & $6 \times 10^{3}$ & $10^{3}$ & $7.0 \times 10^{4}$ & $2.6 \times 10^{3}$ \\
\hline & $4 \times 10^{5}$ & $6.4 \times 10^{5}$ & $3.1 \times 10^{3}$ & & $1.7 \times 10^{3}$ & $10^{3}$ & $7.0 \times 10^{4}$ & $4.7 \times 10^{3}$ \\
\hline & $7 \times 10^{5}$ & $6.0 \times 10^{5}$ & $7.4 \times 10^{3}$ & $2.5 \times 10^{3}$ & $4.2 \times 10^{3}$ & $10^{2}$ & $7.0 \times 10^{4}$ & $7.0 \times 10^{4}$ \\
\hline & $9 \times 10^{5}$ & $7.6 \times 10^{5}$ & $6.6 \times 10^{3}$ & $2.0 \times 10^{3}$ & $4 \times 10^{3}$ & $10^{2}$ & $7.0 \times 10^{4}$ & $9.3 \times 10^{3}$ \\
\hline & $1 \times 105$ & $5.0 \times 10^{5}$ & $1.3 \times 10^{3}$ & $6.4 \times 10^{2}$ & $4 \times 10^{3}$ & $10^{2}$ & $5.5 \times 10^{3}$ & $2.1 \times 10^{3}$ \\
\hline & $5 \times 10^{4}$ & $5.2 \times 10^{5}$ & $3.7 \times 10^{2}$ & $12 \times 10^{3}$ & $6 \times 10^{2}$ & & $1.1 \times 10^{3}$ & $7.3 \times 10^{2}$ \\
\hline & $\times 10^{4}$ & $7.4 \times 10^{5}$ & $3.8 \times 10^{2}$ & $4.3 \times 10^{2}$ & $5.1 \times 10^{2}$ & $10^{2}$ & $2.5 \times 10^{3}$ & $7.3 \times 10^{2}$ \\
\hline & $5 \times 10^{4}$ & $4.4 \times 10^{5}$ & $8.4 \times 10^{2}$ & $6.0 \times 10^{2}$ & $6.7 \times 10^{2}$ & $10 !$ & $2.3 \times 10^{3}$ & $1.7 \times 10^{3}$ \\
\hline & $2 \times 10^{4}$ & $5.3 \times 10^{5}$ & $9.0 \times 10^{2}$ & $5.5 \times 10^{2}$ & $8.4 \times 10^{2}$ & $10^{0}$ & $22 \times 10^{3}$ & $1.7 \times 10^{3}$ \\
\hline & $4 \times 10^{4}$ & $8 \times 10^{5}$ & $1.8 \times 10^{3}$ & $1.5 \times 10^{3}$ & $2.2 \times 10^{3}$ & $0^{0}$ & $5.3 \times 10^{3}$ & $4.5 \times 10^{3}$ \\
\hline & $0 \times 10^{4}$ & $\times 10^{5}$ & $3.2 \times 10^{3}$ & $2.8 \times 10^{3}$ & $4.0 \times 10^{3}$ & $0^{-1}$ & $7.8 \times 10^{3}$ & $6.4 \times 10^{3}$ \\
\hline & $\times 10^{4}$ & $8.4 \times 10^{5}$ & $1.3 \times 10^{3}$ & $8.8 \times 10^{2}$ & $1.5 \times 10^{3}$ & & $3.9 \times 10^{3}$ & $2.6 \times 10^{3}$ \\
\hline & $9 \times 10^{4}$ & $5.1 \times 10^{5}$ & $1.3 \times 10^{3}$ & $6.9 \times 10^{2}$ & $1.2 \times 10^{3}$ & & $4.2 \times 10^{3}$ & $2.4 \times 10^{3}$ \\
\hline & $\times 104$ & $5.7 x$ & $1.2 \times 10^{3}$ & $8.0 \times 10^{2}$ & $1.3 \times 10^{3}$ & & $3.4 \times 10^{3}$ & $2.3 \times 10^{3}$ \\
\hline & $\therefore$ & $8.4 x$ & $1.2 \times 10^{3}$ & $6.0 \times 10^{2}$ & $9.2 \times 10^{2}$ & & $3.7 \times 10^{3}$ & $2.4 \times 10^{3}$ \\
\hline & $j \times 10^{4}$ & & $1.3 \times 10^{3}$ & & $1.3 \times 10^{3}$ & & $4.8 \times 10^{3}$ & $1.8 \times 10^{3}$ \\
\hline & $\times 10^{4}$ & $7.1 \times 10^{5}$ & $2.0 \times 10^{3}$ & $1.4 \times 10^{3}$ & $2.4 \times 10^{3}$ & $3.0 \times 10^{-1}$ & $7.0 \times 10^{4}$ & $2.6 \times 10^{3}$ \\
\hline & $7.0 \times 10^{4}$ & $4.0 \times 10^{5}$ & $1.5 \times 10^{3}$ & & $2.1 \times 10^{3}$ & & $5.4 \times 10^{3}$ & $3.5 \times 10^{3}$ \\
\hline & $7.0 \times 10^{4}$ & $2.4 \times 10^{5}$ & $1.8 \times 10^{2}$ & $1.4 \times 10^{3}$ & $1.6 \times 10^{3}$ & & $3.5 \times 10^{3}$ & $3.0 \times 10^{3}$ \\
\hline & & $7.0 x$ & & & & & & \\
\hline & & $3.0 \times 10^{3}$ & & & & & & \\
\hline & & $7.0 \times 10^{4}$ & & & & & & \\
\hline 19 & $2.5 \times 10^{2}$ & $5.0 \times 101$ & & & & & & \\
\hline & & & & & & & & \\
\hline & & $2.1 \times 10$ & & & & & & \\
\hline
\end{tabular}


Table 5-3. Dose to the Maximum Individual from SRS Atmospheric Releases

Dose (mrem)

\begin{tabular}{|c|c|c|c|c|c|c|c|c|c|}
\hline Year & $4 I_{\mathrm{Ar}}$ & $85 \overline{K r}$ & $85 \mathrm{~m}_{\mathrm{Kr}}$ & $87 \mathrm{Kr}$ & ${ }^{88} \mathrm{Kr}$ & 131mXe & ${ }^{133} \mathrm{Xe}$ & $135 \mathrm{Xe}$ & Total \\
\hline 100 & $6.2 \times 10^{-2}$ & $0.0 \times 10$ & $8.5 \times 10^{-6}$ & & $1.4 \times 10^{-4}$ & $0.0 \times 10^{0}$ & & & \\
\hline 195 & $1.7 \times 10^{-1}$ & $2.3 \times 10^{-3}$ & $2.1 \times 10^{-5}$ & & $3.4 \times 10^{-4}$ & $0.0 \times 10^{0}$ & $1.1 \times 10^{-5}$ & $1.1 \times 10^{-4}$ & $1.7 \times 10^{-1}$ \\
\hline 1956 & $3.1 \times 10^{-1}$ & $2.3 \times 10^{-3}$ & $6.4 \times 10^{-5}$ & & $6.8 \times 10^{-4}$ & $0.0 \times 10^{0}$ & $2.3 \times 10^{-5}$ & $1.8 \times 10^{-4}$ & $3.1 \times 10^{-1}$ \\
\hline 1957 & $3.6 \times 10^{-1}$ & $2.3 \times 10^{-3}$ & $1.5 \times 10^{-4}$ & & $2.0 \times 10^{-3}$ & $0.0 \times 10^{0}$ & $5.7 \times 10$ & $3.6 \times 10^{-5}$ & $3.6 \times 10^{-1}$ \\
\hline 1958 & $4.2 \times 10^{-1}$ & $2.3 \times 10^{-3}$ & $3.8 \times 10^{-4}$ & & $5.7 \times 10^{-3}$ & $0.0 \times 10^{0}$ & $1.5 \times 10^{-}$ & $1.5 \times 10^{-3}$ & $4.3 \times 10^{-1}$ \\
\hline 1959 & $5.4 \times 10^{-1}$ & $2.3 \times 10^{-3}$ & $7.2 \times 10^{-4}$ & & $1.1 \times 10^{-2}$ & $0.0 \times 10^{0}$ & $2.9 \times 10$ & $2.4 \times 10^{-3}$ & $5.6 \times 10^{-1}$ \\
\hline 1960 & $4.9 \times 10^{-1}$ & $2.3 \times 10^{-3}$ & $9.8 \times 10^{-4}$ & & $1.6 \times 10^{-2}$ & $9.7 \times 10^{-6}$ & $4.2 \times 10$ & $3.5 \times 10^{-3}$ & $5.2 \times 10^{-1}$ \\
\hline 61 & $5.2 \times 10^{-1}$ & $2.3 \times 10^{-3}$ & $5.1 \times 10^{-4}$ & & $7.8 \times 10^{-3}$ & $7.0 \times 10^{-6}$ & $2.3 \times 10$ & $1.7 \times 10^{-3}$ & $5.3 \times 10^{-1}$ \\
\hline 62 & $5.3 \times 10^{-1}$ & $2.3 \times 10^{-3}$ & $3.8 \times 10^{-4}$ & & $5.7 \times 10^{-3}$ & $4.1 \times 10^{-6}$ & $1.5 \times 10$ & $1.2 \times 10^{-3}$ & $5.4 \times 10^{-1}$ \\
\hline 1963 & $5.5 \times 10^{-1}$ & $2.3 \times 10^{-3}$ & $1.5 \times 10^{-3}$ & & $22 \times 10^{-2}$ & $2.0 \times 10^{-6}$ & $4.8 \times 10$ & $4.4 \times 10^{-3}$ & $5.8 \times 10^{-1}$ \\
\hline 1964 & $4.6 \times 10^{-1}$ & $2.3 \times 10^{-3}$ & $1.9 \times 10^{-4}$ & & $1.7 \times 10^{-3}$ & $2.4 \times 10^{-6}$ & $1.1 \times 10$ & $2.9 \times 10^{-4}$ & $4.6 \times 10^{-1}$ \\
\hline 1965 & $3.3 \times 10^{-1}$ & $2.3 \times 10^{-3}$ & $4.2 \times 10^{-4}$ & & $4.1 \times 10^{-3}$ & $8.5 \times 10^{-6}$ & $2.4 \times 10$ & $6.6 \times 10^{-4}$ & $3.4 \times 10^{-1}$ \\
\hline 1966 & $3.4 \times 10^{-1}$ & $2.3 \times 10^{-3}$ & $5.1 \times 10^{-4}$ & & $5.1 \times 10^{-3}$ & $3.6 \times 10^{-6}$ & $2.5 \times 10$ & $7.6 \times 10^{-4}$ & $3.6 \times 10^{-1}$ \\
\hline 1967 & $3.9 \times 10^{-1}$ & $2.3 \times 10^{-3}$ & $7.0 \times 10^{-3}$ & & $6.9 \times 10^{-2}$ & $2.7 \times 10^{-5}$ & $8.6 \times 10$ & $1.1 \times 10^{-2}$ & $4.9 \times 10^{-1}$ \\
\hline 1968 & $2.7 \times 10^{-1}$ & $2.3 \times 10^{-3}$ & $2.7 \times 10^{-3}$ & & $2.7 \times 10^{-2}$ & $1.3 \times 10^{-5}$ & $2.8 \times 10$ & $4.5 \times 10^{-3}$ & $3.1 \times 10^{-1}$ \\
\hline 1969 & $1.7 \times 10^{-1}$ & $2.3 \times 10^{-3}$ & $1.1 \times 10^{-3}$ & & $1.2 \times 10^{-2}$ & $12 \times 10^{-5}$ & $1.3 \times 10$ & $20 \times 10^{-3}$ & $1.9 \times 10^{-1}$ \\
\hline 1970 & $1.4 \times 10^{-1}$ & $2.3 \times 10^{-3}$ & $5.1 \times 10^{-4}$ & & $5.4 \times 10^{-3}$ & $1.4 \times 10^{-5}$ & $1.0 \times 10^{-}$ & $9.5 \times 10^{-4}$ & $1.5 \times 10^{-1}$ \\
\hline 1971 & $1.7 \times 10^{-1}$ & $2.3 \times 10^{-3}$ & $6.5 \times 10^{-4}$ & & $5.8 \times 10^{-3}$ & $1.5 \times 10^{-5}$ & $1.4 \times 10$ & $1.7 \times 10^{-3}$ & $19 \times 10^{-1}$ \\
\hline 1972 & $2.1 \times 10^{-1}$ & $2.2 \times 10^{-3}$ & $1.6 \times 10^{-3}$ & $1.6 \times 10^{-3}$ & $1.4 \times 10^{-2}$ & $4.1 \times 10^{-6}$ & $22 \times 10$ & $4.3 \times 10^{-3}$ & $23 \times 10^{-1}$ \\
\hline 973 & $2.3 \times 10^{-1}$ & $2.8 \times 10^{-3}$ & $1.4 \times 10^{-3}$ & $1.3 \times 10^{-3}$ & $2.5 \times 10^{-2}$ & $7.1 \times 10^{-6}$ & $1.3 \times 10^{-3}$ & $3.4 \times 10^{-3}$ & $2.6 \times 10^{-1}$ \\
\hline 1974 & $1.3 \times 10^{-1}$ & $1.8 \times 10^{-3}$ & $2.9 \times 10^{-4}$ & $4.1 \times 10^{-4}$ & $4.8 \times 10^{-3}$ & $2.0 \times 10^{-6}$ & $3.1 \times 10$ & $7.7 \times 10^{-4}$ & $1.4 \times 10^{-1}$ \\
\hline 975 & $8.0 \times 10^{-2}$ & $1.9 \times 10^{-3}$ & $7.9 \times 10^{-5}$ & $7.6 \times 10^{-4}$ & $2.9 \times 10^{-3}$ & $8.4 \times 10^{-8}$ & $6.2 \times 10$ & $2.7 \times 10^{-4}$ & $8.6 \times 10^{-2}$ \\
\hline 76 & $1.0 \times 10^{-1}$ & $2.7 \times 10^{-3}$ & $8.0 \times 10^{-5}$ & $2.8 \times 10^{-4}$ & $1.7 \times 10^{-3}$ & $10^{-6}$ & $1.4 \times 10$ & $2.7 \times 10^{-4}$ & $1.1 \times 10^{-1}$ \\
\hline 77 & $8.0 \times 10^{-2}$ & $1.6 \times 10^{-3}$ & $1.8 \times 10^{-4}$ & $3.9 \times 10^{-4}$ & $23 \times 10^{-3}$ & $10^{-7}$ & $13 \times 10$ & $6.0 \times 10^{-4}$ & $8.5 \times 10^{-2}$ \\
\hline 1978 & $6.4 \times 10^{-2}$ & $1.9 \times 10^{-3}$ & $1.9 \times 10^{-4}$ & 3.62 & $2.8 \times 10^{-3}$ & $10^{-8}$ & $1.2 \times 10$ & $6.1 \times 10^{-4}$ & $7.0 \times 10^{-2}$ \\
\hline 1979 & $6.6 \times 10^{-2}$ & $1.8 \times 10^{-3}$ & $3.9 \times 10^{-4}$ & $9.9 \times 10^{-4}$ & $7.5 \times 10^{-3}$ & $10^{-7}$ & $3.0 \times 10$ & $1.6 \times 10^{-3}$ & $79 \times 10^{-2}$ \\
\hline 1980 & $8.6 \times 10^{-2}$ & $2.1 \times 10^{-3}$ & $6.8 \times 10^{-4}$ & 1.8 & $10^{-2}$ & $10^{-9}$ & $4.5 \times 10$ & $23 \times 10^{-3}$ & $1.1 \times 10^{-1}$ \\
\hline 1981 & $7.7 \times 10^{-2}$ & $3.1 \times 10^{-3}$ & $2.8 \times 10^{-4}$ & $5.7 \times 10^{-4}$ & $5.0 \times 10^{-3}$ & $10^{-8}$ & $2.2 \times 10$ & $9.4 \times 10^{-4}$ & $8.8 \times 10^{-2}$ \\
\hline 1982 & $7.4 \times 10^{-2}$ & $1.9 \times 10^{-3}$ & $2.7 \times 10^{-4}$ & 4.5 & $4.0 \times 10^{-3}$ & $8.3 \times 10^{-7}$ & $2.4 \times 10$ & $8.7 \times 10^{-4}$ & $82 \times 10^{-2}$ \\
\hline 1983 & $5.1 \times 10^{-2}$ & $2.1 \times 10^{-3}$ & $2.6 \times 10^{-4}$ & 5.2 & $4.3 \times 10^{-3}$ & $10^{-7}$ & $19 \times 10$ & $8.5 \times 10^{-4}$ & $5.9 \times 10^{-2}$ \\
\hline & $4.4 \times 10^{-2}$ & $3.1 \times 10^{-3}$ & $2.6 \times 10^{-4}$ & $3.9 \times 10^{-4}$ & 3.1 & $2.5 \times 10^{-7}$ & $2.1 \times 10$ & $8.8 \times 10^{-4}$ & $5.2 \times 10^{-2}$ \\
\hline & $6.3 \times 10^{-2}$ & $2.4 \times 10^{-3}$ & $2.8 \times 10^{-4}$ & $6.8 \times 10^{-4}$ & $4.3 \times 10^{-3}$ & $8.4 \times 10^{-8}$ & $2.8 \times 10$ & $6.6 \times 10^{-4}$ & $7.1 \times 10^{-2}$ \\
\hline & $1.0 \times 10^{-1}$ & $2.6 \times 10^{-3}$ & $4.3 \times 10^{-4}$ & $9.0 \times 10^{-4}$ & $8.1 \times 10^{-3}$ & $4.2 \times 10^{-3}$ & $6.1 \times 10$ & $9.3 \times 10^{-4}$ & $12 \times 10^{-1}$ \\
\hline & $1.1 \times 10^{-1}$ & $1.5 \times 10^{-3}$ & $3.1 \times 10^{-4}$ & 6.5 & $6.9 \times 10^{-3}$ & $0.0 \times 10$ & $3.1 \times 10$ & $1.3 \times 10^{-3}$ & $12 \times 10^{-1}$ \\
\hline & $3.6 \times 10^{-2}$ & $8.8 \times 10^{-4}$ & $3.9 \times 10^{-5}$ & $8.8 \times 10^{-4}$ & $5.3 \times 10^{-3}$ & $0.0 \times 10$ & $2.0 \times 10$ & $1.1 \times 10^{-3}$ & $4.5 \times 10^{-2}$ \\
\hline & & $1.5 \times 10^{-4}$ & & & & & & & $15 \times 10^{-4}$ \\
\hline & & $1.1 \times 10$ & & & & & & & $1.1 \times 10^{-5}$ \\
\hline & & $3.7 \times 10$ & & & & & & & $3.7 \times 10^{-5}$ \\
\hline & $0^{-4}$ & $1.8 \times 10^{-7}$ & & & & & & & $3.1 \times 10^{-4}$ \\
\hline
\end{tabular}

Total $\quad 7.8 \times 10^{0} \quad 7.5 \times 10^{-2} \quad 2.5 \times 10^{-2} \quad 1.3 \times 10^{-2} \quad 3.2 \times 10^{-1} 1.4 \times 10^{-4} \quad 2.7 \times 10^{-2} 5.8 \times 10^{-2} \quad 8.3 \times 10^{0}$. Percent . $\quad 9.4 \times 10^{1} \quad 9.0 \times 10^{-1} \quad 3.0 \times 10^{-1} \quad 1.5 \times 10^{-1} \quad 3.8 \times 10^{0} 1.7 \times 10^{-3} 3.2 \times 10^{-1} 7.0 \times 10^{-1}$ 
Table 5-4. Population Dose from SRS Atmospheric Releases

Population Dose (person-rem)

\begin{tabular}{|c|c|c|c|c|c|c|c|c|c|}
\hline & & & & & & & & & \\
\hline $2 a r$ & ${ }^{41} \mathrm{Ar}$ & ${ }^{85} \mathrm{Kr}$ & ${ }^{85} \mathrm{~m} \mathrm{Kr}$ & ${ }^{87} \mathrm{Kr}$ & $88 \mathrm{Kr}$ & $131 \mathrm{mXe}$ & ${ }^{133} \mathrm{Xe}$ & ${ }^{135} \mathrm{Xe}$ & Total \\
\hline & $5 \times 10^{0}$ & $0.0 \times 10$ & $3.8 \times 10^{-4}$ & & $4.7 \times 10^{-3}$ & 10 & $2.4 \times 10^{-4}$ & $1.6 \times 10^{-3}$ & \\
\hline & & $0^{-1}$ & $4 \times 10^{-4}$ & & & & $7.9 \times 10^{-4}$ & $6.1 \times 10^{-3}$ & \\
\hline 1 & $\times 10^{0}$ & $1.6 \times 10^{-1}$ & $2.8 \times 10^{-3}$ & & $0^{-2}$ & & $1.6 \times 10^{-3}$ & $1.0 \times 10^{-2}$ & \\
\hline 57 & $8.9 \times 10^{0}$ & $1.6 \times 10^{-1}$ & $6.6 \times 10^{-3}$ & & $1 \times 10^{-2}$ & & $4.0 \times 10^{-4}$ & $2.0 \times 10^{-3}$ & $9.2 \times 10^{0}$ \\
\hline & $1.0 \times 10^{1}$ & $1.6 \times 10^{-1}$ & $1.7 \times 10^{-2}$ & & $2.0 \times 10^{-1}$ & & $1.0 \times 10^{-2}$ & $10^{-2}$ & $1.1 \times 10^{1}$ \\
\hline & $1.4 \times 10^{1}$ & $1.6 \times 10^{-1}$ & $3.2 \times 10^{-2}$ & & $3.8 \times 10^{-1}$ & 0. & $2.0 \times 10^{-2}$ & $10^{-1}$ & $1.4 \times 10^{1}$ \\
\hline & $1.2 \times 10^{1}$ & $1.6 \times 10^{-1}$ & $4.3 \times 10^{-2}$ & & $5.7 \times$ & $10^{-4}$ & $2.9 \times 10^{-2}$ & $1.9 \times 10^{-1}$ & $1.3 \times 10^{1}$ \\
\hline 1 & $\times 10^{1}$ & $1.6 \times 10^{-1}$ & $2.3 \times 10^{-2}$ & & $10^{-1}$ & $10^{-4}$ & $1.6 \times 10^{-2}$ & $9.5 \times 10^{-2}$ & $1.4 \times 10^{1}$ \\
\hline 62 & $1.3 \times 10^{1}$ & $1.6 \times 10^{-1}$ & $1.7 \times 10^{-2}$ & & $2.0 \times 10^{-1}$ & $10^{-4}$ & $1.0 \times 10^{-2}$ & $6.9 \times 10^{-2}$ & $1.4 \times 10^{1}$ \\
\hline 63 & $1.4 \times 10^{1}$ & $1.6 \times 10^{-1}$ & $6.6 \times 10^{-2}$ & & $10^{-1}$ & $10^{-4}$ & $3.3 \times 10^{-2}$ & $2.4 \times 10^{-1}$ & $1.5 \times 10^{1}$ \\
\hline 64 & 1.1 & $1.6 \times$ & $8.5>$ & & $0^{-2}$ & $10^{-4}$ & $7.9 \times 10^{-3}$ & $1.6 \times 10^{-2}$ & $1.2 \times 10^{1}$ \\
\hline 0 & $0^{0}$ & $1.6 x$ & $10^{-2}$ & & $\sigma^{-1}$ & $10^{-4}$ & $1.7 \times 10^{-2}$ & $3.7 \times 10^{-2}$ & 8.7 \\
\hline & $8.6 \times 10^{0}$ & $1.6 x$ & $2.3 \times 10^{-2}$ & & $0^{-1}$ & $10^{-4}$ & $1.8 \times 10^{-1}$ & $4.2 \times 10^{-2}$ & $9.2>$ \\
\hline 0 & $.9 .9 \times 10^{0}$ & $1.6 \times 10^{-1}$ & $3.1>$ & & $2.4 \times 10^{0}$ & $10^{-3}$ & $5.9 \times 10^{-1}$ & $6.0 \times 10^{-1}$ & $1.4 \times 10^{1}$ \\
\hline 108 & $6.8 \times 10^{0}$ & $1.6 \times 10^{-1}$ & $1.2 \times 10^{-1}$ & & $9.4 \times 10^{-1}$ & $10^{-4}$ & $1.9 \times 10^{-1}$ & $2.5 \times 10^{-1}$ & $10^{0}$ \\
\hline 969 & $4.3 \times 10^{0}$ & $1.6 \times 10^{-1}$ & $5.1 \times 10^{-2}$ & & $10^{-1}$ & $10^{-4}$ & $8.7 \times 10^{-2}$ & $1.1 \times 10^{-1}$ & 5.1 \\
\hline 970 & $3.4 \times 10^{0}$ & $1.6 \times 10^{-1}$ & $2.3 \times 10^{-2}$ & 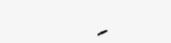 & $10^{-1}$ & $10^{-4}$ & $7.1 \times 10^{-2}$ & $5.3 \times 10^{-2}$ & 3.9 \\
\hline 971 & $4.3 \times 10^{0}$ & $1.7 \times 10^{-1}$ & $2.9 \times 10^{-2}$ & & $2.0 \times 10^{-1}$ & $10^{-3}$ & $1.0 \times 10^{-2}$ & $9.6 \times 10^{-2}$ & 4.9 \\
\hline $9 \sqrt{2}$ & $\times 10^{0}$ & $1.5 \times 10^{-1}$ & $7.0 \times 10^{-2}$ & $10^{-2}$ & $5.0 \times 10^{-1}$ & $10^{-4}$ & $1.5 \times 10^{-1}$ & $2.4 \times 10^{-1}$ & $0^{0}$ \\
\hline 12 & $\times 10^{0}$ & $2.0 \times 10^{-1}$ & $6.2 \times 10^{-2}$ & $10^{-2}$ & $8.7 \times 10^{-1}$ & $10^{-4}$ & $8.9 \times 10^{-2}$ & $1.9 \times 10^{-1}$ & $10^{0}$ \\
\hline $1 / 4$ & $\times 10^{0}$ & $1.3 \times 10^{-1}$ & $1.3 \times 10^{-2}$ & $7.2 \times 10^{-3}$ & $1.7 \times 10^{-1}$ & $10^{-4}$ & $2.2 \times 10^{-2}$ & 4.3 & $3.7 \times 10^{0}$ \\
\hline प्रा & $10^{0}$ & $1.3 \times 10^{-1}$ & $3.5 \times 10^{-3}$ & $1.3 \times 10^{-2}$ & $1.0 \times 10^{-1}$ & $10^{-6}$ & $4.3 \times 10^{-3}$ & $1.5 \times 10^{-2}$ & $2.3 \times 10^{0}$ \\
\hline n & $0^{0}$ & $\times 10^{-1}$ & $3.6 \times 10^{-3}$ & $4.9 \times 10^{-3}$ & $6.0 \times 10^{-2}$ & 6.2 & $9.8 \times 10^{-3}$ & $1.5 \times 10^{-2}$ & $2.8 \times 10^{c}$ \\
\hline$y$ & $10^{0}$ & $1.1 \times$ & $7.9 \times 10^{-3}$ & $6.8 \times$ & $10^{-2}$ & 1.2 & $9.3 \times 10^{-3}$ & $3.3 \times 10^{-2}$ & $2.3 \times 10^{0}$ \\
\hline & $10^{0}$ & $1.4 \times$ & $8.4>$ & 6.2 & 9.9 & $0^{-6}$ & $8.6 \times 10^{-3}$ & $3.4 \times 10^{-2}$ & $1.9 \times 10^{0}$ \\
\hline$\partial^{2}$ & 1.7 & $1.2 \times$ & $10^{-2}$ & $1.7 \times 10^{-2}$ & 2.6 & $10^{-6}$ & $2.1 \times 10^{-2}$ & $9.1 \times 10^{-2}$ & $10^{0}$ \\
\hline 98 & $2.2 \times 10^{0}$ & $1.5 \times$ & 3.0 & $3.2 \times 10^{-2}$ & $4.7 \times 10^{-1}$ & $10^{-7}$ & $3.1 \times 10^{-2}$ & $1.3 \times 10^{-1}$ & $3.0 \times 10^{0}$ \\
\hline 38 & $1.9 \times 10^{0}$ & $2.2 \times 10^{-1}$ & $1.2 \times 10^{-2}$ & $9.9 \times 10^{-3}$ & $1.7 \times 10^{-1}$ & $10^{-6}$ & $1.5 \times 10^{-2}$ & $5.2 \times 10^{-2}$ & $2.4 \times 10^{0}$ \\
\hline 98 & $1.8 \times 10^{0}$ & $1.3 \times 10^{-1}$ & $1.2 \times 10^{-2}$ & $7.8 \times 10^{-3}$ & $1.4 \times 10^{-1}$ & $10^{-5}$ & $1.7 \times 10^{-2}$ & $4.9 \times 10^{-2}$ & $2.2 \times 10^{0}$ \\
\hline $98^{2}$ & $1.3 \times 10^{0}$ & $1.5 \times 10^{-1}$ & $1.2 \times 10^{-2}$ & $9.0 \times 10^{-3}$ & $1.5 \times 10^{-1}$ & $10^{-5}$ & $1.3 \times 10^{-2}$ & $4.7 \times 10^{-2}$ & $1.7 \times 10^{0}$ \\
\hline 98 & $1.1 \times 10^{0}$ & $2.2 \times 10^{-1}$ & $1.2 \times 10^{-2}$ & $6.8 \times 10^{-3}$ & $1.1 \times 10^{-1}$ & $1.8 \times 10^{-5}$ & $1.5 \times 10^{-2}$ & $4.9 \times 10^{-2}$ & $1.5 \times 10^{0}$ \\
\hline 98 & $1.6 \times 10^{0}$ & $1.7 \times 10^{-1}$ & $1.2 \times 10^{-2}$ & $1.2 \times 10^{-2}$ & $1.5 \times 10^{-1}$ & $4.9 \times 10^{-6}$ & $1.9 \times 10^{-2}$ & $3.7 \times 10^{-2}$ & $2.0 \times 10^{0}$ \\
\hline 98 & $2.6 \times 10^{0}$ & $1.8 \times 10^{-1}$ & $1.9 \times 10^{-2}$ & $1.6 \times 10^{-2}$ & $2.8 \times 10^{-1}$ & $2.9 \times 10^{-7}$ & $4.2 \times 10^{-2}$ & $5.2 \times 10^{-2}$ & $3.2 \times 10^{0}$ \\
\hline 198 & $2.7 \times 10^{0}$ & $1.0 \times 10^{-1}$ & $1.4 \times 10^{-2}$ & $1.1 \times 10^{-2}$ & $2.4 \times 10^{-1}$ & 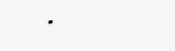 & $2.1 \times 10^{-2}$ & $7.0 \times 10^{-2}$ & $3.2 \times 10^{0}$ \\
\hline 198 & $.1 \times 10^{-1}$ & $6.2 \times 10^{-2}$ & $1.7 \times 10^{-3}$ & $1.5 \times 10^{-2}$ & $1.8 \times 10^{-}$ & & $1.4 \times 10^{-2}$ & $6.1 \times 10^{-2}$ & $1.2 \times 10^{0}$ \\
\hline & & 1. & & & & & & & $1.1 \times 10^{-2}$ \\
\hline & & $7.7 \times 10^{-}$ & & & & & & & $7.7 \times 10^{-4}$ \\
\hline & & 2.6 & & & & & & & $2.6 \times, 10^{-3}$ \\
\hline A & $7.7 \times 10^{-3}$ & $1.3 \times 10^{-6}$ & & & & & & & $7.7 \times 10^{-}$ \\
\hline
\end{tabular}

Total $\quad 2.0 \times 10^{2} \quad 5.3 \times 10^{0} \quad 1.1 \times 10^{\circ} \quad 2.3 \times 10^{-1} \quad 1.1 \times 10^{1} \quad 9.9 \times 10^{-3} \quad 1: 9 \times 10^{0} \quad 3.2 \times 10^{0} \quad 2.2 \times 10^{2}$ Percent $9: 0 \times 10^{1} \quad 2.4 \times 10^{0} \quad .5 .0 \times 10^{-1} \quad 1.0 \times 10^{-1} \quad 5.1 \times 10^{0} \quad 4.5 \times 110^{-3} \quad 8.6 \times 10^{-1} \quad 1.5 \times 10^{0}$ 


\section{References}

Bauer, L. R., 1991, "Modeling Chronic Atmospheric Releases at the SRS: Evaluation and Verification of XOQDOQ(U)," WSRC-RP-91-320, Westinghouse Savannah River Company, Aiken, SC.

Cooper, R. E., 1975, "Computer Programs at SRL to Evaluate Environmental Effects of SRP Operations and Postulated Accidental Releases, "DPST-75-384, Savannah River Laboratory, E.I. du Pont de Nemours \& Co., Aiken, SC.

Cummins, C. L., D. K. Martin, and J. L. Todd, 1990, "Savannah River Site Environmental Report for 1989," p. XV, WSRC-MM-90-60, Westinghouse Savannah River Company, Aiken, SC.

DOE, 1988, "Internal Dose Conversion Factors for Calculation of Dose to the Public," DOE/EH-0071, Washington, DC.

Eckerman, K. F., F. J. Congel, A. K. Roecklein, and W. J. Pasciak, 1980, "User's Guide to GASPAR Code," NUREG-0597, U. S. Nuclear Régulatory Commission, Washington, DC.

Ellis, K. J., S. H. Cohn, H. Susskind, and H. L. Atkins, 1977, "Kinetics of Inhaled Krypton in Man," Health Physics 33:515-522, 1977.

EPA, 1989, 40 CFR Part 61, "National Emission Standards for Hazardous Air Pollutants; Regulation of Radionuclides; Final Rule and Notice of Reconsideration," Federal Register, Vol. 54, No. 240.

Hamby, D. M., 1991, "Land and Water Use Characteristics in the Vicinity of the Savannah River Site (U)," WSRC-RP-91-17, Westinghouse Savannah River Company, Aiken, SC.

Hamby, D. M., and M. J. Parker, 1991, "Gaussian Dispersion and Dosimetric Modeling Sensitivity to Area-Specific 1982-1986 Meteorological Data Collected at the Savannah River Site (U)," WSRCRP-91-909, Westinghouse Savannah River Company, Aiken, SC.
ICRP, 1979, "Limits for Intake of Radionuclides by Workers, "ICRP Publication 30, Part 1, Annals of the ICRP.

ICRP, 1981, "Limits for Intake of Radionuclides by Workers," ICRP Publication 30, Supplement to Part 2, Annals of the ICRP.

ICRP, 1989, "Age-Dependent Doses to Members of the Public from Radionuclides," ICRP Publication 56, Annals of the ICRP.

ICRP, 1991, "Risks Associated with Ionizing Radiations," Vol. 22, No. 1, Annals of the ICRP.

Marter, W. L., 1984, "Environmental Dosimetry for Normal Operations at SRP, ". DPST-83-270, Rev. 1, Savannah River Laboratory, E.I. du Pont de Nemours \& Co. Aiken SC.

NRC, 1977a, "Methods for Estimating Atmospheric Transport and Dispersion of Gaseous Effluents in Routine Releases from Light-Water-Cooled Reactors," Regulatory Guide 1.111, Rev. 1, Washington, DC.

NRC, 1977b, "Calculation of Annual Doses to Man from Routine Releases of Reactor Effluents for the Purpose of Evaluating Compliance with 10 CFR Part 50, Appendix I," Regulatory Guide 1.109, Rev. 1, Washington, DC.

Sagendorf, J. F., J. T. Goll, and W. F. Sandusky, 1982, "XOQDOQ: Computer Program for the Meteorological Evaluation of Routine Effluent Releases at Nuclear Power Stations," NUREG/CR2919, U.S. Nuclear Regulatory Commission, Washington, DC.

Susskind, H., H. L. Atkins, S. H. Cohn, K. J. Ellis, and P. Richards, 1977, "Whole-Body Retention of Radioxenon," J. Nucl Med 18:462-471. 